

AIAA-2000-1770

\title{
AN OVERVIEW OF UNSTEADY PRESSURE MEASUREMENTS IN THE TRANSONIC DYNAMICS TUNNEL
}

\author{
David M. Schuster", John W. Edwards ${ }^{\dagger}$, and Robert M. Bennett ${ }^{\ddagger}$ \\ NASA Langley Research Center, Hampton, VA 23681-2199
}

\begin{abstract}
The NASA Langley Transonic Dynamics Tunnel has served as a unique national facility for acroelastic testing for over forty years. A significant portion of this testing has been to measure unsteady pressures on models undergoing flutter, forced oscillations, or buffet. These tests have ranged from early launch vehicle buffet to flutter of a generic high-speed transport. This paper will highlight some of the test techniques, model design approaches, and the many unsteady pressure tests conducted in the TDT. The objectives and results of the data acquired during these tests will be summarized for each case and a brief discussion of ongoing research involving unsteady pressure measurements and new TDT capabilities will be presented.
\end{abstract}

\section{INTRODUCTION}

A wide variety of tests have been conducted in the NASA Langley Transonic Dynamics over the last forty years. The tests have encompassed flutter clearance', flutter trend studies, launch vehicle ground wind loads, aircraft gust response, active controls research ${ }^{3}$, and many other problems ranging from helicopters ${ }^{4}$ to the space shuttle ${ }^{2}$. During some projects only a few measurements have been taken, such as dynamic pressure and frequency at flutter, whereas in others, extensive detailed measurements have been made. In particular, unsteady pressures have been measured on several models in order to evaluate the details of the various aeroelastic phenomena. A comprehensive list of these tests, their dates, and a brief description of their

\footnotetext{
"Aerospace Engineer, Associate Fellow AIAA

'Senior Rescarch Scientist, Associate Fellow AIAA

Retired, Distinguished Research Associate, Associate Fellow AIAA

Copyright $(2000$ by the American Institute of Acronautics and Astronautics, Inc. No copyright is asserted in the United States under Title 17, U.S. Code. The U.S. Government has a royalty-free license to exercise all rights under the copyright claimed herein for Governmental Purposes. All other rights are reserved by the copyright owner.
}

purpose is presented in Table 1. Highlights of these efforts are presented with a brief resume of the background and implication of the results. The cases are grouped into two primary categories: Unsteady pressure measurements supporting flutter research and unsteady pressure measurements supporting buffet research. Finally, a third category is included that covers two TDT unsteady pressure tests which don't fall into the primary categories, but are included for completeness. Within each section the tests are ordered chronologically.

A critical item in the cvolution of the unsteady pressure measurements is the development of instrumentation, measurement techniques, data acquisition, and storage systems. These systems have significantly evolved in capability during the life of the lunnel and they will be highlighted.

In this overview we have attempted to provide an account of the TDT tests in which unsteady pressures have been the prime objective or were a major aspect of the test. Completeness cannot be assured, especially for the early tests where there is little documentation.

\section{TRANSONIC DYNAMICS TUNNEL (TDT)}

The NASA Langley Transonic Dynamics Tunnel (TDT) is a national facility dedicated to identifying, understanding, and solving relevant problems in aeroelasticity, unsteady aerodynamics, and controls 
Table 1. TDT tests involving unsteady pressure measurements.

\begin{tabular}{|c|c|c|c|}
\hline Test No. & Test Tille & Datc & Comments \\
\hline \multicolumn{4}{|c|}{ Unsteady Pressure Measurements Supporting Configuration Research } \\
\hline $\begin{array}{l}272 \\
290 \\
328 \\
334 \\
\end{array}$ & $\begin{array}{l}\text { Clipped Delta Wing Pressure } \\
\text { Model }\end{array}$ & $\begin{array}{l}01 / 22 / 76-02 / 03 / 76 \\
03 / 18 / 77-06 / 03 / 77 \\
02 / 20 / 80-04 / 15 / 80 \\
10 / 14 / 80-12 / 24 / 80 \\
\end{array}$ & $\begin{array}{l}\text { Rigid pitching model with trailing } \\
\text { edge control surface }\end{array}$ \\
\hline $\begin{array}{l}338 \\
364\end{array}$ & $\begin{array}{l}\text { Large Scale Oscillator Rig } \\
\text { (LSOR) }\end{array}$ & $\begin{array}{l}06 / 22 / 81-06 / 30 / 81 \\
05 / 26 / 83-06 / 29 / 83\end{array}$ & $\begin{array}{l}\text { 2-D oscillating airfoil, surface and } \\
\text { wake measurements, rotor blade } \\
\text { applications. Unsteady pressure } \\
\text { measurements on pitching airfoils }\end{array}$ \\
\hline $\begin{array}{l}318 \\
332 \\
342\end{array}$ & $\begin{array}{l}\text { Energy Efficient Transport } \\
\text { Wing Oscillating Control } \\
\text { Pressure Model }\end{array}$ & $\begin{array}{l}04 / 02 / 79-06 / 02 / 79 \\
06 / 12 / 79-06 / 15 / 79 \\
06 / 23 / 80-08 / 08 / 80 \\
08 / 10 / 81-09 / 14 / 81\end{array}$ & $\begin{array}{l}\text { Rigid wing, several oscillating leading } \\
\text { and trailing edge control surfaces }\end{array}$ \\
\hline 353 & $\begin{array}{l}\text { Rectangular Supercritical } \\
\text { Wing }\end{array}$ & $07 / 22 / 82-09 / 03 / 82$ & $\begin{array}{l}\text { Oscillating pressures, pitching rigid } \\
\text { rectangular wing }\end{array}$ \\
\hline $\begin{array}{l}367 \\
389\end{array}$ & DAST ARW-2 Wing & $\begin{array}{l}09 / 22 / 83-10 / 11 / 83 \\
12 / 19 / 85-01 / 24 / 86\end{array}$ & $\begin{array}{l}\text { Steady and unsteady pressure } \\
\text { measurements on flexible wing }\end{array}$ \\
\hline 382 & Supercritical Transport Wing & $05 / 14 / 84-05 / 30 / 84$ & $\begin{array}{l}\text { Measurement of upper-lower unsteady } \\
\text { pressures including flutter and engines } \\
\text { on and off. }\end{array}$ \\
\hline \multicolumn{4}{|c|}{ Benchmark Model Tests } \\
\hline $\begin{array}{l}459 \\
468\end{array}$ & NACA $0012 / \mathrm{PAPA}$ & $\begin{array}{l}05 / 27 / 90-07 / 28 / 90 \\
01 / 30 / 91-02 / 16 / 91\end{array}$ & $\begin{array}{l}\text { Pressure measurements during flutter } \\
\text { NACA } 0012 \text { airfoil wing on PAPA }\end{array}$ \\
\hline 470 & $\begin{array}{l}\text { Benchmark Supercritical } \\
\text { Wing Model/PAPA }\end{array}$ & $\begin{array}{l}02 / 16 / 92-03 / 14 / 92 \\
03 / 30 / 92-04 / 13 / 92\end{array}$ & $\begin{array}{l}\text { Pressure measurements during flutter } \\
\text { supercritical airfoil wing on PAPA, } \\
\text { installed } 9 / 91\end{array}$ \\
\hline $\begin{array}{l}485 \\
502\end{array}$ & $\begin{array}{l}\text { Benchmark Active Controls } \\
\text { Testing (BACT) }\end{array}$ & $\begin{array}{l}10 / 01 / 93-11 / 05 / 93 \\
01 / 16 / 95-02 / 10 / 95\end{array}$ & $\begin{array}{l}\text { Rigid wing, active spoiler and aileron, } \\
\text { loads and pressures and flutter on } \\
\text { PAPA }\end{array}$ \\
\hline 478 & Advanced Business Jet & $02 / 05 / 93-03 / 18 / 93$ & $\begin{array}{l}\text { Pressure measurements on flexible } \\
\text { wing }\end{array}$ \\
\hline 493 & Benchmark 64A010/PAPA & $04 / 04 / 94-04 / 13 / 94$ & $\begin{array}{l}\text { Pressure measurements during flutter } \\
\text { NACA } 64 \text { A010 airfoil wing on PAPA }\end{array}$ \\
\hline \multicolumn{4}{|c|}{ High Speed Rescarch Tests } \\
\hline 499 & HSR-RSM Balance & $09 / 06 / 94-10 / 26 / 94$ & Aerodynamic forces and pressures \\
\hline 508 & HSR-RSM PAPA Test & $05 / 22 / 95-06 / 20 / 95$ & $\begin{array}{l}\text { Unsteady pressure measurement effort } \\
\text { with flexible mount }\end{array}$ \\
\hline 513 & HSR-RSM II On Balance & $09 / 05 / 95-09 / 20 / 95$ & $\begin{array}{l}\text { Aerodynamic forces and pressures, } \\
\text { model core failure, no data }\end{array}$ \\
\hline 520 & HSR-RSM II On Balance & $03 / 15 / 96-04 / 05 / 96$ & Aerodynamic forces and pressures \\
\hline 521 & HSR-FSM & $04 / 13 / 96-05 / 06 / 96$ & $\begin{array}{l}\text { Flutter model with pressure } \\
\text { measurements }\end{array}$ \\
\hline 530 & HSR RSM/PAPA & $08 / 24 / 98-10 / 04 / 98$ & $\begin{array}{l}\text { Unsteady pressure measurements } \\
\text { during flutter on PAPA }\end{array}$ \\
\hline
\end{tabular}


Table I. TDT tešts involving unsteady pressure measürements. (Concluded)

\begin{tabular}{|c|c|c|c|}
\hline Test No. & Test Title & Date & Comments \\
\hline \multicolumn{4}{|c|}{ Launch Vehicle Buffet Tests } \\
\hline $\begin{array}{l}24 \\
31\end{array}$ & Saturn-Apollo Pressure Model & $\begin{array}{l}08 / 24 / 61-09 / 14 / 61 \\
11 / 07 / 61-11 / 20 / 61\end{array}$ & $\begin{array}{l}\text { Buffet pressure measurements in air } \\
\text { and Freon for different size models }\end{array}$ \\
\hline 38 & Project FIRE Buffet Model & $03 / 12 / 62-04 / 03 / 62$ & $\begin{array}{l}\text { Buffet pressure measurements on re- } \\
\text { entry nose }\end{array}$ \\
\hline 102 & PSTL-1 Saturn Apollo Model & $02 / 28 / 66-03 / 25 / 66$ & $\begin{array}{l}\text { Buffet pressure measurements on rigid } \\
\text { model in several tunnels }\end{array}$ \\
\hline 423 & $\begin{array}{l}\text { Atlas-Centaur Large Payload } \\
\text { Fairing }\end{array}$ & $06 / 12 / 88-07 / 15 / 88$ & $\begin{array}{l}\text { Buffeting, bulbous payload fairing and } \\
\text { buffet measurements }\end{array}$ \\
\hline 510 & $\begin{array}{l}\text { Delta II Launch Vehicle, } \\
\text { Composite Payload }\end{array}$ & $06 / 22 / 95-07 / 06 / 95$ & $\begin{array}{l}\text { Buffeting response and buffet } \\
\text { measurements }\end{array}$ \\
\hline 519 & Delta III Launch Vehicle & $02 / 26 / 96-03 / 12 / 96$ & $\begin{array}{l}\text { Buffeting response and buffet } \\
\text { measurements }\end{array}$ \\
\hline \multicolumn{4}{|c|}{ Aircraft Buffet Tests } \\
\hline 100 & RF-4C Fuselage Model & $01 / 18 / 66-02 / 23 / 66$ & $\begin{array}{l}\text { Fuselage only, buffel pressures, } \\
\text { addressed operational problem }\end{array}$ \\
\hline \multicolumn{4}{|c|}{ Aircraft Twin Tail Buffet Tests } \\
\hline $\begin{array}{l}511 \\
531\end{array}$ & F-18 Tail Buffet & $\begin{array}{l}07 / 10 / 95-07 / 29 / 95 \\
10 / 05 / 99-10 / 18 / 99\end{array}$ & $\begin{array}{l}\text { Active control of vertical tail buffeting } \\
\text { response and buffet measurements }\end{array}$ \\
\hline 532 & F-22 Fin-Tail Buffet & $10 / 19 / 99-11 / 08 / 99$ & $\begin{array}{l}\text { Some active control of vertical tail } \\
\text { buffeting response and buffet } \\
\text { measurements }\end{array}$ \\
\hline \multicolumn{4}{|c|}{ Miscellancous Tests } \\
\hline 148 & $\begin{array}{l}\text { Saturn Apollo Command } \\
\text { Module + Explosive Charges }\end{array}$ & $02 / 28 / 69-03 / 27 / 69$ & $\begin{array}{l}\text { Pressure measurements on Apollo SC, } \\
\text { TNT charges simulated booster } \\
\text { explosion }\end{array}$ \\
\hline $\begin{array}{l}233 \\
238\end{array}$ & AEDC Transition Cone & $\begin{array}{l}02 / 13 / 74-02 / 15 / 74 \\
04 / 15 / 74-04 / 18 / 74\end{array}$ & $\begin{array}{l}\text { Tunnel turbulence measurements in } \\
\text { many wind tunnels }\end{array}$ \\
\hline
\end{tabular}

technology. A more complete history of the tunnel and its capabilities is presented in Reference 5. The TDT, shown in Figure 1, is a large-scale, closed-return, continuous flow tunnel capable of operating at subsonic through low supersonic specds. It is a variable pressure facility with a $16-$ foot cropped-corner slotted test section as shown in Figure 2. Either air or a heavy gas can be used as a test medium and the tunnel can be operated at pressures ranging from near vacuum to atmospheric conditions. The maximum Reynolds number capability of the tunnel is approximately 3 million per foot in air, and 10 million per foot in heavy gas. The TDT used dichlorodifluoromethane, R-12, as the heavy gas test medium until 1997 when the tunnel was converted to operate in $1,1,1,2$ tetrafluoroethane, R-134a $\mathrm{a}^{6.7}$. Model mount systems include a sidewall turntable for semispan models, a variety of stings for full-span models, and a cable mount system to simulate flying models. The TDT was designed and developed specifically for flutter testing with high model visibility from the control room and a unique bypass valve system that rapidly reduces the lunnel velocity and dynamic pressure. Test engineers can activate this latter system from the control room when severe model instabilities are encountered during testing.

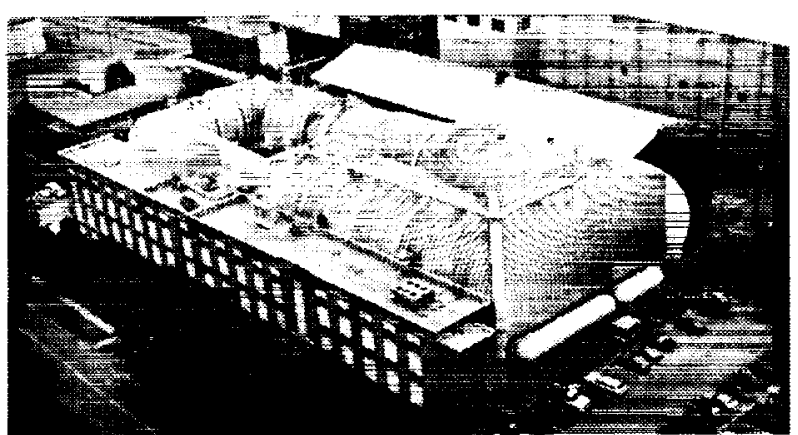

Figure 1. Aerial view of the Transonic Dynamics Tunnel. 


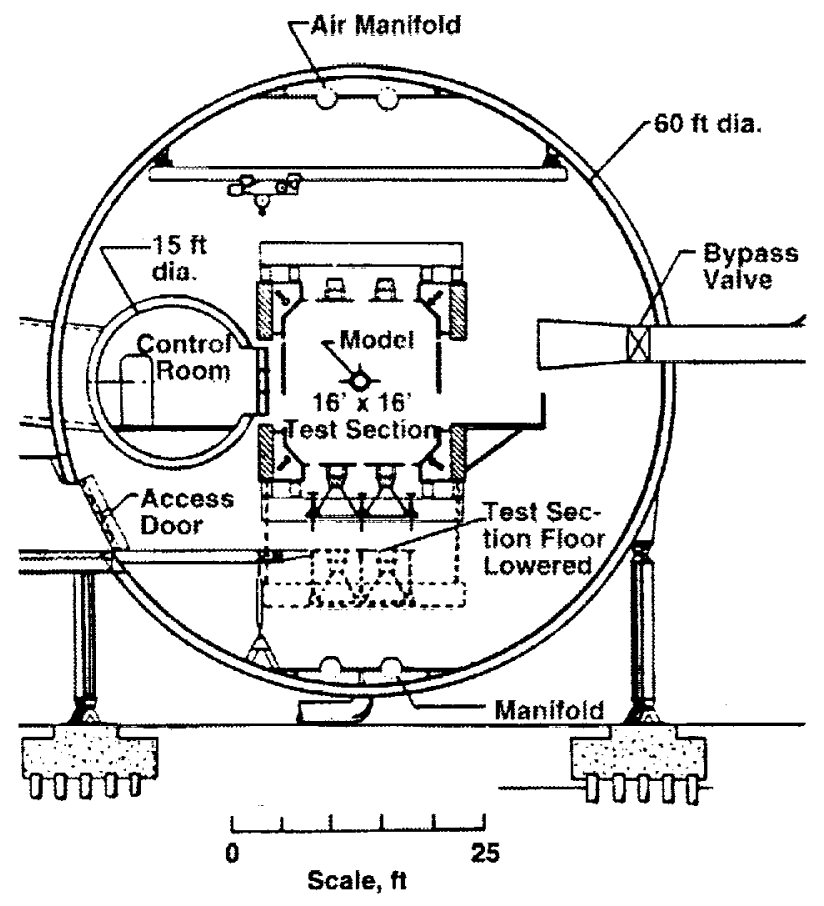

Figure 2. Cross-section of TDT test section, control room, and plenum chamber.

\section{INSTRUMENTATION, MODEL CONSTRUCTION, AND MEASUREMENT TECHNIQUES}

Over the history of the TDT, a great deal has been learned about the selection, installation, and application of unsteady pressure instrumentation in wind-tunnel models. TDT researchers have found that small, seemingly insignificant, details surrounding these issues can have a very significant impact on the quality and usefulness of the resulting unsteady pressure data. Features such as size, sensitivity, measurement range, installation, and the measurement approach of the unsteady pressure instrumentation suite influence the development process when designing wind-tunnel models for unsteady pressure measurements. The installation of the gages has a significant impact on the quality of the measurement and can also affect the time required to set up and calibrate the instrumentation as well as to reduce the data acquired during the test. Accurate, efficient, and repeatable procedures for calibrating, assessing, and monitoring the health of the instrumentation during testing is imperative to obtaining quality measurements. Finally, an accurate, efficient, and robust data acquisition system is often an enabling technology for performance of many tests involving unsteady data measurements. TDT researchers have developed and employed a variety of hardware, software, and techniques for acquiring unsteady pressure data.

Pressure transducer technology and its integration in wind tunnel models for unsteady pressure testing has evolved steadily over the period in which TDT rescarchers have acquired unsteady pressure data. While some progress has been realized in reducing the size of the transducers, the primary advances have come in the sensitivity, temperature stability, ruggedness, and DC response of the instruments. Figure 3 shows two pressure transducers and a portion of a typical unsteady pressure model tested in the TDT. The figure shows a popular method of installing unsteady pressure transducers in a wind tunnel model. The instrument on the lower right is the basic gage with its associated wiring and reference tube. The transducer on the upper left has been installed in a protective sleeve, which in this case is simply a section of brass tubing. This sleeve is then installed in the wind-tunnel model through access ports to the orifices drilled in the model surface. Dimensions for these transducers are on the order of 0.10 inches in diameter and 0.75 inches in length.

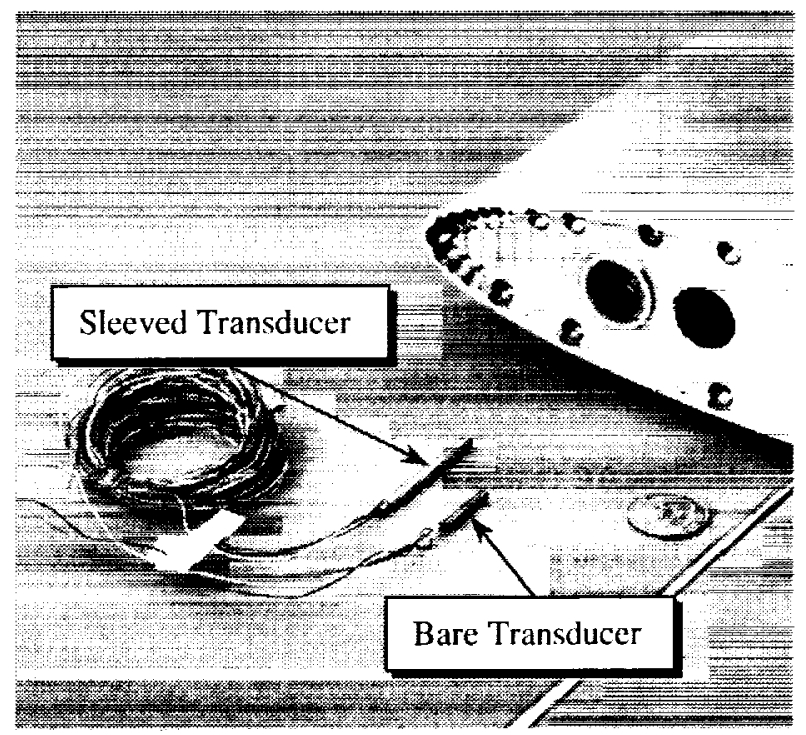

Figure 3. Transducers used in unsteady pressure testing.

The TDT is a pressure facility that usually operates at sub-atmospheric pressures. Therefore, the type of transducer, differential or absolute, employed in unsteady pressure testing can have a large impact on the quality of data acquired. Differential transducers are used for most testing in the TDT since by referencing them to the tunnel plenum pressure, their sensitivity can be closely tailored to the anticipated pressure fluctuations on the model. Another benefit 
of differential gages is that they can all be calibrated in a single pass by referencing them to a single adjustable pressure source and applying a known pressure to the reference side of the transducers. Absolute gages have been utilized on occasion however, typically for tests performed at or near atmospheric conditions. The F-18 and F-22 fin buffet studies described in this paper are recent examples where absolute gages have been effectively employed.

There are two primary techniques that have been used for measuring unsteady pressure at the TDT. The preferred technique is to place the transducer at or very near the pressure orifice on the model. This type of transducer mounting technique, known as an in situ transducer, significantly reduces the distance over which the unsteady pressure signal must travel, minimizing attenuation and phase shifts in the pressure signal. The second technique allows for the remote location of the transducers, which are ultimately connected to the model orifices via a length of tubing. This approach can greatly simplify model design and construction by allowing the transducer to be located in a readily accessible location in or outside the model. However, the addition of the tube between the orifice and transducer severely complicates the calibration of the transducers and the reduction of the unsteady pressure data. The phase and damping characteristics of the tubes must be accounted for in the data reduction, and the flow over the orifice has also been shown to have a significant impact on the calibration ${ }^{8}$, requiring the further complication of calibrating the orifices windon. The Acroelastic Research Wing (ARW-2) and Rectangular Supercritical Wing (RSW) data described in this paper were acquired using this approach. All other tests documented in this paper were performed using in situ transducers and this installation technique has become virtually the standard for TDT testing.

In situ gages significantly complicate the model design, construction and installation into the wind tunnel. Figure 4 shows a typical in situ pressure gage installation on a relatively simple wind-tunnel model. This figure shows the wiring and reference tubing associated with each transducer along a single row of pressure orifices in the model surface. Finding adequate volume, even in the relatively large-scale models tested in the TDT, is often a challenge. Also, even though the transducers have steadily become more reliable, they are still delicate instruments, and it is not uncommon to have several gages become nonfunctional during the course of testing. Therefore, it is highly desirable to be able to readily access the gages during testing to make repairs and/or replace specific transducers.

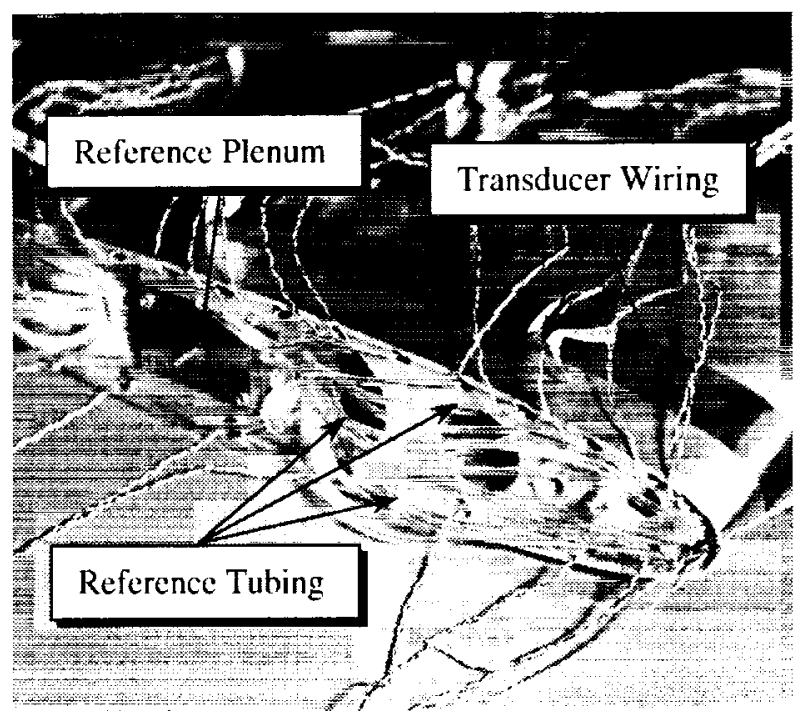

Figure 4. Typical transducer installation on a simple unsteady pressure model

All of these factors quickly add up and can significantly increase the time and cost to develop an unsteady pressure model. Numerous model construction techniques have been developed to facilitate the installation of unsteady pressure gages, and a thorough discussion of each is beyond the scope of this paper. However, it should be mentioned that modern model construction and particularly numerically controlled machining techniques are greatly influencing the way these models are being designed and fabricated. Precisely fit transducer holders, such as those shown in Figure $5^{45}$, can now be integrated directly into the model surface so that the transducers can be readily accessed and removed during testing. The holder shown in the figure is a two-piece machined aluminum part with one section holding the transducer, and the other honded to the underside of the wing skin of the model. An orifice is drilled through the skin and portion of the holder bonded to the model. The transducer side of the holder is attached using small bolts and an O-ring to prevent pressure leaks. The entire system is accessed from outside the model via small flush-mounted hatches near each pressure orifice. This system allowed the majority of transducers on the model to be maintained and/or replaced without having to disassemble major model components. It also made for a very clean installation with minimal marring of the model surface. 


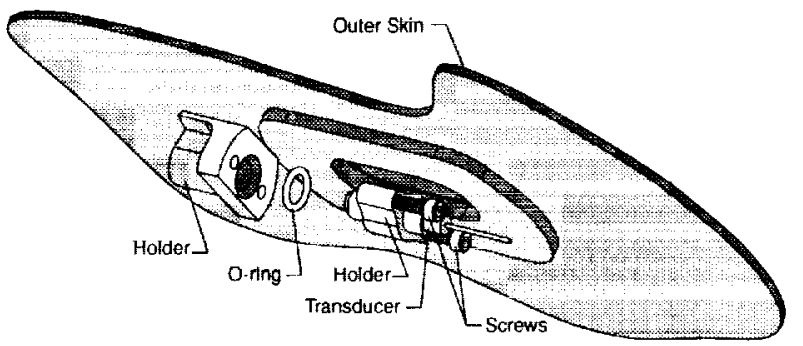

Figure 5. Transducer holder developed for the High Speed Research semispan models.

The acquisition and reduction of unsteady pressure data is a daunting task for the heavily instrumented models that are typically studied in the TDT. Issues of sampling rales and filtering can have a significant impact on the quality of the unsteady data. Nonphysical phenomena due to the poor selection of sample rate and filtering can creep into unsteady data sometimes rendering the dataset virtually unusable. This phenomenon, known as aliasing, can be catastrophic when the dynamic analog signals are not recorded, but are converted directly to digital data during testing. Thus it is imperative that the designers of experiments that acquire unsteady pressure data have a good understanding of the limitations of the data acquisition system they will be employing as well as some expectations of the general characteristic of the unsteady data they hope to be measuring.

The availability of high speed/high capacity data storage also greatly influences the design and conduction of experiments involving unsteady pressure data. The ability to quickly acquire and store the raw unsteady pressure signals is imperative, especially when performing aeroelastic testing. In these cases, the model is often at substantial risk of damage due to aeroelastic vibrations, and researchers cannot afford to hold the model on-point in the tunnel for extended periods of time while the data system processes and stores the unsteady data. They must be able to move rapidly from one test condition to the next to minimize the risk to the model due to dynamics. Finally, if time-synchronized data is to be acquired for all of the transducers on the model, the data system must have sufficient channel capacity to simultaneously sample all of the gages on the model. The evolution of computer technology has certainly relieved these problems in recent years, shifting the burden to the researcher who must now determine the best way to manage and present extremely large quantities of experimental data. The current data acquisition system available in the TDT ${ }^{5}$ can simultaneously sample 256 channels of analog data at sample rates up to 1000 samples per second, or a smaller number of channels at higher rates.

\section{UNSTEADY PRESSURE MEASUREMENTS SUPPORTING FLUTTER RESEARCH}

TDT researchers have been measuring unsteady pressure distributions since the early 1960's. Chronologically these tests have evolved from those primarily focusing on the understanding of unsteady aerodynamics and aeroelasticity for production and/or conceptual aircraft to benchmark models of simple generic configurations (see Table 1). These latter models were developed specifically to provide unsteady pressure data for use in analytical method evaluation. Recent and planned unsteady pressure measurements continue to focus on the generation of high-quality code validation data, but more realistic configurations have become the subject of these tests. The HSR program is the most definitive example of this transition, where a number of tests were performed using identical or very similar geometries for a variety of unsteady acrodynamics problems. This series of tests simultaneously supported code validation and configuration development objectives. The MAVRIC-I testing discussed later in this paper, is an upcoming unsteady pressure measurement test that follows along this path in that the primary purpose of the test is code validation, but the configuration is that of a realistic geometry.

\section{CASES SUPPORTING CONFIGURATION RESEARCH}

\section{Clipped Delta Wing}

This investigation involved the measurement of unsteady pressures for a delta wing with a clipped tip undergoing rigid body pitching and trailing-edge control surface oscillations "111. Bennett and Walker ${ }^{11}$ documented the dataset for this wing in detail, and it has been selected as a test case for a NATO Research and Technology Organization (RTO) working group document on experimental and computational test cases for computational method validation ${ }^{12}$.

The wing planform was derived from a proposed design of a supersonic transport known as the Boeing 2707-300 ${ }^{13}$. The leading-edge strake was removed from this configuration as were all camber and iwist. The wing thickness was also increased to 6 percent chord from the typical 2.5 to 3 percent chord to accommodate instrumentation. The resulting airfoil is a circular arc profile with $t / c=0.06$. 
A layout of the wing planform and associated model instrumentation is shown in Figure 6. The model was of standard construction using stainless steel ribs and spars and Kevlar-epoxy skins. The trailing-edge control surface, shown in the figure, was constructed using ribs, spars, and skins of graphite-epoxy for low weight and high stiffness. Pressure instrumentation for this wing was localed primarily on the upper surface. Lower surface pressure instrumentation is sparse and was only used to check model symmetry and angle-of-attack. As seen in the figure, there are four, well populated, rows of transducers designated as Chord A, B, D, and E. A fifth, less populated row, Chord $\mathrm{C}$, was included to improve the resolution of data near the edges of the control surface. There were two orifices located at the majority of locations represented by dots on the figure. One orifice was used to make static pressure measurements while the other was used for dynamic measurement with an in situ transducer. At locations near the wing trailingedge that could not accommodate a transducer due to model volume constraints, only static pressure measurements were acquired. An interesting feature of this instrumentation setup is that the static pressure port was connected to the reference side of the corresponding dynamic transducer via 35 feet of 0.020 -inch diameter tubing. This allowed the dynamic transducer to read only the fluctuating pressure about the static mean. The large length of tubing connecting the static orifice and the dynamic transducer reference serves to damp unsteady effects on the static orifice.

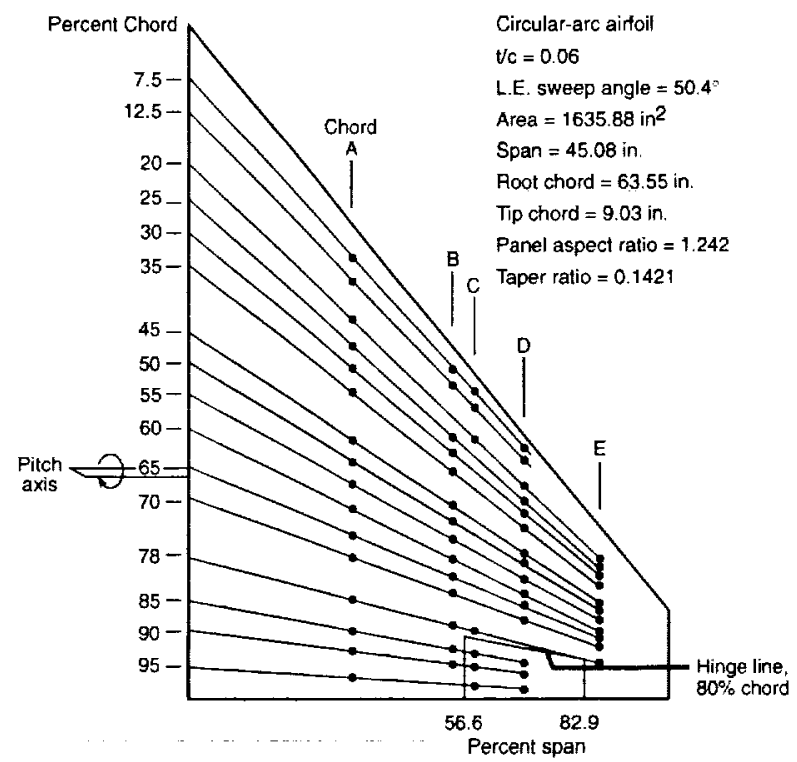

Figure 6. Wing planform and instrumentation layout for the clipped delta wing model.
The model is shown installed in the TDT in Figure 7. It was mounted to a splitter plate that was offset from the TDT wall, and the root of the wing was attached to an endplate that moved with the wing during pitching oscillations. The model was oscillated in pitch using a large, hydraulically driven, spring system mounted behind the TDT wall. The mean angle-of-attack and the amplitude and frequency of pitch oscillation could be varied using this device. A miniature hydraulic actuator located in the wing drove the trailing-edge control surface.

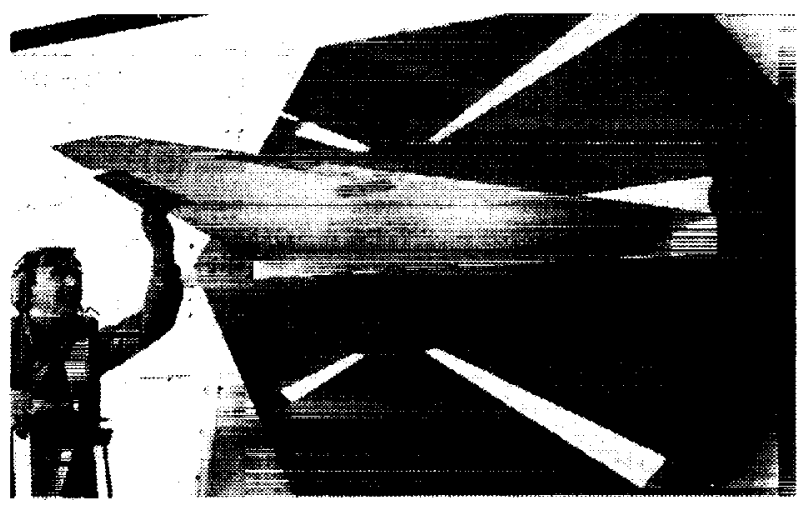

Figure 7. Clipped delta wing model installed in the TDT.

All tests were performed in heavy gas, R-12. Test conditions ranged from Mach 0.40 to 1.12 and static angles-of-attack between 0.0 and 5.5 degrees. The Reynolds number for this dataset is approximately 10 million based on the average wing chord. Forced pitch oscillation data were acquired at frequencies of 4,6 , and $8 \mathrm{~Hz}$, and amplitudes of 0.25 and 0.50 degrees. Control surface oscillations were performed at frequencies of 8,16 , and $22 \mathrm{~Hz}$ with amplitudes of 2,4 , and 6 degrees.

Sample static data from this test are plotted in Figure 8. These data were acquired at Mach $0.90,0.05$ degrees angle-of-attack, and a Reynolds number of 9.77 million based on the average wing chord. The pressures plotted on this figure are at the 54 .I percent span station, which is just inboard of the trailing-edge control surface. Figure 9 shows dynamic data at similar flow conditions and the same spanwise station. In this case, the wing has been oscillated at a frequency of $8 \mathrm{~Hz}$ with amplitude of 0.46 degrees about a mean angle-of-attack of zero degrees. Both the in-phase and out-of phase components of the pressure coefficient normalized by the pitching amplitude are included in this figure. All data for the static and first harmonic unsteady pressure distributions are provided in Reference 9, and selected cases are available in Reference 12. 


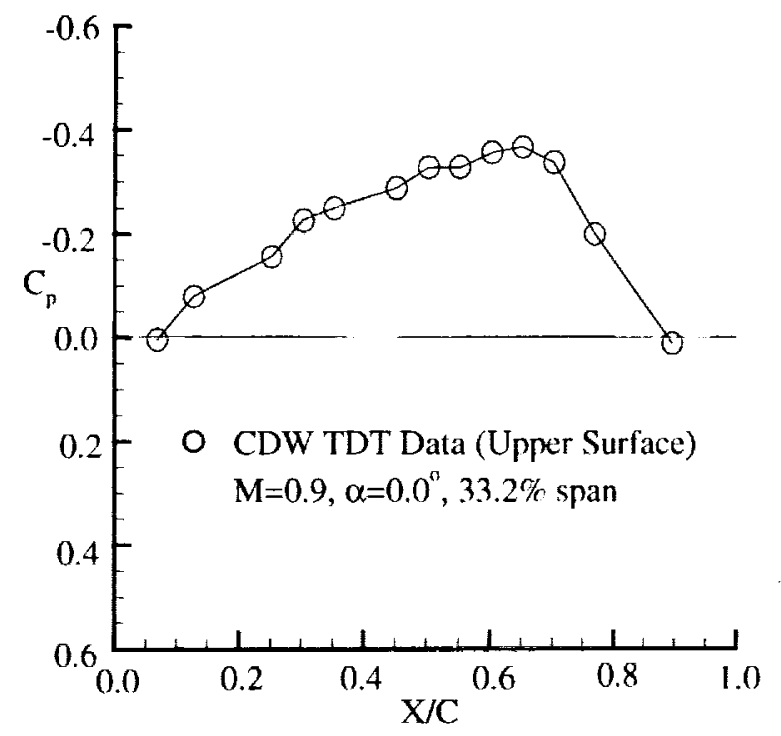

Figure 8. Sample upper surface static pressure data for the Clipped Delta Wing.

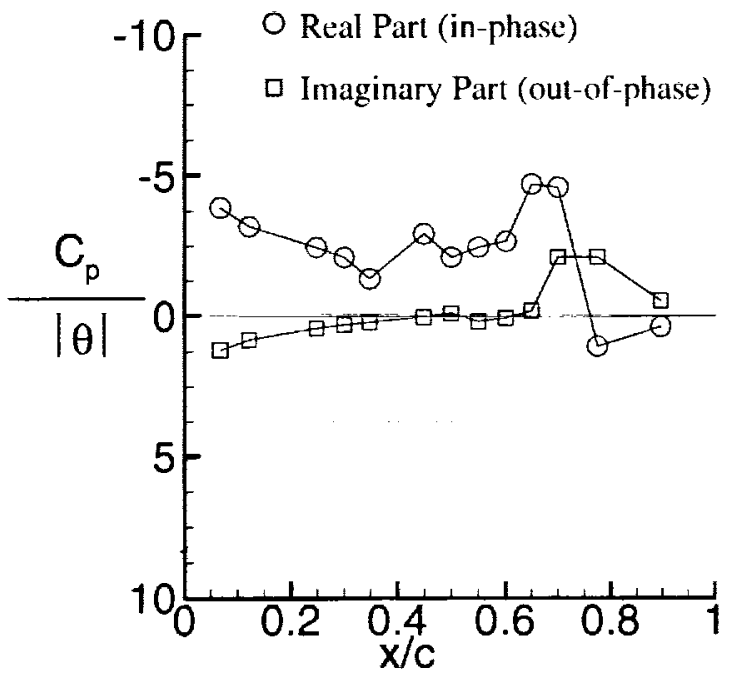

Figure 9. Sample upper surface dynamic data for the Clipped Delta Wing.

\section{Large-Scale Oscillation Rig}

Motivated by the need to investigate dynamic stall effects, a mechanism to generate oscillations up through the stall angle of attack was developed. This mechanism is shown in Figure 10 and was called the Large - Scale Oscillation Rig (LSOR). The airfoil section was located between end plates and was driven by hydraulic actuators located within the fairings on the outside of the splitter plates. One row of unsteady pressure transducers was located in a center metric section. Three airfoils were developed for the tests. During TDT Test 338 the drive mechanism malfunctioned. The system was retested as TDT Test 364. These two tests were preceded by two lests that involved some boundary layer and flow field measurements (Tests 282 and 311). Although TDT Test 364 was successfully carried out the results were not published.

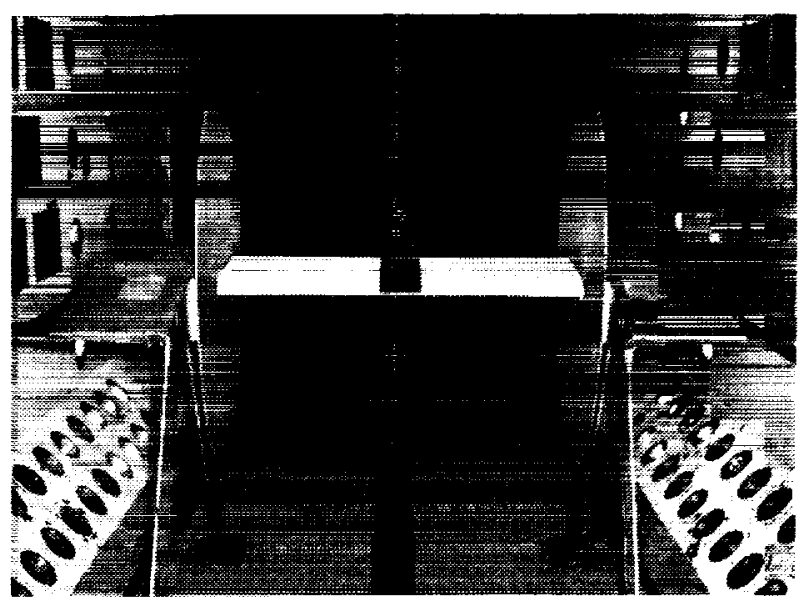

Figure 10. LSOR rig installed in the TDT.

\section{Energy-Efficient Transport Wing with Oscillating Control Surfaces}

This model ${ }^{14}$ consisted of a half-body fuselage similar to that of a "wide-body" transport and a rigid semispan wing representative of "energy efficient" transport designs. The model was mounted on the tunnel sidewall to a turntable mechanism that allowed the mean angle of attack to be varied (see Figure 11). A sketch of the wing is presented in Figure 12. The wing had a leading-edge sweep of 28.8 degrees, an aspect ratio of 10.76 , and a semispan of 2.286 meters. The side of the half-body was located at wing station 0.219 meters.

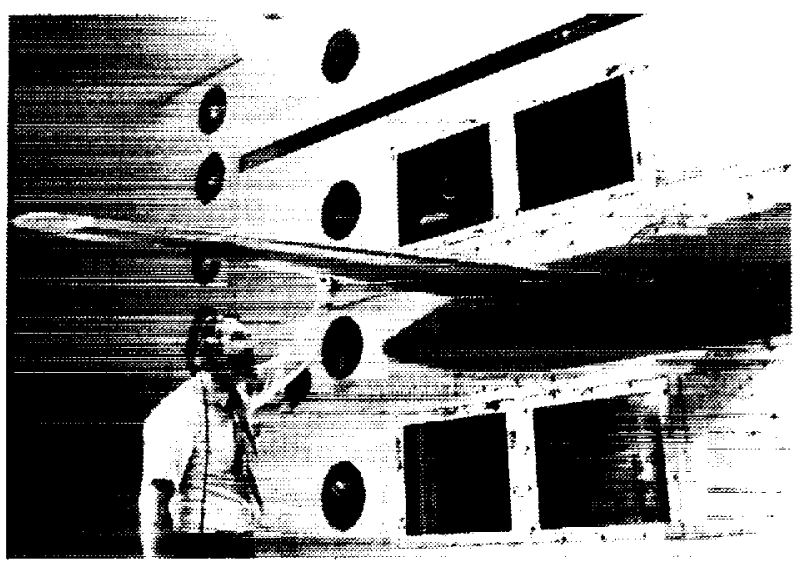

Figure 11. Energy efficient transport wing mounted in TDT. 


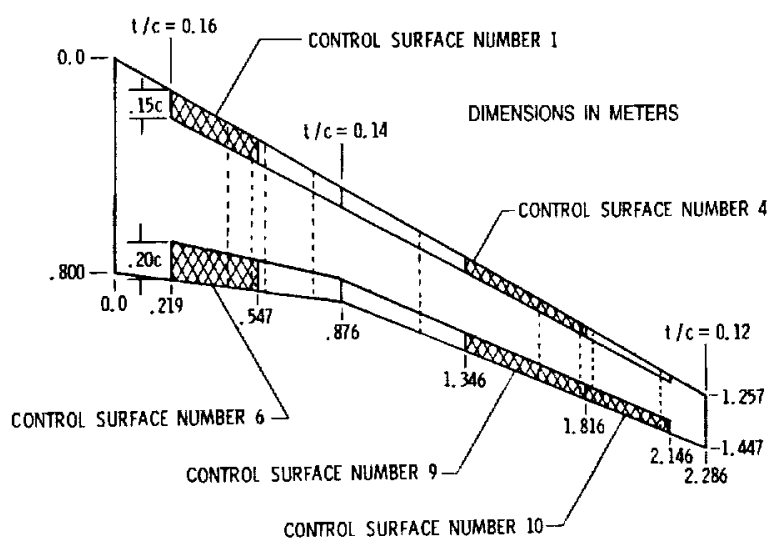

Figure 12. Planform and control surface layout for the energy-efficient transport wing.

The wing contour was formed from three different supercritical airfoils. These three airfoils were located at wing stations $0.219,0.876$, and $2.286 \mathrm{~m}$. and had thickness-to-chord ratios of $0.16,0.14$, and 0.12 , respectively. The three supercritical airfoil shapes are shown in Figure 13. Straight-line interpolation along constant percent chords was used between adjacent airfoil sections. The section twist angles at each station are also shown in Figure 13.

The wing was constructed from aluminum alloy with a layer of Boron for stiffness, and consisted of upper and lower sections. The sections were permanently bonded together to form a box cross-section. This stiff, lightweight structure had a fundamental frequency of $23 \mathrm{~Hz}$., well above the maximum control surface excitation frequency of $15 \mathrm{~Hz}$. used during the tests. The lightweight control surfaces were constructed of Kevlar-balsawood sandwich material and were actuated with miniature rotary hydraulic actuators for static deflections of up to \pm 6 deg. and oscillatory deflections at frequencies of 5 , 10 , and $15 \mathrm{~Hz}$.

The wing was equipped with 10 oscillating control surfaces that are outlined in Figure 12. The leadingedge control surfaces were 15 percent of the chord and the trailing-edge control surfaces were 20 percent of the chord. Only 5 of the control surfaces were tested during the three tunnel entries made with this model in $1979^{15}, 1980^{16}$, and $1981^{17}$. These control surfaces are shown crosshatched in Figure 12: numbers $I$ and 4 on the leading edge and numbers 6 , 9 , and 10 on the trailing edge. The model was instrumented with 252 static pressure orifices and 164 in situ dynamic pressure transducers located on 9

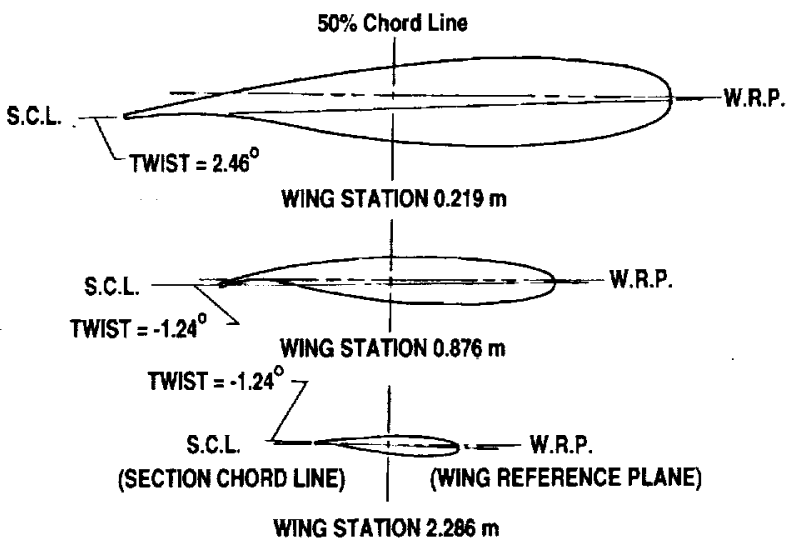

Figure 13. Airfoil contours for the energy-efficient transport wing.

spanwise chords indicated by dashed lines in Figure 12. There were a maximum of 5 steady orifices and 2 unsteady pressure transducers on the leading-edge control surfaces (both upper and lower surfaces). The trailing-edge control surfaces had 3 steady orifices and 3 unsteady pressure transducers (both upper and lower surfaces). The wing was mounted to a fivecomponent balance that measured the wing static forces and moments. Other instrumentation included the wing root angle of attack, the control surface positions, and six accelerometers mounted in the wing.

Steady pressures were measured using six 48 -port scanning valves that were stepped simultaneously from port to port. For each measurement, the pressure was allowed to settle for 0.3 second and then was averaged for approximately I second to acquire a mean value of pressure coefficient for each orifice. Unsteady pressure time-history signals were sampled for 75-100 cycles of control surface oscillation at 1000 samples per second and recorded on digital tape for subsequent playback and analysis. During playback of the digital tapes, the Fourier components of the data were determined at the frequency of oscillation of the control surface. Values of pressure coefficient magnitude and phase angle relative to the oscillating control surface position were calculated for each transducer. To analyze 28 channels of data simultaneously, it was necessary to limit the number of samples per channel to 1000 samples due to computer memory limitations. Thus, all unsteady pressure results were analyzed at sample rates of 71 , 125 , and 200 samples per second for the 5-, 10-, and 15-Hz. data. 
Reference 15 gives data for the first test in which control surfaces 6 and 9 were actuated (see Figure 12). During the second test, control surfaces 4,6 , and 9 were actuated ${ }^{16}$ and the third test involved actuation of control surfaces 1, 6, and $10^{17}$. Two Reynolds numbers were investigated: 2.2 million and 4.7 million hased on average wing chord. During the first test, steady data was obtained for Mach numbers from 0.40 to 0.84 . The model configuration variations included angles of attack from -3 to 4 degrees and control surface deflection angles from -6 to 12 degrees for control surface number 6 , and from -9 to 9 degrees for control surface number 9 . For this test, unsteady data was obtained at the model design cruise Mach number of $\mathrm{M}=0.78$ and for two angles of attack for each test Reynolds number: 0 degrees and approximately 2 degrees. At each angle of attack, the two control surfaces were tested independently for three different mean deflections angles, at three different amplitudes of oscillation $( \pm 2, \pm 4$, and \pm 6 degrees), and three different oscillation frequencies $(5,10$, and $15 \mathrm{~Hz})$. The reduced frequency, based on root semichord covers a range of roughly 0.1 to 0.3 for the test conditions.

The second test added control surface number 4 actuation and was focused upon two Mach numbers, $\mathrm{M}=0.60$ and 0.78 . Configuration variations were similar to those of the first test. In addition, phasingeffects due to simultaneous actuation of control surfaces 4 and 9 were investigated. The third test investigated similar configuration variations for control surfaces 1,6 , and 10 for Mach numbers of $0.60,0.78$, and 0.86 . Complete details of the test results for these configuration variations can be found in References 15 through 17.

Steady pressure data from these tests are shown in Figure 14 at 71 percent semispan for two Mach numbers: $M=0.78$ and 0.86 and for varying angle-ofattack. Trailing-edge flow separation is seen on the upper surface for the higher Mach number. Lifting pressure magnitude and phase angle at 18 percent semispan are shown in Figure 15 for oscillations of the inboard trailing-edge control surface (number 6). The effect of varying Mach number is seen over the
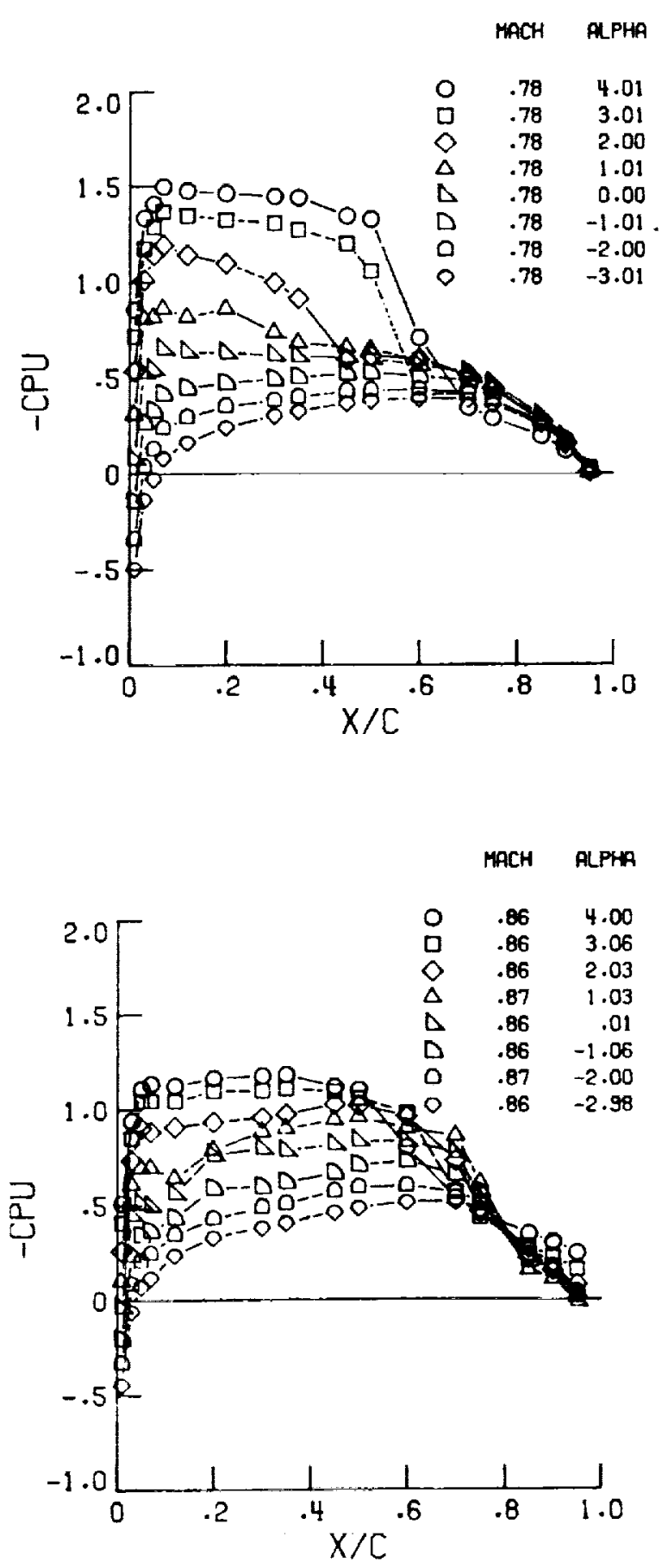

Figure 14. Steady upper surface pressure distributions for the energy efficient transport wing. 

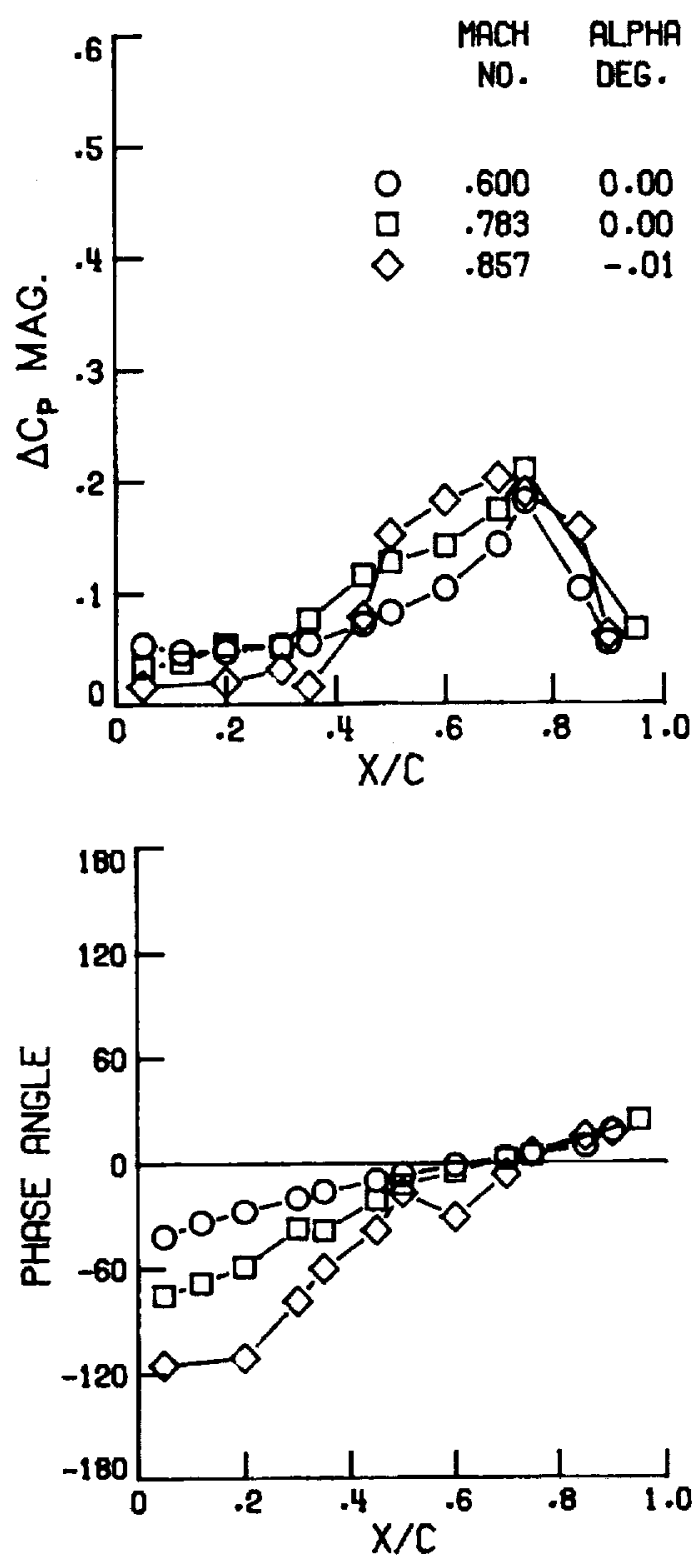

Figure 15. Unsteady differential pressure coefficient as a function of Mach number for the energy efficient transport wing.

forward portion of the chord in both amplitude and phase, whereas little variation is seen in the vicinity of the control surface. The effect of varying frequency of oscillation of the outboard control surface (number 9) on lifting pressure at $7 \mathrm{I}$ percent semispan is shown in Figure 16. For $M=0.78$, the frequency affects the amplitude of the 'shock pulse' seen near 40 percent chord and the phase forward of the shock. Again, there is little effect in the vicinity of the control surface.

$$
M=0.78 ; R N=2.2 \times 10^{6} ; a_{0}=2.05^{\circ} ; \delta= \pm 6^{\circ}
$$
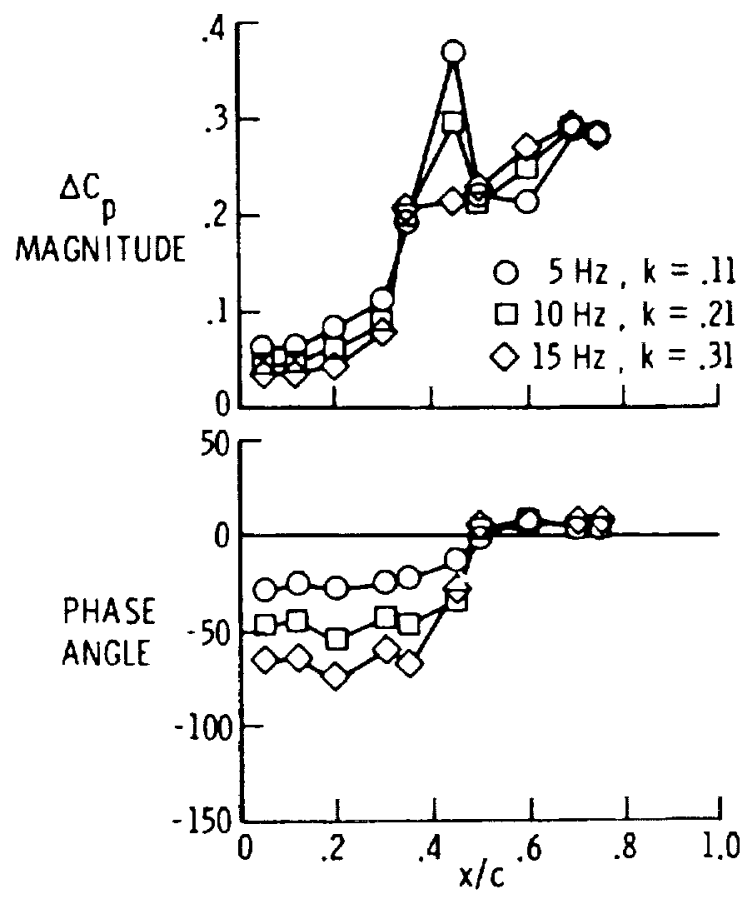

Figure 16. Unsteady differential pressure coefficient as a function of control surface oscillation frequency for the energy efficient transport wing.

\section{Rectangular Supercritical Wing}

In the early 1980's, a simple rectangular planform wing with a supercritical airfoil section was tested in the TDT to investigate the unsteady aerodynamic characteristics of wings employing supercritical airfoils, and to provide correlation data for Computational Fluid Dynamics (CFD) methods. This wing, known as the Rectangular Supercritical Wing $(\mathrm{RSW})^{18.19 .20}$, was oscillated in pitch and unsteady pressure measurements were acquired using a combination of in situ transducers and matched-tube orifices. Bennett and Walker ${ }^{2 t}$ present a selection of computational test cases from this investigation.

A photograph of the model installed in the TDT is shown in Figure 17. The RSW had an unswept rectangular planform with a tip of revolution, a panel aspect ratio of 2.0 , a twelve percent thick supercritical airfoil, and no twist. The constant airfoil section of the wing was 48 inches in span, and the tip of revolution made the overall span of the wing 49.43 inches. The wing chord was 24 inches. The airfoil 
for the RSW is shown in Figure 18. It was derived from an 11 percent thick section ${ }^{22}$ by increasing the thickness to 12 percent while maintaining the mean camber line. Reference 20 quotes the design Mach number and lift coefficient to be 0.80 and 0.60 , respectively. A complete set of measured ordinates for the model are available, and in general, they compare very well with the theoretically derived airfoil contour ${ }^{21}$.

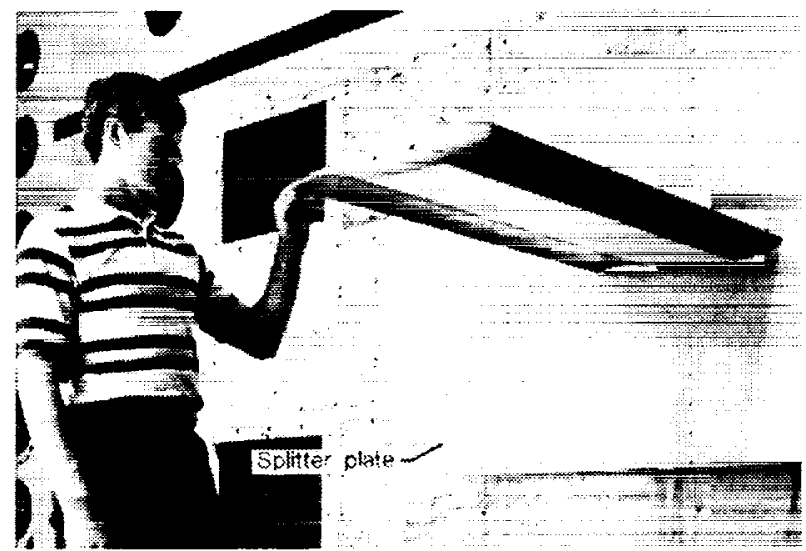

Figure 17. Rectangular Supercritical Wing mounted on splitter plate in the TDT.

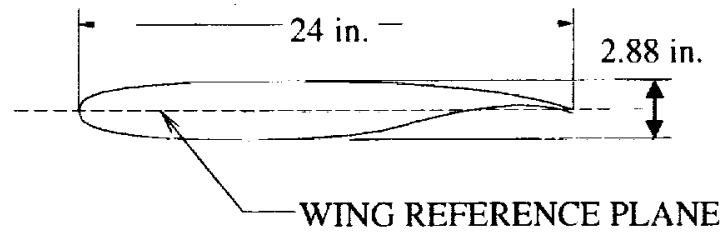

Figure 18. Airfoil for Rectangular Supercritical Wing.

The RSW was mounted to a splitter plate in the TDT to offset the model from the boundary layer formed along the wall of the wind tunnel. It was oscillated in pitch about the 46 percent chord line using a hydraulically driven rotary actuator located behind the wind-tunnel wall. Using this device, the model could be set at various mean angles, and the amplitude and frequency of oscillation could be varied.

The wing was constructed in three sections. The center section was made of aluminum with upper and lower halves that were pinned and bonded together. The leading and trailing-edge pieces were of balsa and Kevlar construction to minimize inertia loading.

An instrumentation layout for the wing is shown in Figure 19. Unsteady pressures were measured along four chords at $30.9,58.8,80.9$, and 95.1 percent of the 48-inch reference span. There were 14 measurement locations along each chord on the upper and lower surface of the wing and one location in the nose for a total of 29 pressure ports per wing chord. As shown in the figure, pressure measurements in the center section of the wing were made using both in situ transducers and matched-tube orifices. Pressures in the leading and trailing edges were acquired using only matched tube orifices. The matched tube orifices in the center of the wing adjacent to the in situ transducers were used to correct for the dynamic effects of the tubes in the forward and aft section of the wing

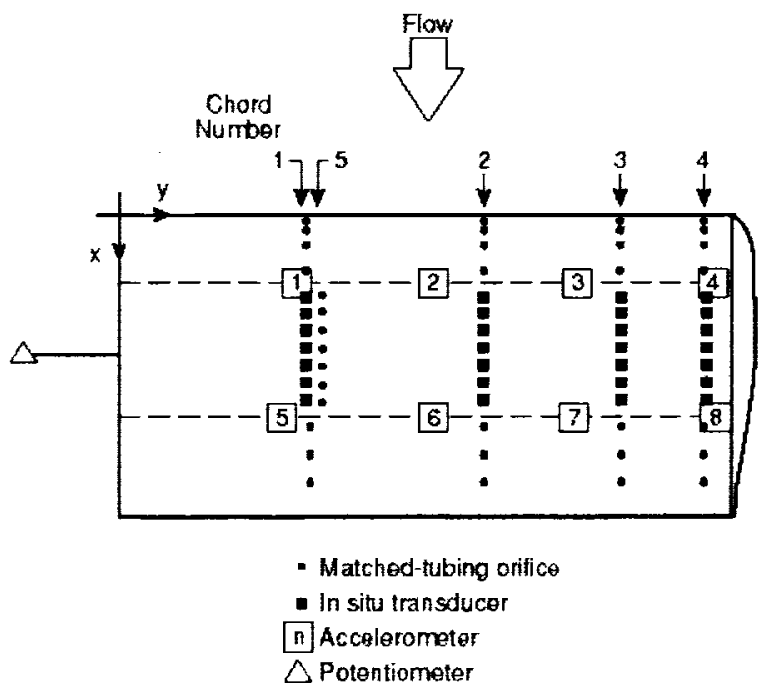

Figure 19. Instrumentation layout for the Rectangular Supercritical Wing.

The majority of test data were acquired in heavy gas, R-12, and these data are generally accepted as the most useful for CFD code validation and verification. The available data for this wing is summarized in Figure 20. The RSW was tested at Mach numbers between 0.40 and 0.90 , and static angles-of-attack between -4 and 14 degrees. The majority of data were acquired at angles-of-attack between -1 and 7 degrees. The high end of the Mach number and angle-of-attack range is well beyond the design point for this airfoil, but these conditions are representative of those that might be required for flutter verification beyond cruise conditions. Forced pitching oscillation data were acquired with amplitudes of $0.5,1.0$, and 1.5 degrees and frequencies of $5,10,15$, and $20 \mathrm{H} z$. Limited data is also available at frequencies below 5 $\mathrm{Hz}$.

Figure 21 shows a sample of the static pressure data acquired a Mach 0.802 , and two degrees angle-ofattack. The figure shows the upper and lower surface pressure coefficient plotted as a fraction of the wing 


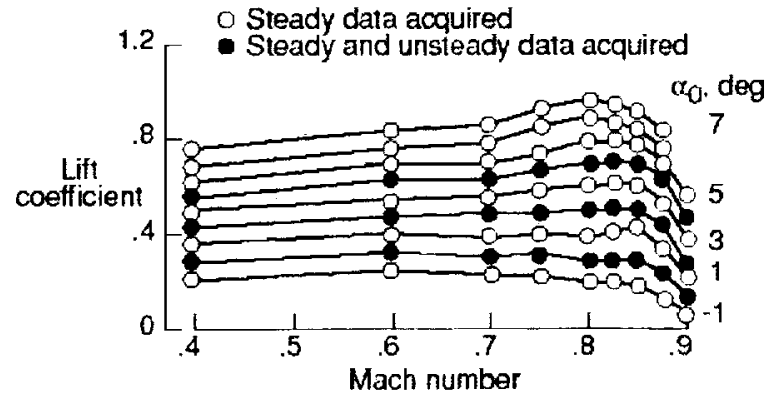

Figure 20. Experimental datapoints acquired during test of Rectangular Supercritical Wing.

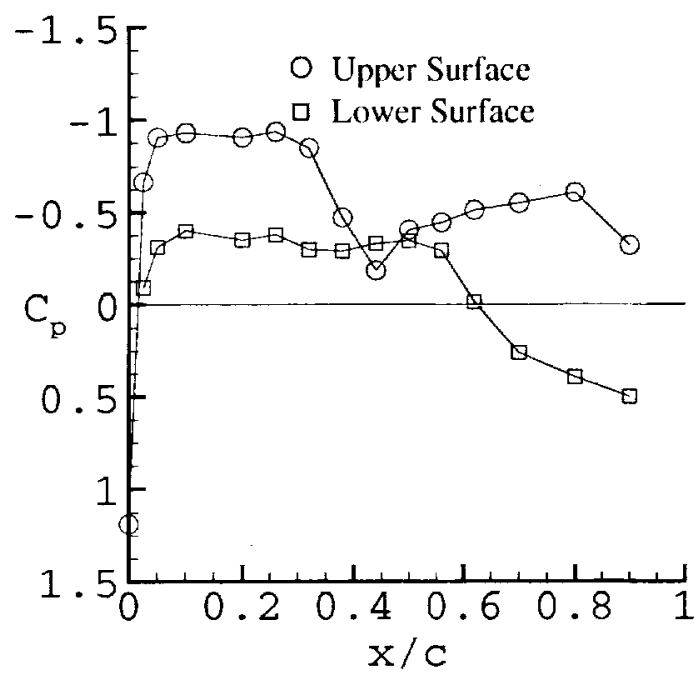

Figure 21. Sample static pressure distribution for the Rectangular Supercritical Wing.

chord at the 30.9 percent span station. A sample of the dynamic data acquired at Mach 0.804, 2.08 degrees mean angle-of-attack, 1.057 degrees pitch amplitude, and a frequency of $9.96 \mathrm{~Hz}$ is presented in Figure 22. In this figure, the top plot shows the real (in-phase) and imaginary (out-of-phase) components of the unsteady pressure for the upper surface orifices, while the bottom plot shows similar data for the lower surface. In both cases, the pressure components are further normalized by the amplitude of the pitching motion.

\section{Aeroelastic Research Wing (ARW-2)}

In NASA's Drones for Aerodynamic and Structural Testing (DAST) program ${ }^{2.3}$ two elastic supercritical wings were designed to be flight-tested on an unmanned remotely-piloted drone aircraft. The purpose of the program was to provide a complement to wind tunnel and full-scale piloted flight-testing of

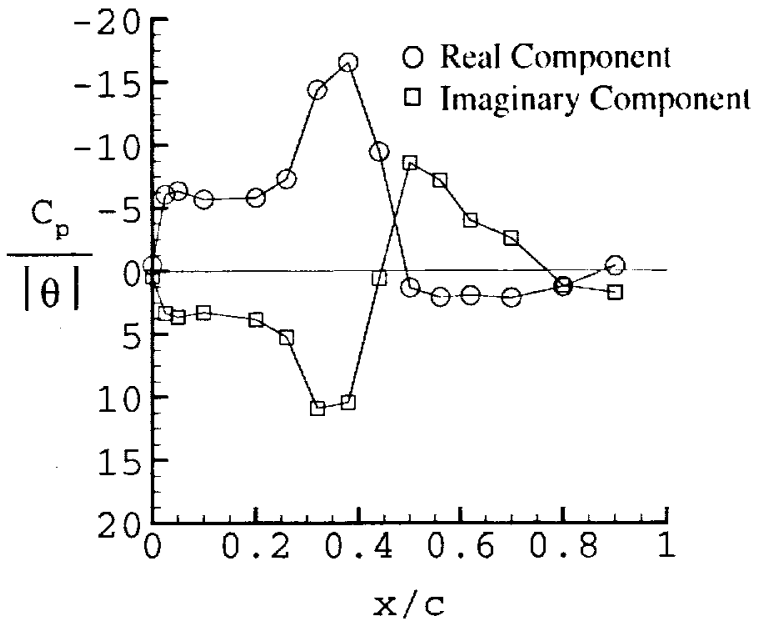

a) Upper Surface

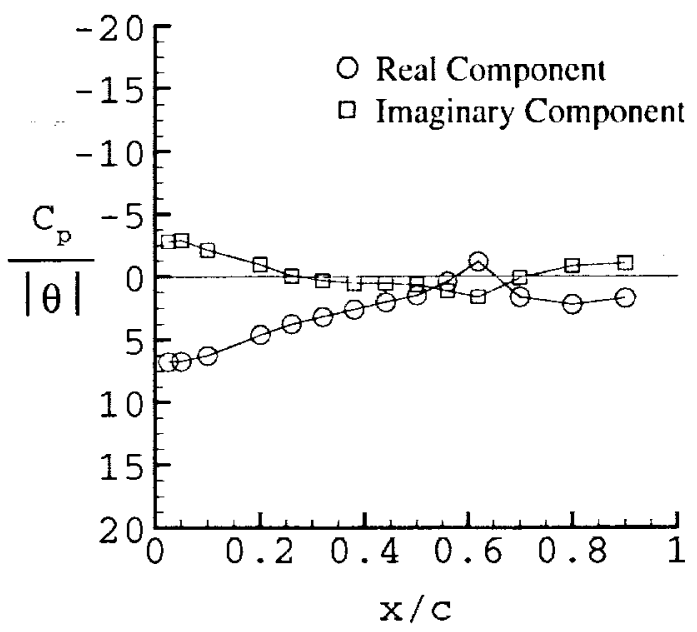

b) Lower Surface

Figure 22. Sample unsteady pressure distributions for the Rectangular Supercritical Wing.

realistically flexible structures, allowing investigation of acroelastic effects such as flutter suppression, gust alleviation, and maneuver load control. A delay and eventual cancellation of the flight test program of the second Aeroelastic Research Wing (ARW-2) made the structure available for testing in the Transonic Dynamics Tunnel. Although the design flutter boundary was outside the tunnel's operational boundary, the availability of the unsteady pressure transducer instrumentation and hydraulically actuated aileron control surface made this an attractive test.

Figure 23 shows the right wing panel installed on the tunnel sidewall on a half-body fuselage used to simulate the drone fuselage. Both the fuselage and the wing were mounted on the remotely controlled 
turntable mechanism located on the tunnel sidewall. The wing had an aspect ratio of 10.3 and a leadingedge sweep of 28.8 degrees. It was equipped with three hydraulically driven control surfaces, two inboard and one outboard aileron. The inboard surfaces were held fixed at 0 -degrees and only the aileron was deflected statically and dynamically. The wing contour was formed from three different supercritical airfoil shapes located at the wingfuselage junction, the wing planform break, and the wing tip. The three sections had thickness-to-chord ratios of $0.15,0.12$, and 0.11 respectively. The wing construction jig shape was derived from the defined cruise Mach number of 0.80 , the corresponding loading conditions, and the flexibility of the wing structure. Geometric and structural details of the model are detailed in Reference 24.

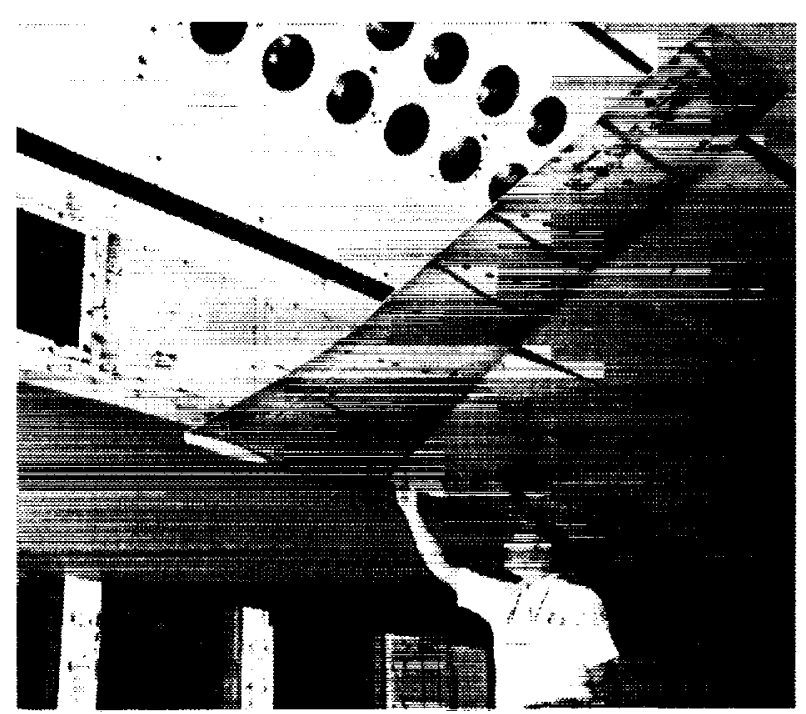

Figure 23. ARW-2 wing mounted on east wall of the TDT.

The locations of the wing instrumentation are shown in Figure 24. The instrumentation consisted of 191 pressure transducers and 10 accelerometers. In addition, strain gages were located near the wing root to measure bending moments. The model angle-ofattack was measurcd by a servo accelerometer that was mounted near the wing root. Both steady and unsteady pressures were obtained using differential pressure transducers referenced to the tunnel's static pressure. Streamwise rows of upper and lower surface pressure orifices were located at six span stations shown in the figure. All these surface orifices were connected to pressure transducers by matched tubes having a 0.040 -in. inner diameter and a length of 18 inches. A row of in situ transducers mounted on the wing upper surface parallel to the

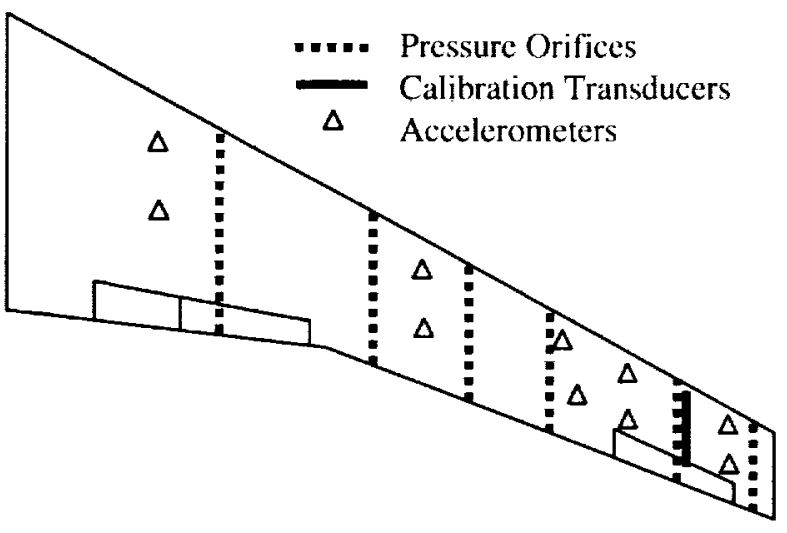

Figure 24. Planform, control surface, and instrumentation layout for the ARW-2 wing.

fifth row of surface orifices was used to derive corrections for the matched-tube transducers.

Two tunnel tests of the model were conducted in 1983 and 1985. The matrix of wind-tunnel test conditions for the steady pressure measurements during the first test is shown in Figure $25^{25}$. Test Mach numbers included $0.60,0.70,0.75,0.80,0.85$, and 0.88 . Al a dynamic pressure of $100 \mathrm{psf}$, the Reynolds number (per foot) varied from 2.5 to 1.7 million at Mach numbers of 0.6 to 0.9 respectively. Measurements were made along lines of constant tunnel stagnation pressure. Additional mcasurements were made for tunnel dynamic pressures of 100 and 200 psf. where unsteady pressures were measured. Reference 26 summarizes results from the first test. The steady pressure data from this test are reported in Reference 25. Model configuration variations included angle of attack values from -2 to +4 degrees and aileron deflection angles from -8 to +8 degrees. An outstanding feature of this test was the extensive photogrammetric measurement of the wing static deflections for these conditions ${ }^{27}$. Figure 26 and Figure 27 show representative steady chordwise pressures for varying span stations at $M=0.80$ and varying Mach number at span station 0.87 , respectively.

Also during this first test, unsteady pressures were measured while oscillating the outboard aileron control surface ${ }^{26}$ and the data is reported in Reference 28. Tunnel conditions were Mach numbers of 0.60 , $0.70,0.80$, and 0.85 and dynamic pressures of 100 and 200 psf. Model configuration variations included angles-of-attack of 0 and 2 degrees, dynamic aileron deflection amplitudes of 1,2 , and 3 degrees about a 


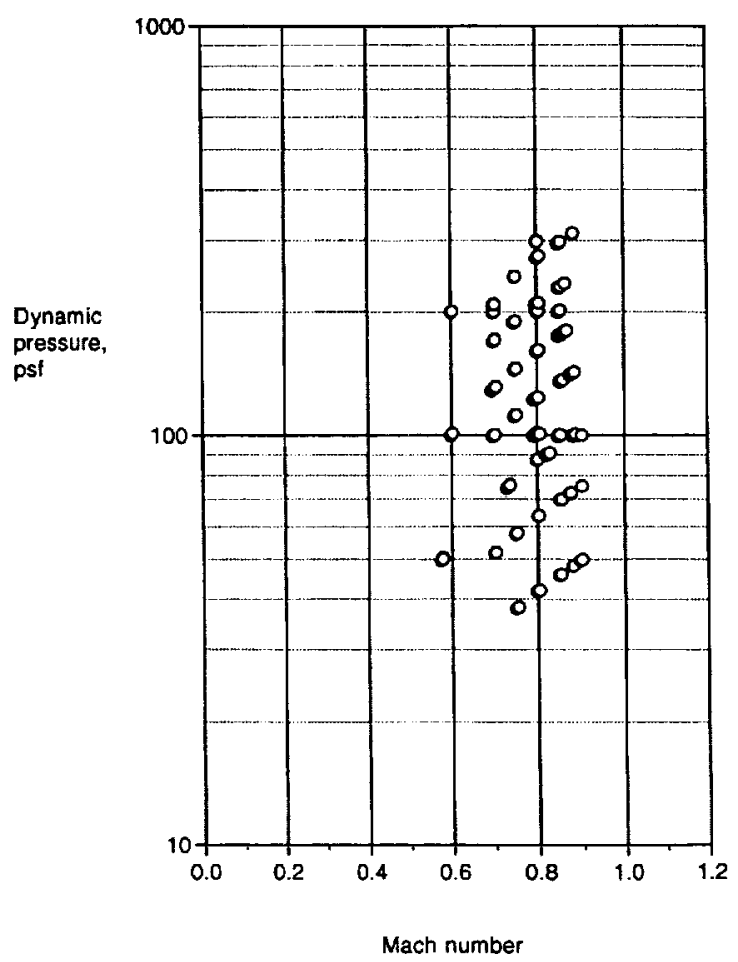

Figure 25. TDT test condition matrix for the ARW-2.
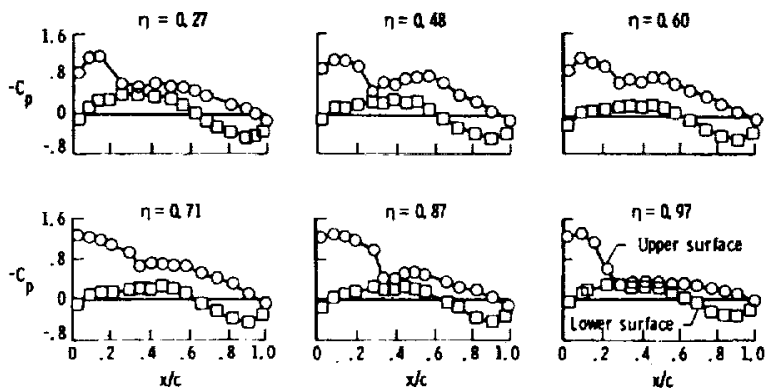

Figure 26. ARW-2 steady pressure distributions at six span stations, $\mathrm{M}=0.8$.
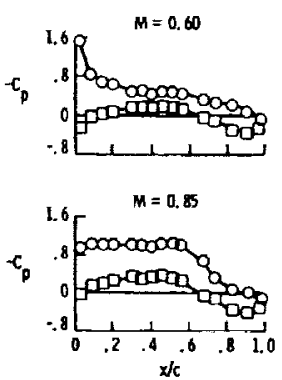
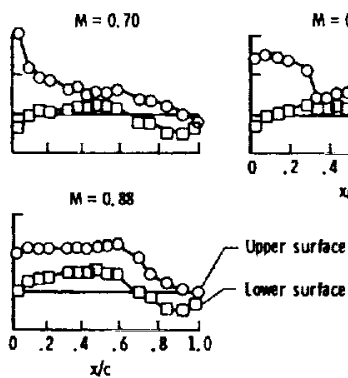

Figure 27. ARW-2 steady pressure distributions at five Mach numbers, $\eta=0: 87$. mean deflection of 0 degrees, and aileron oscillation frequencies of 5,10 , and $15 \mathrm{~Hz}$. Figure 28 shows the effect of Mach number on the magnitude and phase of the unsteady lifting pressure at span station 0.87 . The effect of the upper surface shock motion induced by the aileron oscillations is clearly seen in the lifting pressure magnitude for $\mathrm{M}=0.70,0.80$, and 0.85 .
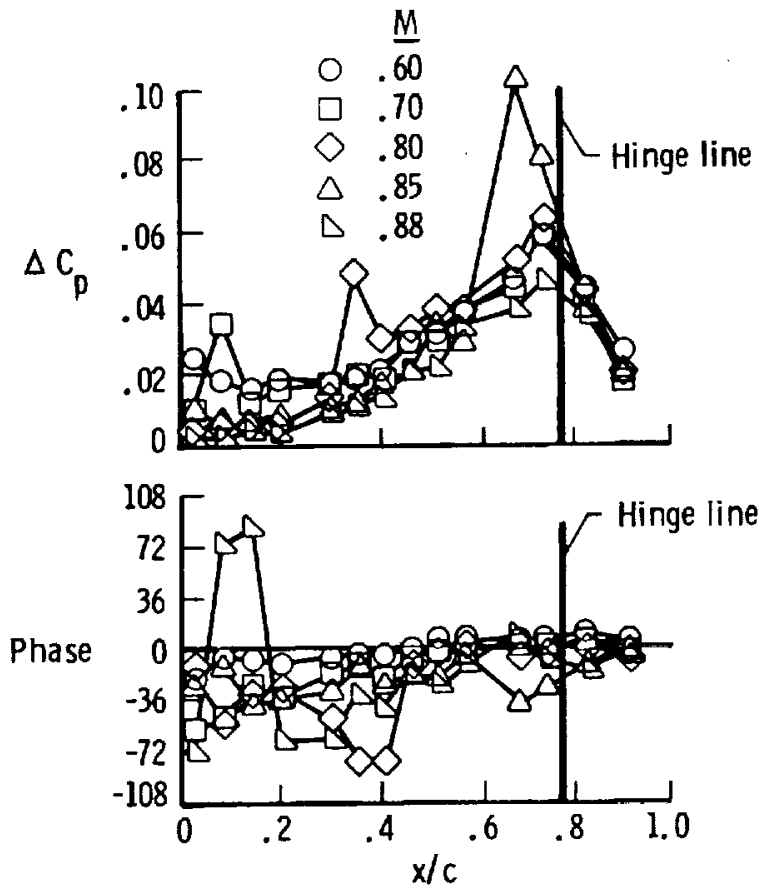

Figure 28. Unsteady lifting pressure distribution as a function of Mach number for the ARW-2 wing.

During this first test, a boundary of high wing dynamic response was observed near $\mathrm{M}=0.90$ which persisted over the complete dynamic pressure range of the tunnel ${ }^{26}$. The wing motion was predominantly in the wing first bending mode, with the frequency varying from $8.6 \mathrm{~Hz}$. at the lowest dynamic pressure and increasing to about $1.3 \mathrm{~Hz}$. at the highest dynamic pressure. The first bending mode wind-off frequency was $8.3 \mathrm{~Hz}$. It was this wing response which limited testing to $\mathrm{M}=0.88$ or less during the first tunnel test. Subsequent interest in this "single-degree-offreedom" type response resulted in the second tunnel test of the model in order to study the unsteady loading involved. Results of this second test are reported in References 29,30 , and 31 .

Figure $29^{\text {?II }}$ indicates the region of high-dynamic response that was measured during this test. (In References 26 and 29 the region is erroneously labeled as an "instability boundary.") The region is well below the calculated linear theory flutter boundary of 
the wing (in air). Three traverses of the region for increasing values of tunnel stagnation (and dynamic) pressure were made. Figure $30^{301}$ shows accelerometer time history and frequency analysis results for increasing Mach number. Maximum response amplitudes occur near $\mathrm{M}=0.92$ and the response subsides by $M=0.96$. The maximum wing response level increased with increasing dynamic pressure. Figure $31^{310}$ shows upper and lower surface pressure time histories and mean pressure distributions at span station 0.87 for four Mach numbers bracketing the high response region. Reference 29 discisses the interpretation of such mean pressure distribution data in light of surface tuft studies that were also conducted during the test. A significant observation is that the tuft studies clearly indicated regions of intermittent flow separation at conditions where this was difficult to discern from the mean pressures. Reference 31 is a comprehensive report of the unsteady pressures measured in this test. The nature of the wing response is certainly that of buffet onset and is due to the initiation of flow separations on the upper and lower surfaces. Unsteadiness in the wing loading drives the wing primarily in its first bending mode somewhat akin to the "torsional wing buzz" reported in Reference 32.

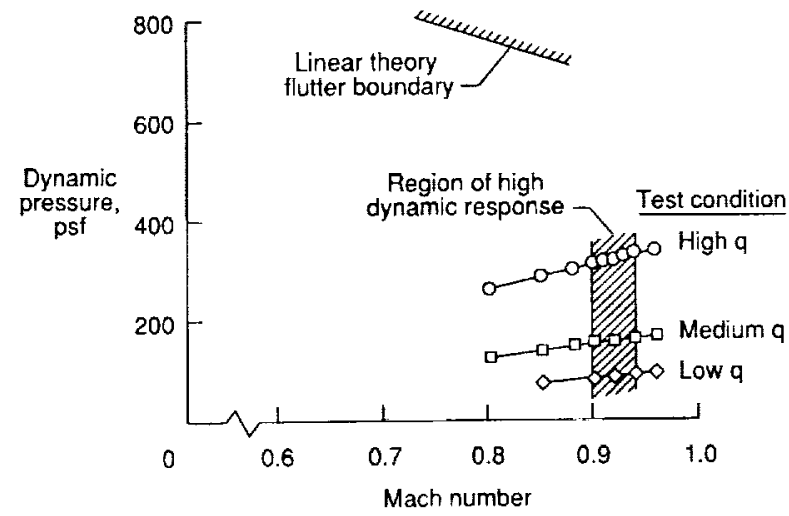

Figure 29. ARW-2 test envelope and regions of high dynamic response.

\section{Supercritical Transport Wing Flutter Test}

A high aspect ratio supercritical transport wing was designed for TDT flutter testing and unsteady pressure measurements by NASA LaRC and the then Lockheed-Georgia Company ${ }^{3.3}$. The objectives of this test were to acquire unsteady pressure measurements at flutter and under forced pitch oscillation for computational method validation.

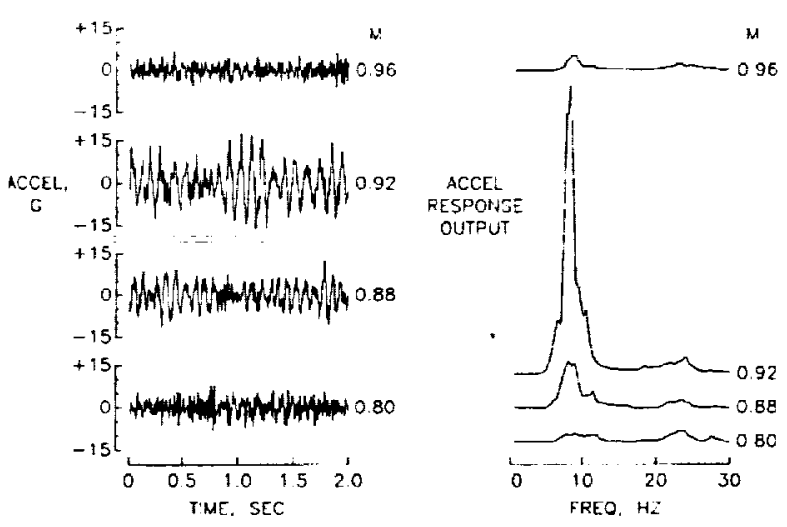

Figure 30. ARW-2 accelerometer time history and frequency response data.

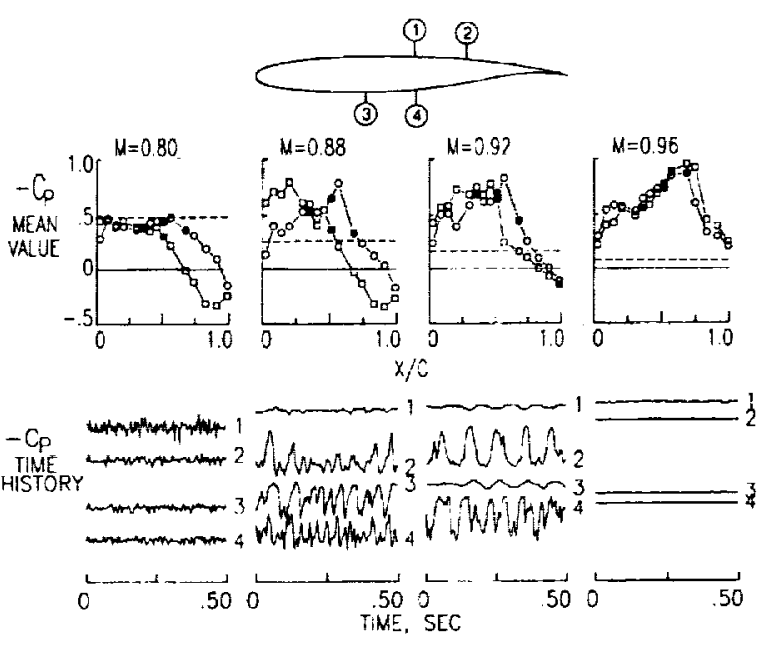

Figure 31. ARW-2 mean pressure distributions and selected unsteady pressure time histories as a function of Mach number.

The model mounted in the TDT is shown in Figure 32. This wing is typical of mid-1980's transport technology with an aspect ratio of 7.84 and a supercritical wing section that varies from 14.2 percent thick at the root to 12.7 percent thick at the tip. The wing had a semispan of 83.5 inches, and a simulated half-fuselage body was included to displace the wing from the tunnel wall boundary layer. The wing was of single-spar construction with sectional covers to provide the external wing contours. The rigid sections twisted about the wing spar in this "pod"-type model. In all there were 11 sections as shown in Figure 33. Nine of these sections were constructed of balsawood. The remaining two sections, which contained the pressure instrumentation, were made of aluminum. 


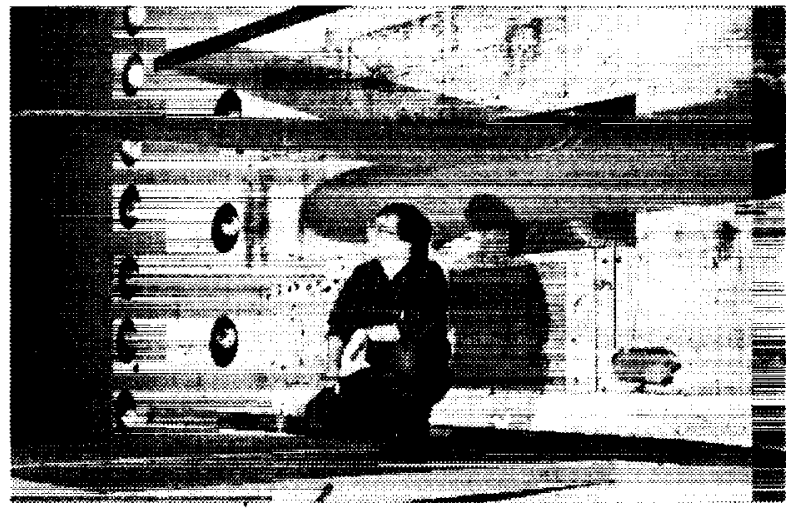

Figure 32. Supercritical transport wing mounted in TDT.

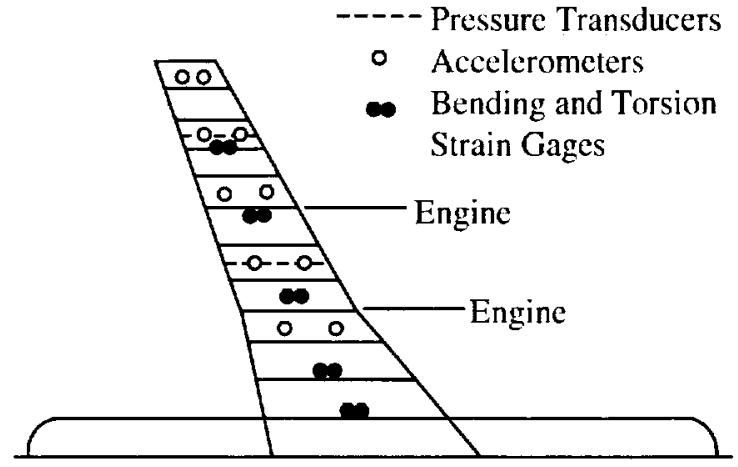

Figure 33. Supercritical transport wing planform and instrumentation layout.

The wing was built with two interchangeable spars.

The baseline spar was used to obtain pressure measurements at flutter and it was designed to flutter at high Mach number and low dynamic pressure. The second spar was four times as stiff as the baseline and it was used to gather unsteady pressure data during forced oscillations in pitch. A custom-built hydraulic servo controller was used to set the model pitch angle and oscillate the wing. Only the wing pitched on this model, the fuselage was fixed a zero angle of attack. The wing angle-of-attack could be adjusted hetween -3 degrees and +2 degrees. Forced oscillation of the wing was performed a $2,4,8$, and $16 \mathrm{~Hz}$, which covered the range of anticipated flutter frequency.

Chordwise pressures were measured at the 49.6 percent and 82.1 percent span stations using in situ transducers located between 2.5 percent and 90 percent chord at each station. The transducers were set up to read the differential pressure between the upper and lower surface of the wing. In addition, five pairs of accelerometers, five bending gages and five torsion gages were included in the instrumentation suite. The strain gages were used to determine the wing's static deflected shape, and in conjunction with the accelerometers, to determine the flutter mode shape and the time varying position of the wing during oscillatory motion.

All tests were conducted in heavy gas, R-12, at Mach numbers ranging from 0.5 to 0.95 , and dynamic pressures between $25 \mathrm{ps} f$ and $300 \mathrm{psf}$. A tolal of four model configurations were tested: the bare wing with the baseline spar; the bare wing with the stiff spar; the wing with the baseline spar; and two mass-simulated engines, and the wing with the baseline spar and two cylindrical now-through nacelles. Steady state, forced response, and flutter data were acquired on each configuration. However, only a single flutter point was acquired with the stiff spar. The engine configurations were used to obtain unsteady data at a second flutter mode, and to determine the acrodynamic effects of the wing/pylon and wing/pylon/nacelle combinations.

\section{BENCHMARK MODELS}

\section{Benchmark Models Program}

The NASA Langley Benchmark Models Program (BMP) $^{34}$ was established to provide experimental unsteady aerodynamics data, particularly at flutter conditions, specifically for computational method validation, verification, and evaluation. Stall flutter and plunge instability phenomena were also observed and studied in the BMP. The program focused on making very high quality unsleady pressure measurements on a geometrically simple wing so as to simplify modeling in the computational methods and to facilitate the interpretation of results. Three wings ${ }^{34-40}$ with the same rectangular planform were tested on a Pitch and Plunge Apparatus (PAPA) ${ }^{41.42}$ at transonic flight conditions. Each wing had a different airfoil profile with different transonic performance characteristics. Figure 34 shows the airfoil profiles used to define the three models. One model was built using a NACA 0012 airfoil and was designated B0012. The second model, designaled B64A010, used a NACA $64 \mathrm{A0} 10$ airfoil, and the third model had a NASA SC(2)-0414 supercritical airfoil and was called BSCW. The airfoils were chosen for their performance characterislics in transonic flow. These characteristics range from a strong, forwardpositioned shock that is relatively insensitive to small changes in flow conditions on the B0012 to a weak, aft-positioned shock whose position is sensitive to 

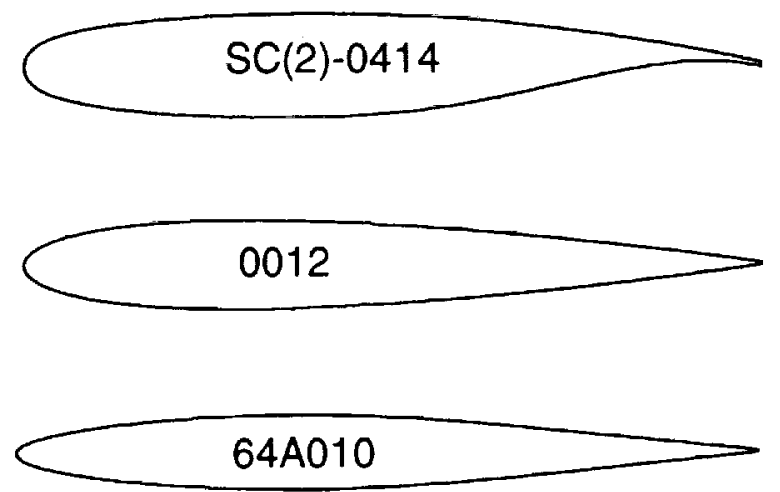

Figure 34. Airfoil sections used to develop BMP models.

flow conditions on the BSCW. The B64A010 was chosen because it has transonic characteristics that fall somewhere between the two extremes.

The three wing models were constructed and instrumented similarly, with slight differences in detail. They were fabricated in three parts, as shown in Figure 35, to provide ready access to the instrumentation. Each had a rectangular planform with a span of 32 inches plus a tip of revolution. The chord for the three wings was 16 inches, giving the wings a panel aspect ratio of two. They were machined of aluminum to a very smooth finish. Detailed geometry measurements were performed for each of the wings along several sections so that astested geometries could be accurately modeled in computational methods.

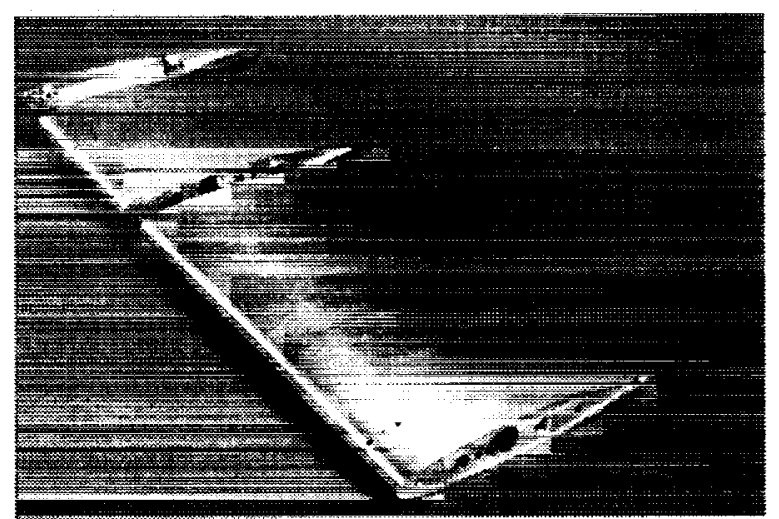

Figure 35. Three-section construction of the BSCW.

Figure 36 shows the BSCW model installed in the TDT. The model was mounted on a large splitter plate offset from the wind-tunnel wall by approximately 40 inches. An end plate that moved with the model was attached to the root of the wing and moved within a recessed section of the splitter plate. A large fairing behind the splitter plate isolated

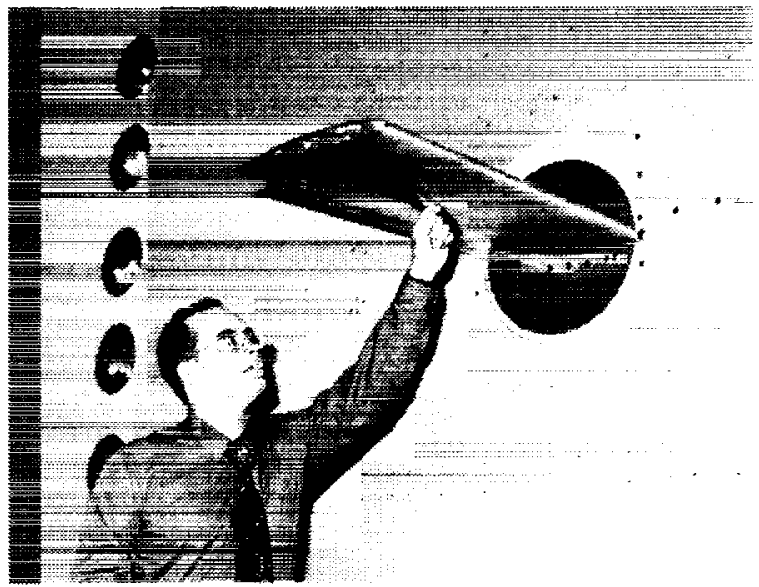

Figure 36. BSCW model installed in the TDT.

the equipment between the plate and the sidewall from the tunnel flow.

These models were flutter tested using the Pitch and Plunge Apparatus (PAPA) ${ }^{41}$, illustrated in the sketch of Figure 37. The PAPA system permits rigid body pitch and plunge motion of the wing and flutter of the system by using four circular rods for flexibility. The rods are arranged such that the elastic axis is at the midchord and the model is balanced to place the center of gravity on the midchord. The system thus gives essentially uncoupled pitch and plunge modes about the midchord of the model. The structural characteristics of the PAPA are summarized in Table 2. In addition to the testing on the PAPA, the B0012 and BSCW models were tested on a rigid mount by locking the PAPA mechanism. The model could be pitched statically with the turntable, but there was no balance in this system for force measurements.

Table 2. PAPA nominal structural dynamic parameters

\begin{tabular}{|l|c|c|}
\hline & Plunge Mode & Pitch Mode \\
\hline Frequency & $3.33 \mathrm{~Hz}$ & $5.20 \mathrm{~Hz}$ \\
\hline Stiffness & $2637 \mathrm{lb} / \mathrm{ft}$ & $2964 \mathrm{ft}-\mathrm{lb} / \mathrm{rad}$ \\
\hline Damping Ratio, $\zeta$ & 0.001 & 0.001 \\
\hline $\begin{array}{l}\text { Effective Mass or } \\
\text { Inertia }\end{array}$ & 6.01 slugs & 2.78 slug-fi \\
\hline
\end{tabular}

The models were instrumented for unsteady pressures at two chords and for dynamic motions. The primary dynamic motion measurements were made with the PAPA strain gages and accelerometers, although four wing accelerometers were included. There were 40 unsteady pressure transducers located along the chord at 60 percent span and 40 located at 95 percent span. The distribution for BSCW is illustrated in Figure 38, but was slightly different for each model. 


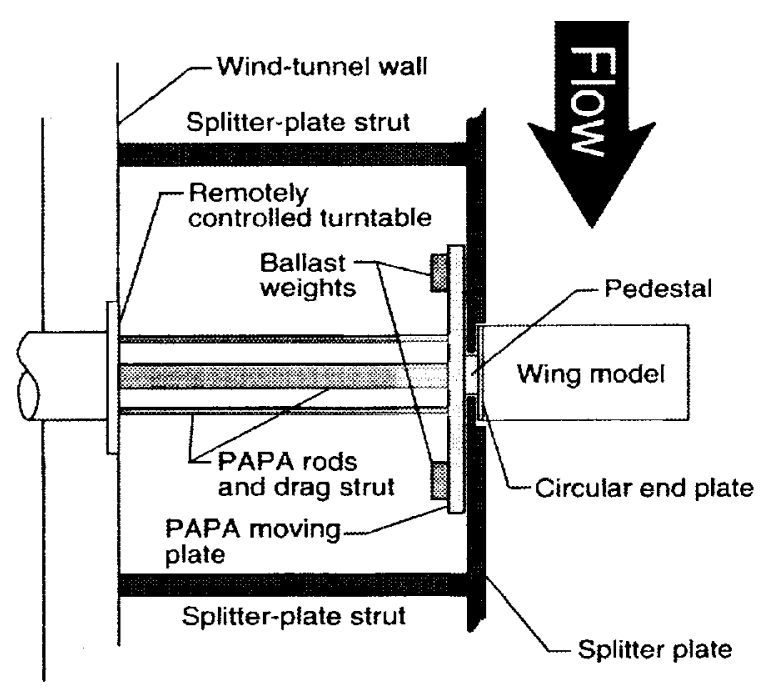

Figure 37. Illustration of the BMP PAPA installation in the TDT.

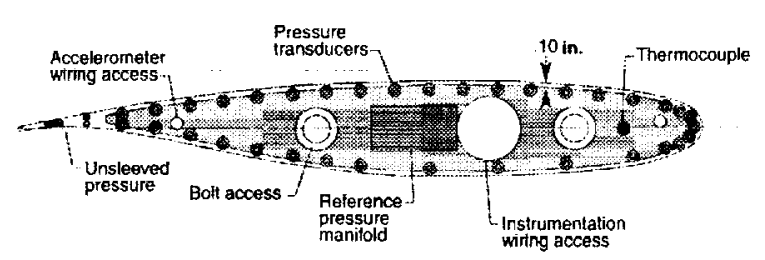

Figure 38. Instrumentation installation in the $\mathrm{BSCW}$ model.

The models were tested both in air and in heavy gas, $\mathrm{R}-12$. TDT test conditions ranged from Mach 0.30 to 0.90 at angles-of-attack between -3 degrees and +5 degrees. Typical Reynolds numbers for these tests ranged between one and seven million based on the wing chord. The models were tested with both free and forced transition via a grit strip at 7.5 percent chord.

Static pressure data from the BSCW test at Mach $0.802,4.83$ degrees angle-of-attack, and the 60 percent span station are shown in Figure 39. This plot shows the classical rooftop upper-surface pressure distribution with a terminating shock and the aft loading associated with supercritical airfoil technology. Figure 40 shows three plots describing the unsteady pressure distribution at 60 percent span on the BSCW at flutter conditions for Mach 0.798 and a mean angle-of-attack of 5.5 degrees. The top plot is the measured mean pressure distribution, which has similar characteristics to a supercritical airfoil at static conditions. The middle and lower plots are the real (in-phase) and imaginary (out-ofphase) components of the pressure distribution as referenced to the pitching motion of the wing during

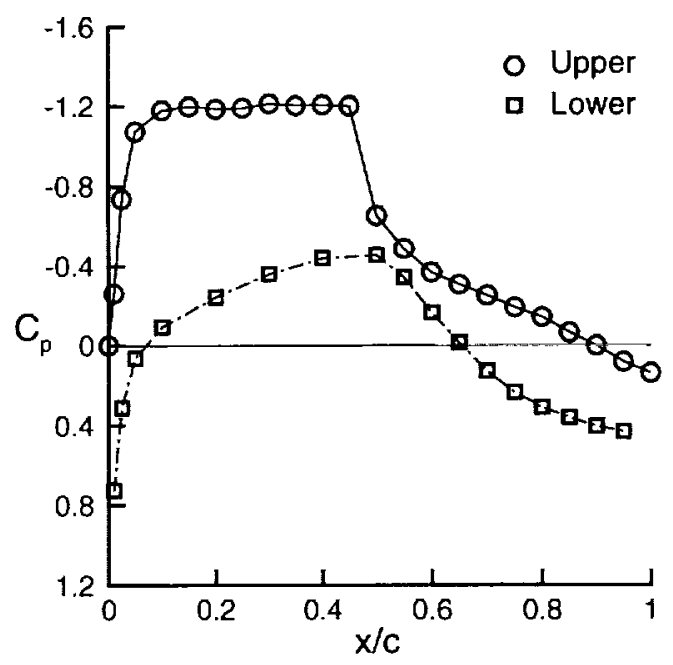

Figure 39. Sample static pressure distribution measured on the BSCW model.

flutter. For this case, the pitch frequency is approximately $5 \mathrm{~Hz}$, and the pitch amplitude is 0.9 degrees. The real and imaginary components of the pressure clearly show the upper surface shock wave at these conditions.

\section{Benchmark Active Controls Technology Wing}

The Benchmark Active Controls Technology (BACT) model $^{43,44}$ was developed under the Benchmark Models Program, described in the previous section, to provide a testbed for active controls research and active flutter suppression technology development. This model differed from the other BMP models in that it was fitted with three hydraulically actuated active control surfaces.

An overall view of the BACT model is shown in Figure 41 . The model was based on the previously described B0012 wing, which had a NACAOOI2 airfoil. The overall dimensions and geometry of the BACT were the same as the B0012, as were the general construction techniques employed. The BACT wing had a 25 percent chord trailing-edge control surface that extended between 45 and 75 percent span. It also had upper and lower surface spoilers of 15 percent chord, hinged at the 60 percent chord location and spanning the same distance as the trailing-edge control surface. The outer surface of the spoilers was flat and a relatively thin trailing-edge extended nearly to the round leading edge radius of the trailing-edge control surface. When both spoilers were deployed, the cavily underneath was open permitting flow between the upper and lower surfaces. The control surfaces were of composite 


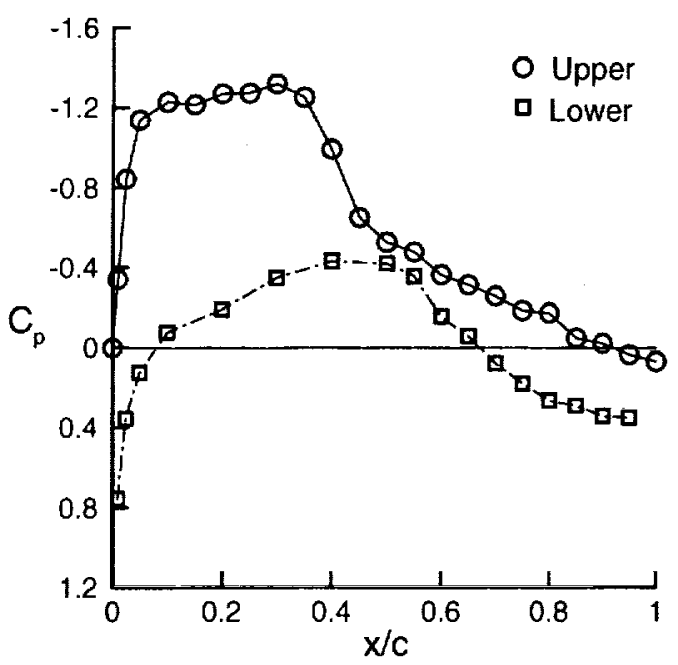

a) Mean Pressure Distribution

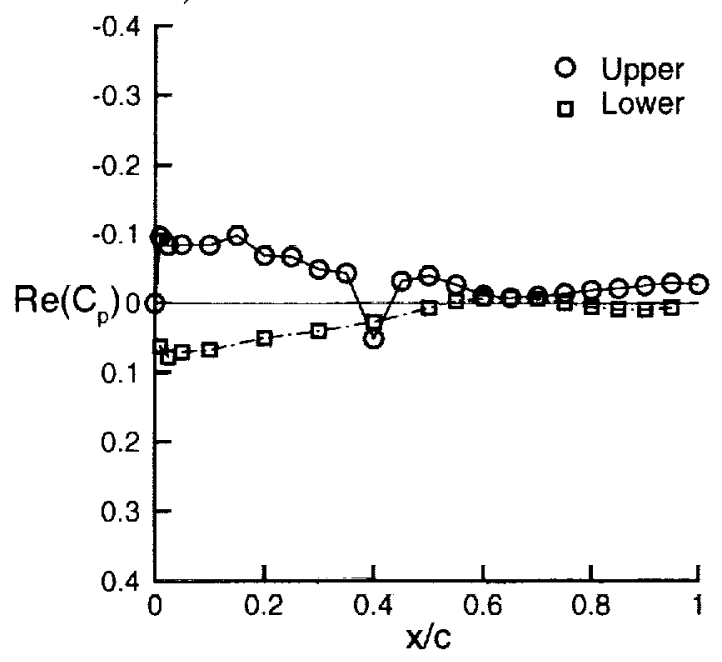

b) Real Component

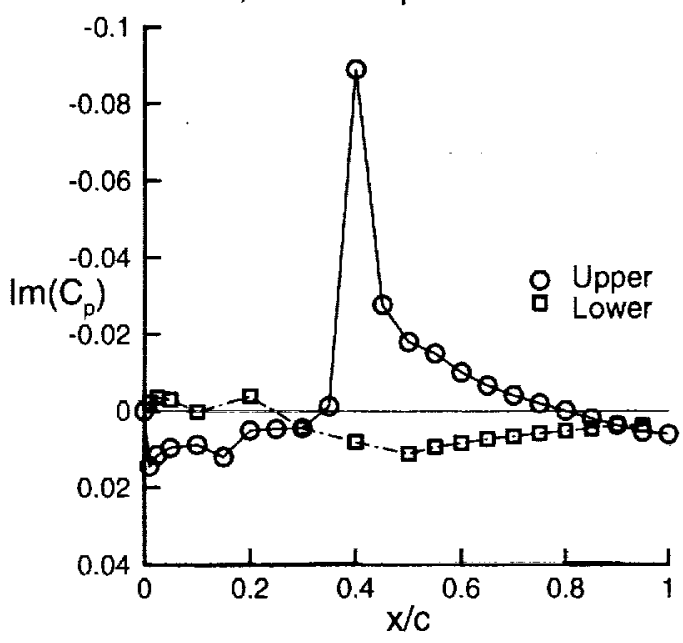

c) Imaginary Component

Figure 40. Sample unsteady pressure distribution on BSCW model at flutter.

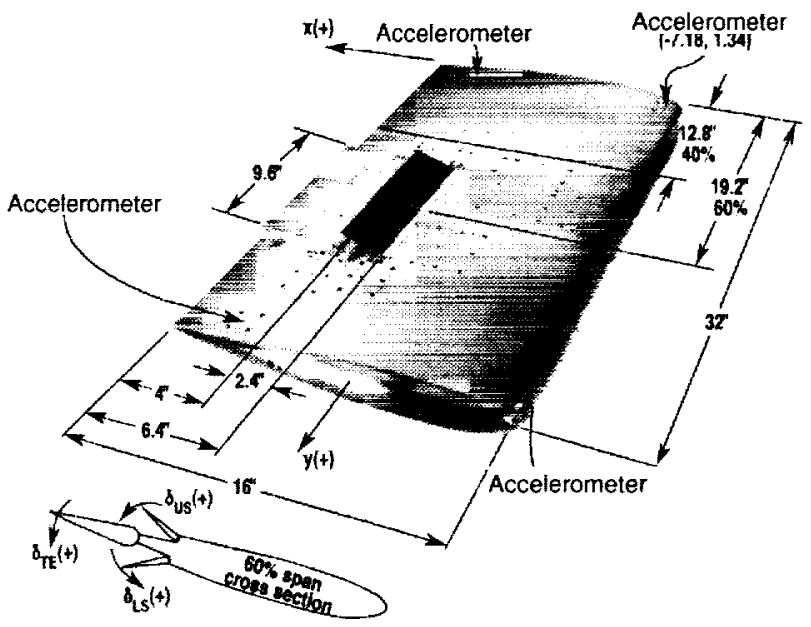

Figure 41. BACT wing with deflected spoiler and trailing-edge control surface.

construction and were driven with miniature hydraulic actuators located in the wing.

The model was instrumented for unsteady pressures at two chords. The transducer layout at the 40 and 60 percent span station is shown in Figure 42. There were 58 unsteady pressure transducers located along the chord at 60 percent span, which is the midspan of the control surfaces. There were 5 transducers on each spoiler and 7 on each of the upper and lower surfaces of the trailing-edge control surface. This relatively dense spacing of the transducers was selected to define the pressures near the control surface hinge lines. In addition there were 17 unsteady pressure transducers located at 40 percent span over the aft portion of the chord that were placed to examine the carry-over loading near the side edge of the control surfaces. Space limitations prevented further pressure instrumentation at other chords.

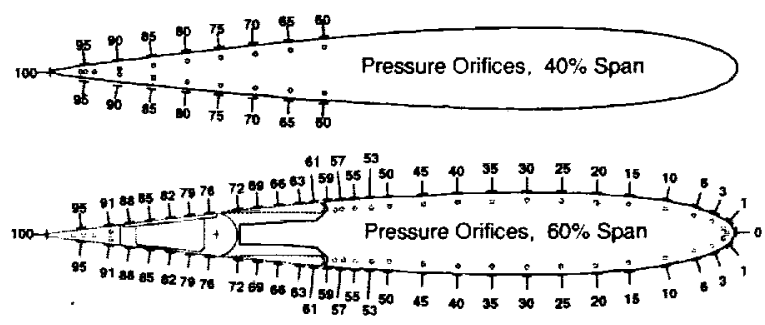

Figure 42. BACT pressure transducer layout.

The model was mounted on the same splitter plate as that used in the previous BMP tests. The BACT was tested on both a rigid strut and the PAPA ${ }^{41}$. A picture of the model mounted on the PAPA is shown in Figure 43. On both devices the static angle-of-attack 


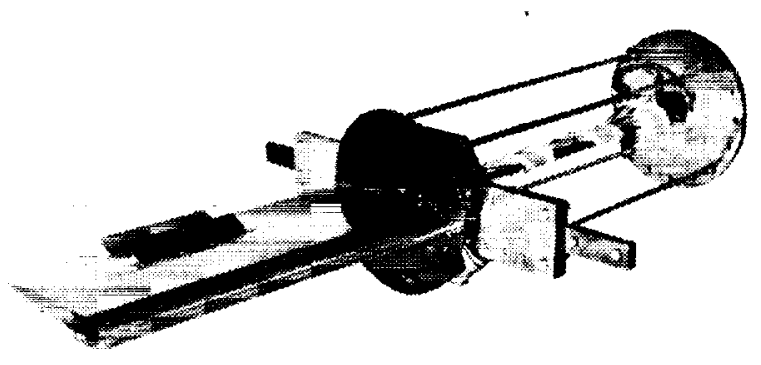

Figure 43. BACT model mounted on the PAPA.

could be controlled via a turntable located behind the wind-tunnel wall.

An extensive experimental dataset has been acquired on the BACT wing. The majority of testing was performed in the heavy gas, $R-12$, but limited data were also acquired in air. Static cases include variation of Mach number and angle-of-attack for the baseline configuration, static deflection of each of the individual control surfaces at a variety of Mach numbers and angles-of-attack, and static deflections of combinations of control surfaces. Dynamic data was also acquired with the model mounted on the rigid strut by oscillating individual control surfaces at a variety of frequencies, amplitudes, and mean deflections. Both flutter data and forced response data were acquired with the model mounted on the PAPA. In general, the model was lested at Mach numbers between 0.63 and 0.94 , at angles-of-attack ranging from $-4 \mathrm{to}+10$ degrees. Trailing-edge control surface static deflections ranged from - 10 to +12 degrees, and spoiler deflections varied between 0 and 40 degrees. Control surface oscillations were accomplished at frequencies up to $10 \mathrm{~Hz}$, and amplitudes of 1,2, and 4 degrees for the trailing-edge control surface and up to 10 degrees for the spoilers. Transition was fixed at five percent chord on both the upper and lower surfaces using a grit strip.

A sample of unsteady pressure data acquired during a trailing-edge control surface oscillation is shown in Figure 44. The flow conditions for this case are Mach 0.77 and 4.0 degrees angle-of-attack and the data are for the $60 \%$ span station. The top figure presents the mean pressure coefficient along the wing chord. The middle and bottom figures show the real (in-phase) and imaginary (out-of-phase) pressure components, respectively, referenced to the trailingedge control surface motion. In these plots, the shock motion is clearly identifiable in the unsteady pressures, as is the pressure disturbance at the hinge line of the control surface.

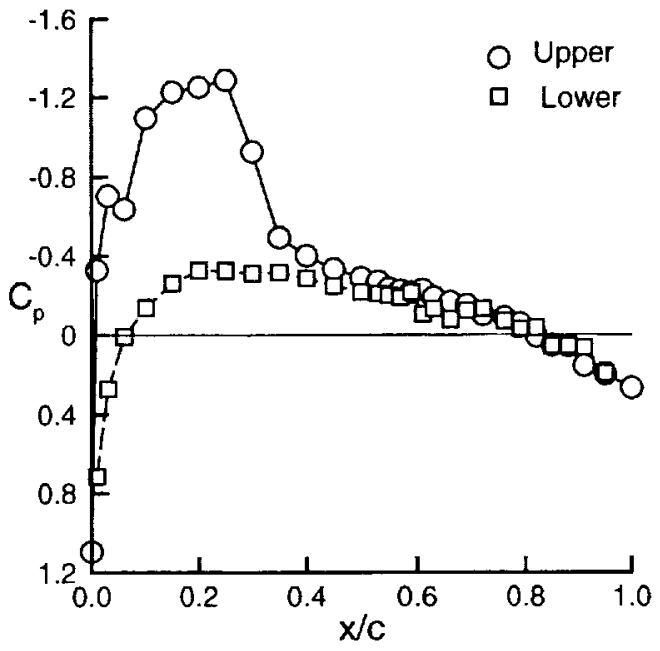

a) Mcan Pressurc Distribution.

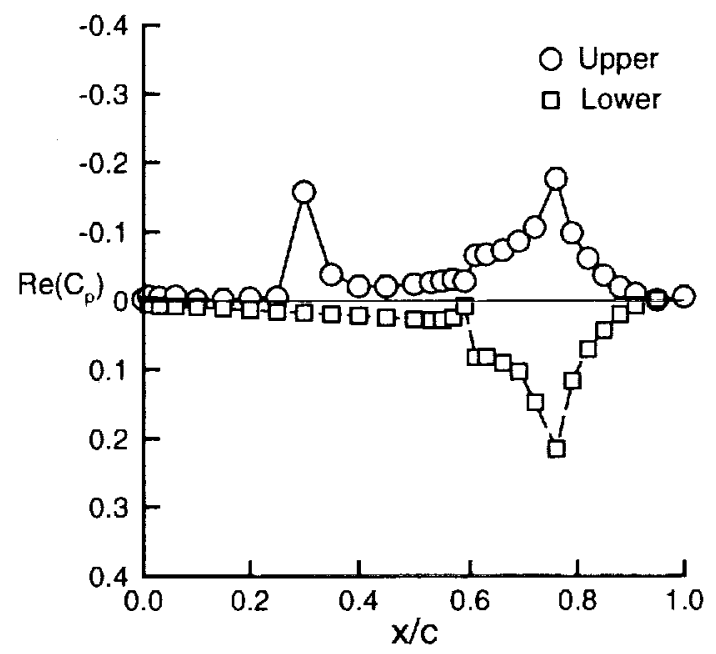

b) Real Pressure Component

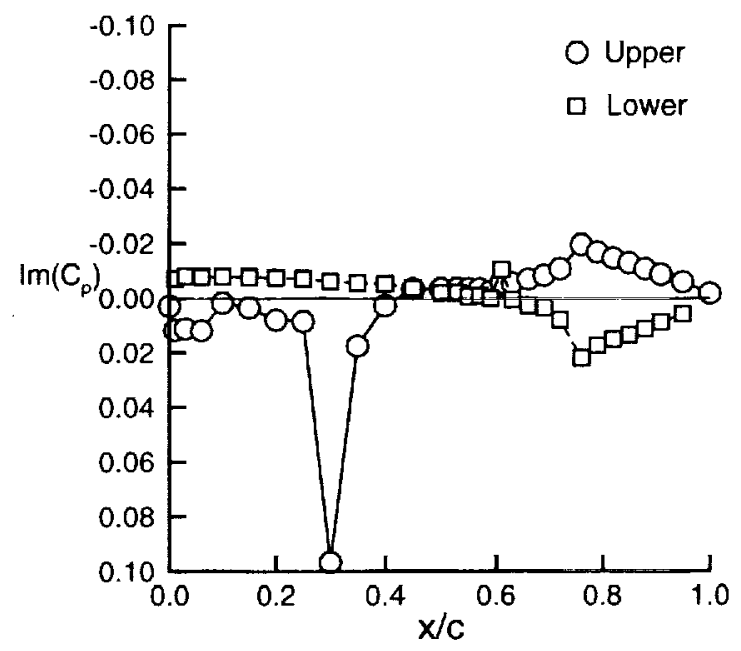

c) Imaginary Pressure Component

Figure 44. Sample unsteady pressure data acquired on the BACT wing. 


\section{Advanced Business. Jet}

As an adjunct to the NASA Benchmark Models Program, a cooperative effort with a business jet manufacturer was undertaken to measure unsteady pressures on an advanced model. A large semispan model was built with a flexible wing and rigid fuselage and is shown mounted in the TDT in Figure 45. The wing had an outboard aileron that could be oscillated and also had a tip exciter. The flexible wing was made of fiberglass and constructed in sections that were fastened together to permit access to the unsteady pressure transducers. The overall arrangement of the model and the three rows of pressure transducers are shown in Figure 46. It was determined late in the test that the wing had ballooned or changed chordwise shape with dynamic pressure. The data were thus not considered to be of benchmark quality and were not published.

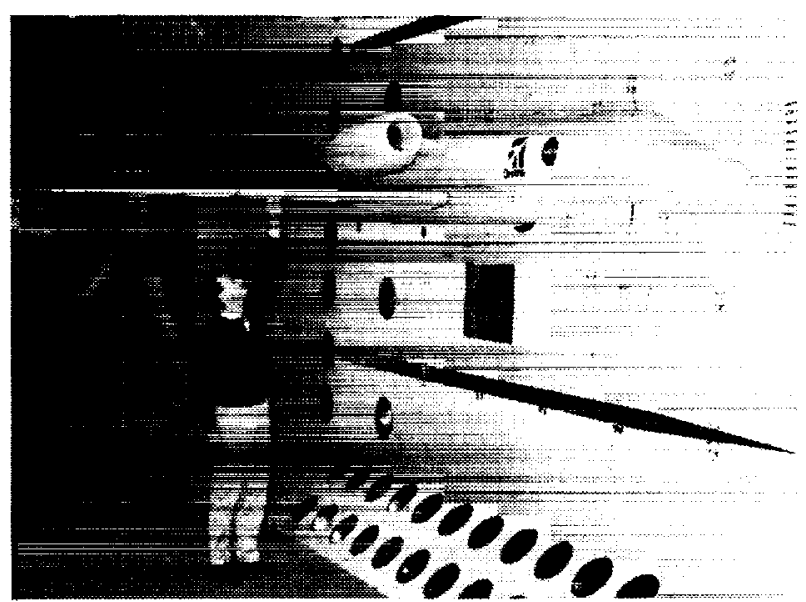

Figure 45. Advanced business jet model mounted in the TDT.

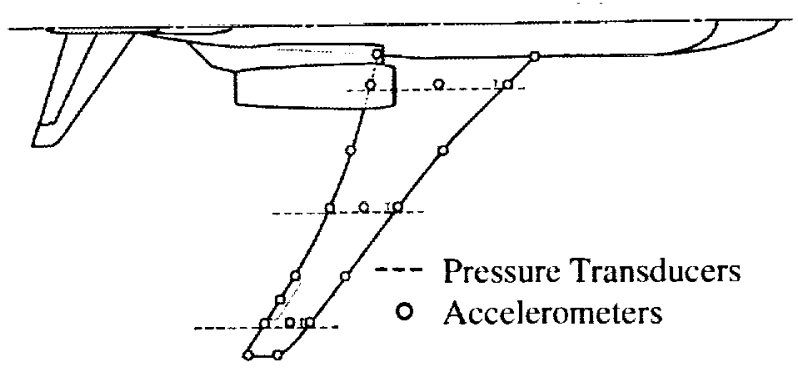

High Speed Research Rigid and Flexible Semispan Models

Under the NASA High-Speed Research (HSR) program, a series of models were developed to acquire static and dynamic pressure data for configuration and computational code evaluation ${ }^{45}$. These models, known as the HSR Rigid Semispan Model (HSR-RSM) and the HSR Flexible Semispan Model (HSR-FSM), were virtually identical in geometry and instrumentation suites. The HSR-RSM is a very stiff model to minimize aeroelastic deflections, while the HSR-FSM was designed with a flexible structure acroelastically scaled to anticipated flight vehicle specifications.

The wings for these models were patterned off an existing High Speed Civil Transport (HSCT) planform known as Reference $H$. Figure $47^{45}$ shows the wing planform and instrumentation layout for these models. To accommodate instrumentation in the wing tip area, the airfoil sections were scaled to be four percent thick over the entire wing planform. The models were constructed using composite materials that consisted of a foam wing core with graphite epoxy (RSM) or fiberglass (FSM) skins bonded to the core. Rigid fuselage fairings were constructed for the models to serve two purposes. First they displaced the wing sufficiently far enough from the wind-tunnel wall so that the wing root would not be in the tunnel wall boundary layer. Second they provide a realistic aerodynamic boundary condition at the wing root.

The models were mounted to a turntable located behind the east wall of the TDT that was used to conirol the model angle-of-attack. A variety of attachment devices were used to mount the models to the turntable. Both models were tested on a balance as shown in the figure. The HSR-RSM was also tested on a variation of the Pitch and Plunge Apparatus (PAPA) ${ }^{41}$ to simulate rigid body, two degree of freedom dynamics on the model. The HSR-FSM was only tested on the balance for subcritical conditions. A rigid strut replaced the balance for flutter testing. The HSR-RSM as it was mounted in the TDT is shown in Figure 48.

Figure 46. Planform and instrumentation layout for the advanced business jet model. 


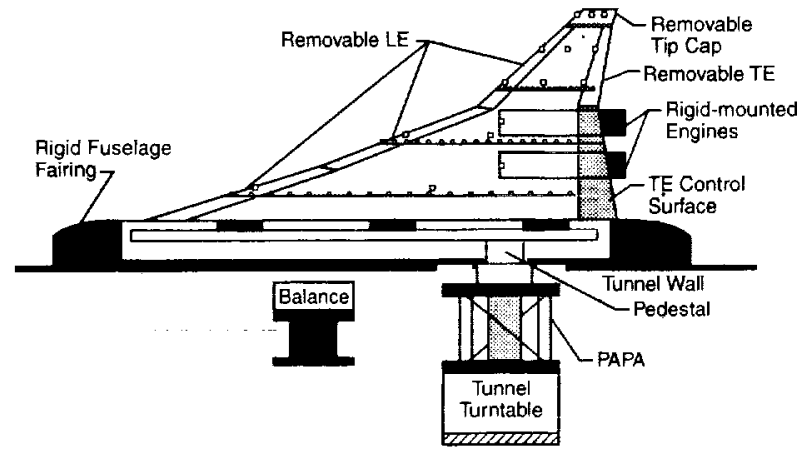

Figure 47. Wing planform and instrumentation layout for the'HSR-RSM and HSR-FSM models

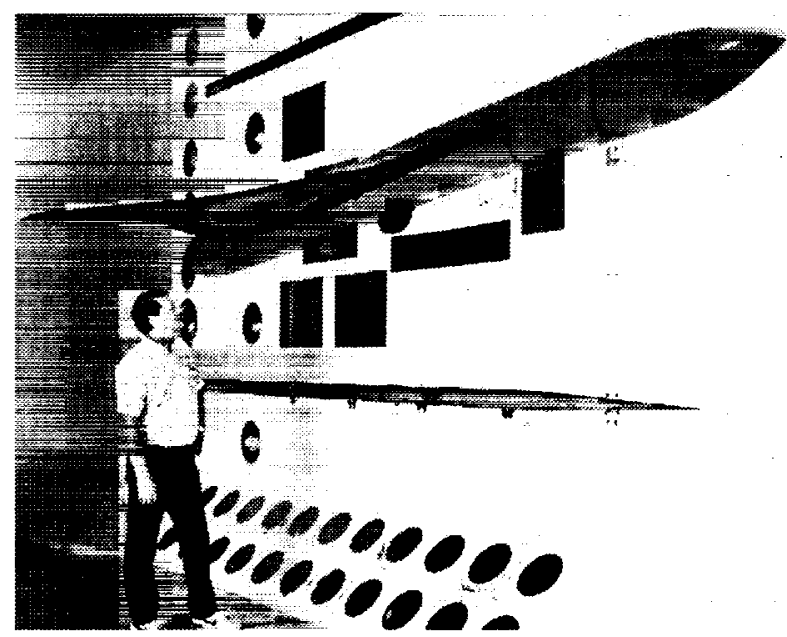

Figure 48. HSR-RSM model mounted in the TDT.

The primary purpose of tests on these models was to acquire unsteady wing pressure data for correlation with theoretical analysis and design methods under development in the HSR program. Each model had 131 in situ unsteady pressure transducers distributed in chordwise bands at the $10,30,60$, and 95 percent span stations. The transducer holders shown in Figure 5 were used to mount the majority of these transducers in the wing. Each model could also be tested with or without a pair of flow-through nacelles and both had a hydraulically actuated inboard control surface that could be oscillated to generate unsteady aerodynamics data. In addition to the dynamic pressure instrumentation, the wings also had 14 accelerometers distributed throughout the wing planform, and the rigid fuselage fairing was instrumented with 120 steady pressure orifices at seven fuselage stations. Since the HSR-FSM was a structurally flexible wing, it included one torsion strain gage and three bending strain gages in its instrumentation suite and photogrammetric deflection measurements were also performed on the wing tip.

The HSR-RSM and HSR-FSM were tested in the spring of 1996 using R-12 as the test medium. The
HSR-RSM was subsequently tested on the PAPA in the fall of 1998 using R-134A as the test gas. Large steady and unsteady force and pressure databases ${ }^{46,47}$ were acquired for all three tests.

Steady and dynamic data were obtained on these models in the form of angle-of-attack polars, steady flap deflection polars and forced dynamic response due to flap deflections. These data are summarized in Table 3 for the three test entries. Due to dynamic constraints, a second, significantly shorter fuselage fairing was constructed for the HSR-RSM model when it was mounted to the PAPA. Therefore, much of the static data acquired during the first tunnel entry of the HSR-RSM was repeated for the PAPA test by initially mounting the model on a rigid strut. The PAPA data described in the table were all acquired on this rigid strut.

Table 3. HSR-RSM/FSM TDT test data summary.

\begin{tabular}{|c|c|c|c|}
\hline $\begin{array}{c}\text { Mach } \\
\text { Range }\end{array}$ & $\begin{array}{c}\text { Dynamic } \\
\text { Pressures } \\
\text { (psf) }\end{array}$ & Steady Data & $\begin{array}{c}\text { Forced } \\
\text { Oscillation } \\
\text { Data }\end{array}$ \\
\hline \multicolumn{4}{|c|}{ HSR-RSM } \\
\hline $0.7-1.15$ & $\begin{array}{c}100,150, \\
200\end{array}$ & $\begin{array}{c}\alpha=-3-+8 \\
\delta=-5-+5\end{array}$ & $\begin{array}{c}\delta= \pm 2, \pm 5 \\
f=1,2,5 \mathrm{~Hz}\end{array}$ \\
\hline \multicolumn{4}{|c|}{ HSR-FSM } \\
\hline $0.8-1.15$ & $\begin{array}{c}100,125, \\
150\end{array}$ & $\begin{array}{c}\alpha=-1-+2.5 \\
\delta=-4-+4\end{array}$ & $\begin{array}{c}\text { Mach/q } \\
\text { Dependent }\end{array}$ \\
\hline \multicolumn{4}{|c|}{ HSR-RSM/PAPA on Rigid Strut } \\
\hline $0.6-1.10$ & 150 & $\alpha=-5-+5$ & $\begin{array}{c}\delta= \pm 0.25, \pm 1 \\
f=1,5,10 \mathrm{~Hz}\end{array}$ \\
\hline
\end{tabular}

Typical pressure distributions obtained on the HSRRSM and the HSR-FSM are shown in Figure 49. This plot of the 60 percent span pressure coefficient versus nondimensional local streamwise coordinate at Mach 0.95, 2 degrees angle-of-attack, and a dynamic pressure of 150 psf clearly shows the effect of static aeroelastic deflections between the HSR-RSM and the HSR-FSM. In addition to the pressure data available in Table 3 , unsteady pressures were also measured at or near flutter for the HSR-FSM and the HSR-RSM on the PAPA. Figure $50^{45}$ summarizes results from the HSR-FSM testing showing areas of high model dynamic responsc and flutter. The squares in the figure represent points where forced response data were acquired by first identifying the dominant structural frequency at the given Mach number/dynamic pressure condition then oscillating the trailing-edge control surface at this frequency to 
obtain the response. A region of high dynamic response was identified in the high transonic Mach number range and is depicted by the shaded area in the figure. This area was characterized by an increased response of the first bending mode at a frequency of approximately $8.5 \mathrm{~Hz}$. While high levels of dynamics were encountered in this region, flutter was not observed. A second area of high dynamic response is labeled as the chimney in the figure. In this area, the dominant response frequency ranged between $11.9 \mathrm{~Hz}$ and $14.0 \mathrm{~Hz}$, significantly higher than the first wing bending mode. A hard flutter point was encountered in this region, at the conditions shown on the figure, which resulted in the catastrophic failure of the model structure. Despite this, a significant amount of unsteady pressure data was acquired in and around the various areas of high dynamic response that should prove very useful in understanding the aeroelastic characteristics of this wing.

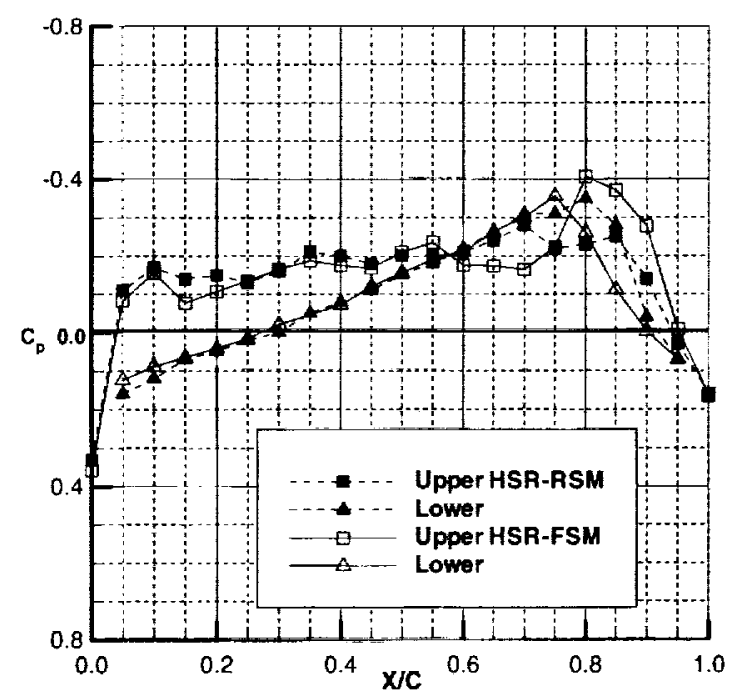

Figure 49. Rigid/Flexible pressure comparison at $60 \%$ span for HSR models at $\mathrm{M}=0.95$, $\alpha=2.0^{\circ}, \mathrm{q}=150 \mathrm{psf}$.

Finally, the HSR-RSM model tested on the PAPA provides two degree of freedom flutter data at a frequency of approximately $4.75 \mathrm{H} z$. The sensitivity of the flutter boundary to variations in angle-of-attack was evaluated during this test. These data showed the model to be unexpectedly sensitive to changes in angle-of-attack suggesting that strong nonlinear effects, aerodynamic and/or structural, were present during these tests.

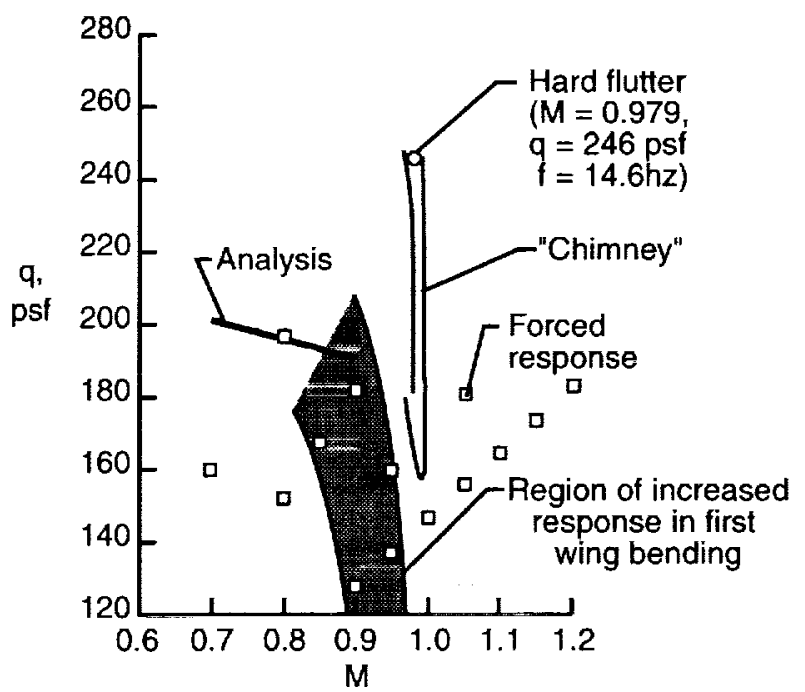

Figure 50. Experimentally observed regions of high dynamic response and flutter for the HSRFSM model.

\section{BUFFET PRESSURE MEASUREMENTS}

One of the fundamental categories of problems in aeroelasticity is that of buffeting and the associated input of buffet. Generally buffeting is used to refer to structural dynamic response whereas buffet refers to the input forcing function such as unsteady acrodynamic forces. In the TDT, unsteady pressure measurements have been made to investigate the buffet pressures on both aircraft and launch vehicles. These have been made to a limited degree both in the investigation of buffeting and on rigid models. Only the tests involving unsteady pressure measurements are reviewed here, but many other tests have been conducted for buffeting only. The unsteady pressure tests have primarily involved launch vehicles in the ascent mode, unusual aircraft configurations, and twin vertical tail aircraft.

\section{LAUNCH VEHICLE BUFFET}

\section{Saturn Apollo}

One of the earliest buffet investigations was on a model of the Saturn-Apollo launch vehicle being developed for the manned lunar landing and was TDT Test 24. The motivation, objectives, and approach are typical of this type of test and are aptly described in May 1963 by the introduction of the report NASA TN D- $1633^{\text {t8 }}$ :

"Several space vehicles have failed during the transonic and low supersonic range of their exit trajectories. Usually, the local aerodynamic loads on 
the vehicle are a maximum at transonic speeds and the presence of unsteady shock boundary-Iayer interactions in the flow around the vehicles has led to the suggestion that buffeting loads may have contributed to some of the failures. Several windtunnel investigations (refs. 1 to 4 [of TN D- 163.3]) have been undertaken to examine the nature of these buffeting flows. Generally, it has been found that the characteristics of buffet pressure fluctuations on launch vehicles are very strongly configuration dependent. Therefore, as part of the work of the Langley Research Center in support of the manned lunar mission, a wind-tunnel investigation of the buffet characteristics of a vehicle representative of the launch vehicle for the manned lunar mission has been made.

Some very early buffet pressure characteristics from a preliminary investigation of a representative launch vehicle were published in reference 5[of TN D-1633]. These early data indicated that, under certain conditions, root-mean-square buffet pressures as high as one-fourth the free-stream dynamic pressure might be obtained behind the first shoulder of the configuration. The magnitude of these buffet loads and peculiarities of the fluctuating pressures were such as to cast doubt on the validity of the usual laws for scaling buffet pressure characteristics from model to full scale. The present more detailed investigation was then undertaken with emphasis on attacking the problems raised by the preliminary investigation.

The twofold purpose of the investigation was: (1) to define any buffet problem areas on the large manned launch vehicle, and (2) to study whether buffet pressure characteristics measured on models of space vehicle configurations can be scaled with confidence to the full-size vehicle by using normal scaling relationships.

To obtain the required data, fluctuating aerodynamic pressures were measured on two rigid models representative of the large manned launch vehicle which were sized, respectively, 8 percent and 1.6 percent of the full-size vehicle. In addition, limited response studies were made on a dynamically and elastically scaled model of a similar vehicle modified to have the same nose shape as the large manned launch vehicle. Various escape-tower configurations were investigated on the models which were tested in the Langley transonic dynamics tunnel with both air and Freon- 12 as test mediums. The investigation covered a Reynolds number range from $0.4 \times 10^{6}$ to $9.0 \times 10^{6}$ (based on second-stage diameter), a Mach number range from 0.4 to 1.2 , and an angle-of-attack range from $0.0^{\circ}$ degrees to $\pm 4.0^{\circ}$."

Two of the models tested in this investigation are shown in Figure 51. The large model is shown mounted in the wind tunnel with the smaller one placed on top. These were rigid models mounted to the wind-tunnel sting. Also, limited tests were made of an elastically and dynamically-scaled model the size of the small model but of a similar vehicle modified to have the same nose shape as the large rigid model. Various escape-tower configurations were also tested on the rigid models.

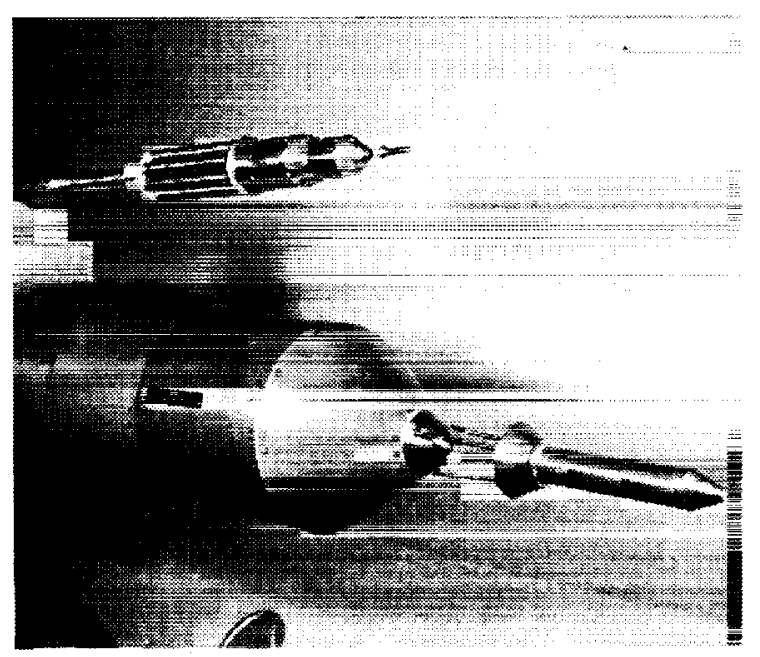

Figure 51. Saturn Apollo launch vehicle models in TDT.

The rigid models were equipped with six unsteady pressure transducers on the upper stages along one streamwise line and the large model had another on the forward cone cylinder shoulder at 180 degrees around the circumference. The models and instrumentation are outlined in Figure 52. The unsteady pressure gages were early NACA gages that were an electrical, variable-gap, inductance type. They were differential pressure gages that were connected through long tubes to an adjacent static orifice in order to sense only the unsteady pressures. The output was passed through amplifiers and recorded on an FM tape recorder. The output of four transducers also were sent to mean square meters and then to a strip chart recorder for online monitoring. Power spectral density (PSD) evaluations were carried out on an analog spectral analyzer from the data recorded on the tape recorder for frequencies up to $600 \mathrm{~Hz}$. It might be noted that these analyses were performed before Fast Fourier Transform methods had been developed. Also, the number of static and dynamic pressure transducers would be considered sparse by current standards. 


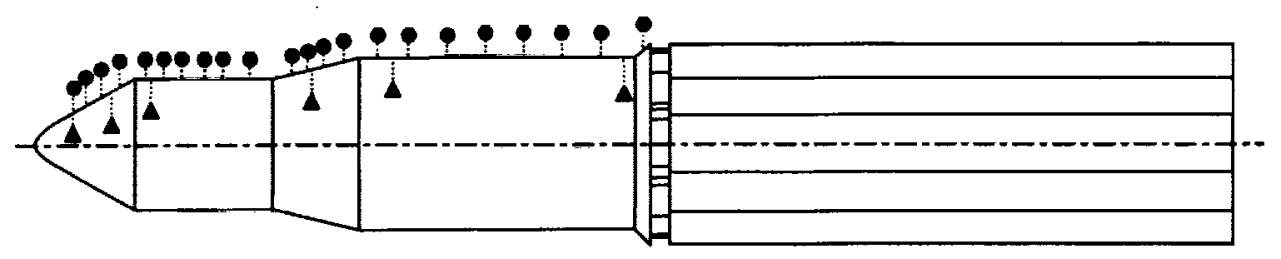

a) $8.035 \%$ and $1.607 \%$ Rigid

- Steady Pressures - 8.035\% Rigid Model

$\Delta$ Unsteady Pressures $-8.035 \%$ and $1.6075 \%$ Rigid

$\nabla$ Models

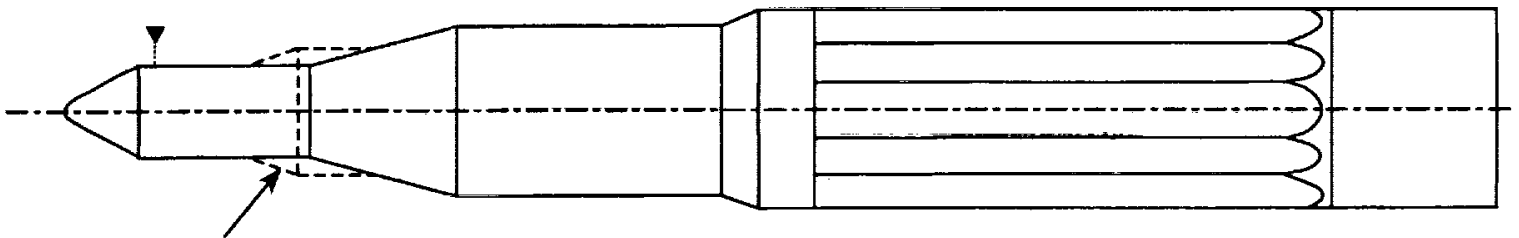

Removable

b) $1.427 \%$ Elastic Model

Figure 52. Saturn launch vehicle buffet model layout.

The large model also was instrumented with 22 staticpressure orifices along the same line and were connected by tubes to a multiple-glass manometer board. A photograph of the manometer board was taken for later manual data reduction of the static pressures.

A sample of the resulting static and root-mean-square of the unsteady pressures is given in Figure 53 for several Mach numbers. There are large peaks in both the steady and unsteady pressures just aft of the expansion corners. The peaks are particularly pronounced for the Mach 0.96 case. An example of the scaled PSDs is given in Figure 54. The result shows that the values for the two models compared favorably as scaled.

The following section, taken from the summary of the report NASA TN D-163. ${ }^{48}$ succinctly summarizes the results of this test:

"The results of the investigation show that, for the configurations tested, the wake from the escape tower under certain flow conditions produced relatively high noise levels (about 168 decibels) on the nose cone and on the area just aft of the cone-cylinder shoulders on the vehicle upper stages. In addition, independently of the presence or absence of the
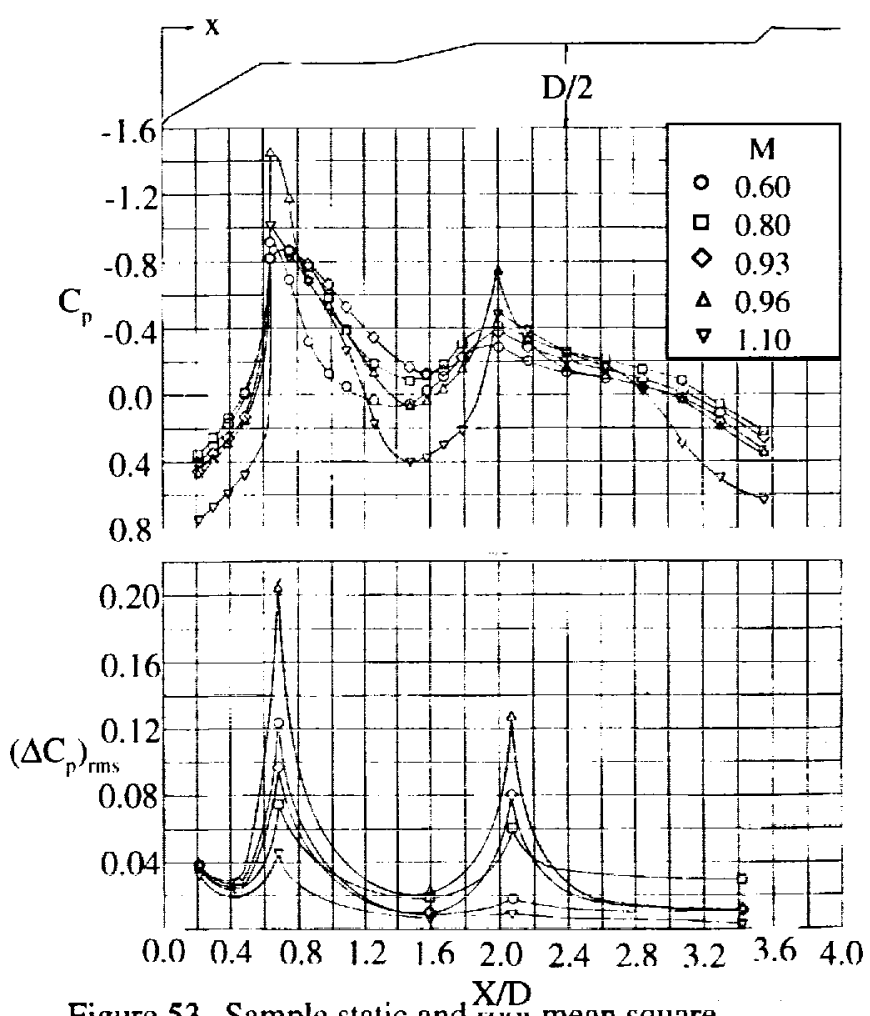

Figure 53. Sample static and ruou mean square pressures from the Saturn launch vehicle test. 


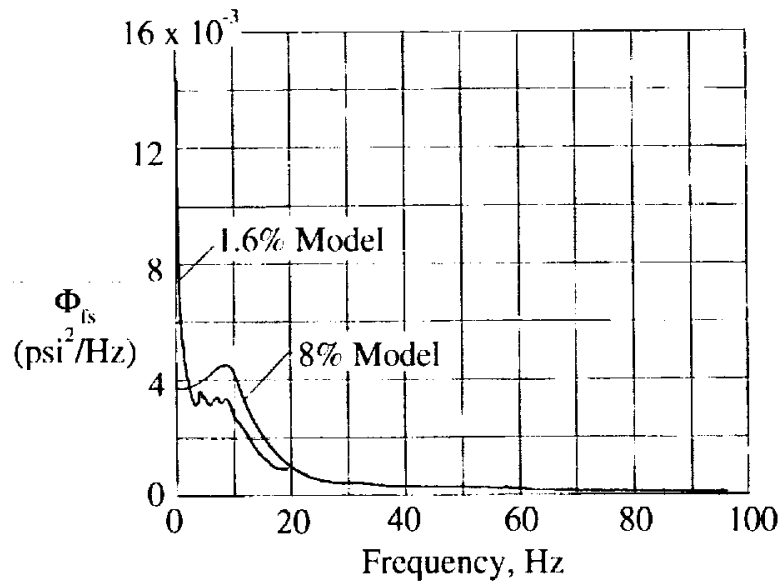

Figure 54. Sample pressure power spectral densities from the Salurn launch vehicle lest.

escape tower, large pressure fluctuations occur on the vehicle just aft of the two cone-cylinder shoulders in a narrow band of Mach numbers just below 1.0. These pressure fluctuations present a design problem in venting unpressurized portions of the vehicle but do not present a structural response problem in the free-free bending or rigid-body pitch modes. These pressure fluctuations have a time-history wave form which resembles "square waves." However, only one such pressure fluctuation is expected to occur during the exit trajectory of the vehicle. An evaluation of buffet scaling relationships derived from simple dimensional considerations lends confidence to the use of suitably scaled models in determining the buffet pressure characteristics of large launch vehicles."

The conclusion on buffet scaling was particularly important in validating model testing both for enabling this technique for further testing of this type and for application of the results to the full scale design. A supplementary test for buffeting of the lower flexible modes is presented in Reference 49.

\section{Project FIRE}

A test with similar objectives and concerns was conducted for project FIRE (Flight Investigation of Reentry Environment). FIRE was a flight reentry program by NASA to study heat transfer and related phenomena during atmospheric reentry. The vehicle consisted of a blunt shaped reentry package and rocket motor (velocity package) mounted to an Atlas $D$ launch vehicle $e^{51.51 .52}$. In light of the results for the Saturn-Apollo vehicle discussed above, the blunt nose of the project FIRE vehicle was considered to have the possibility of buffet problems at transonic and low supersonic Mach numbers. A 1/6 scale rigid model of the reentry vehicle, the interstage fairing, the velocity package, and three diameters of the Atlas stage was built and tested in the TDT as Test 38. The model included wooden pods to simulate explosive bolt covers and the spin rockets housing. A photograph of the forward portion of the model is shown mounted in the wind tunnel in Figure 55. The instrumentation was similar to that of the Saturn Apollo model, with 10 unsteady pressure gages and 69 static pressure orifices at 12 to 15 longitudinal stations.

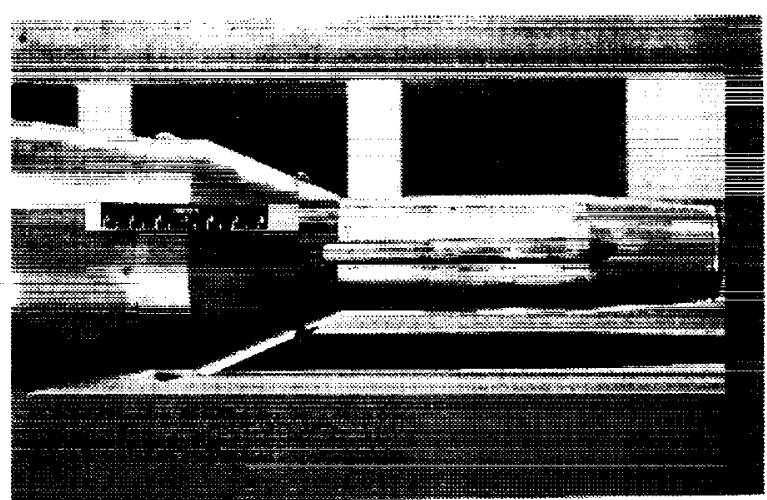

Figure 55. FIRE launch vehicle mounted in TDT.

Four configurations were tested. Configuration I was the basic model with the pods to simulate the bolt covers and spin rockets housing, and configuration II was the model with the wooden pods removed. Configurations III and IV included a doughnut-shaped fairing to enclose four spin rocket motors and were tested with and without the wooden pods. The test was conducted over a Mach number range of approximately 0.60 to 1.13 at various angles of attack for Reynolds numbers up to $5 \times 10^{h}$. The unsteady pressure coefficients were in a range similar to the Saturn-Apollo model previously discussed. No published results from this test are known to be available.

\section{PSTL-1 Saturn-Apollo Model}

In the continuing effort to define the Saturn-Apollo structural loads during the ascent phase after launch, a series of models were tested in several tunnels. These models were called the PSTL models (for Pressure, Static, Transient, Launch) ${ }^{5.3}$. Two models, identified as PSTL- 1 and PSTL-2 were built and tested in several wind tunnel These models were supposedly built to be as large as reasonably possible given facility limitations. Reference 53, published in December 1966, covers models tested through October of 1964 and discusses three facilities in which the PSTL-I and PSTL-2 models were tested, 
the North American Aviation Trisonic Wind Tunnel, the Ames 14-ft Transonic Wind Tunnels, and the Ames Unitary Plan Wind Tunnel. Although the TDT is not mentioned, records indicate that a test of the PSTL-I model was conducted in the TDT in February and March of 1966 which is after the period of time covered by Reference 53. Figure 2 shows the PSTL-1 model sting-mounted in the TDT. Although no information is available about this test other than the photographs, it would be expected that it would be carried out in similar fashion to the earlier SaturnApollo and project FIRE tests. These tests would also permit correlation of test data from the larger TDT facility with the results from the other three facilities. Again no published results from this test are known to be available.

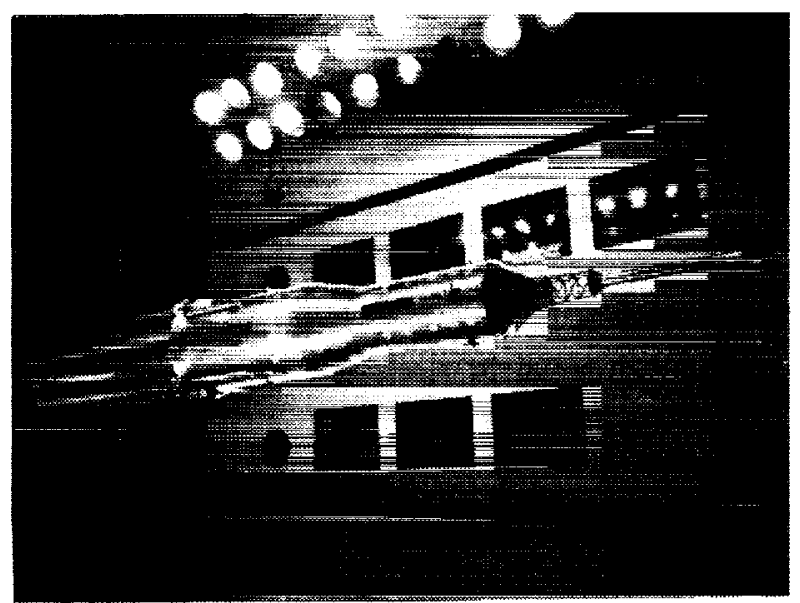

Figure 56. Photograph of the PSTL1 model stingmounted in the TDT.

\section{Atlas-Centaur Large Payload Fairing Model}

In order to handle larger payloads, the Atlas-Centaur launch vehicle was equipped with a large "hammerhead" type fairing and was referred to as Atlas-I LPF. The new fairing raised questions about possible buffeting on this vehicle compared to the base vehicle that had a smooth forebody. A 1/10scale aeroelastically-scaled model was built and tested in the TDT ${ }^{54}$. A photograph of the model as tested in the TDT is shown in Figure 57. Several different payload fairings were investigated with particular emphasis on the transonic speed range. The effects of angle of attack were also examined. Although the primary emphasis of the test was on measuring buffeting response, there were 20 unsteady pressure transducers that could be mounted at 23 different locations. The instrumentation layout is given in figure Figure 58. The unsteady pressures

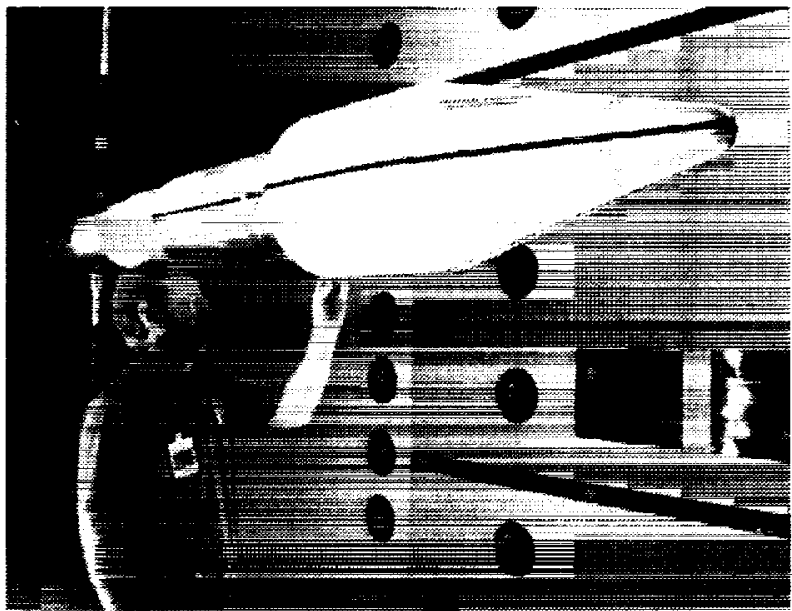

Figure 57. Atlas-Centaur model mounted in the TDT.

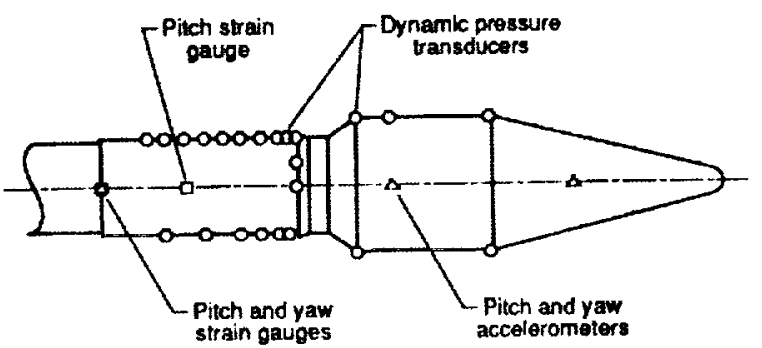

Figure 58. Instrumentation layout for the AtlasCentaur model.

were furnished to the manufacturer and were not published.

\section{Delta Launch Vehicles}

Even after several decades of time have passed, there is still concern about launch vehicle buffet loads. More recent tests on launch vehicle buffet and buffeting have been conducted on the Delta II and Delta III launch vehicles. The primary focus of these tests was buffet on the aft end of the bulbous nose or forebody of these vehicles. The Delta II model is shown in the TDT in Figure 59. It was instrumented with 40 static pressure orifices connected to an ESP (Electronically Scanned Pressure) system and with 80 unsteady pressure transducers along with a balance and accelerometers to investigate any correlation of possible motion-induced pressures. Of course with improved low frequency characteristics of the unsteady transducers, they are also used for steady pressures.

The Delta III model is shown in Figure 60. This launch vehicle has a different nose shape, a longer 
cylindrical section of the bulbous nose, and has simulated solid booster rockets on the aft portion. It was similarly instrumented, but with 60 static pressure ports, and 91 unsteady pressure gages with the addition of measurements on the solid boosters.

These buffet measurements were provided to the companies involved and no results are published. For these cases, there is about an order of magnitude increase in instrumentation over the early tests, which was enabled by improvements in transducers, the data processing system, and storage lechnology. Data analysis and computer technologies have also progressed to facilitate data evaluation.

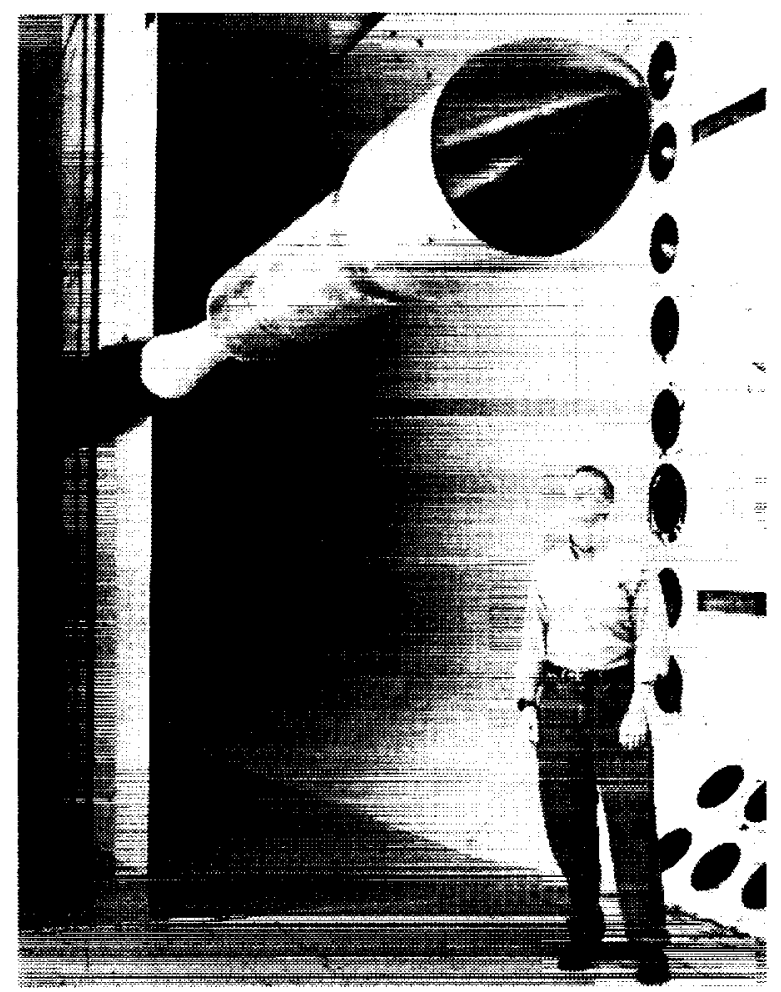

Figure 59. Delta II launch vehicle mounted in the TDT.

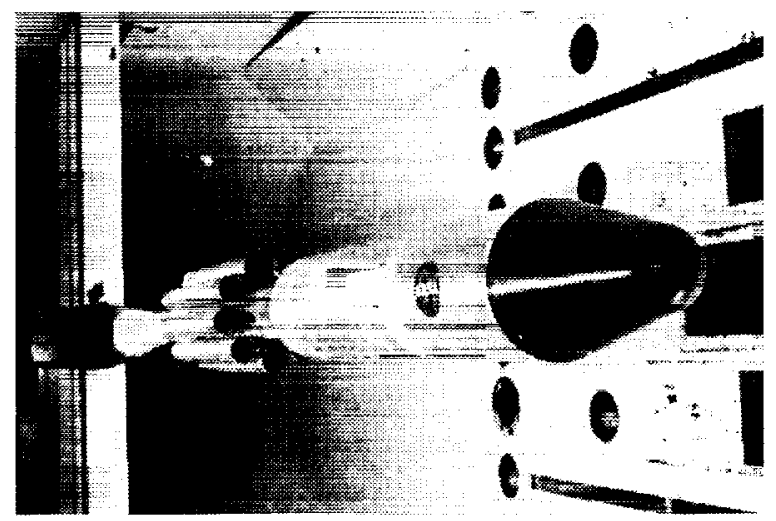

Figure 60. Delta III launch vehicle mounted in the TDT.

\section{AIRCRAFT BUFFET}

\section{RF-4C Buffet}

Operational problems were encountered with vibration in the nose of the $\mathrm{RF} 4-\mathrm{C}$ reconnaissance aircraft that had a rather pronounced flat-faced ramp housing the forward-looking camera ${ }^{55}$. A 1/4-scale rigid model of only the nose portion of the RF4-C was built along with a model of the nose of the F-4C fighter and a faired generic equivalent. The models of the RF4-C and F4-C noses are shown in Figure 61. The models were instrumented with 8 unsteady pressure sensors and tested in the TDT at Mach numbers of 0.5 to 1.15 as TDT Test 100 . It was found that the fluctuating pressures behind the camera housing peaked to large values over a small range of Mach numbers as shown in Figure 62. The pressures for the other two noses were considerably less. It was recommended that the forward camera chin be refaired or that the operational time spent in this regime be minimized.

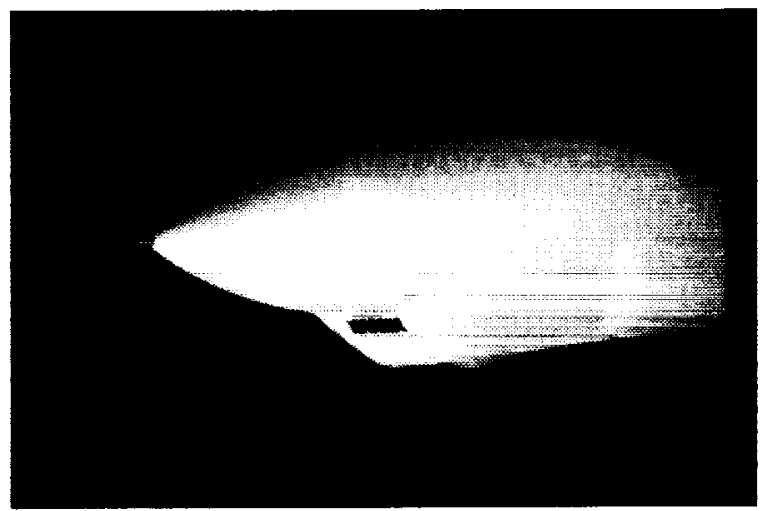

a) RF-4C Nose Model

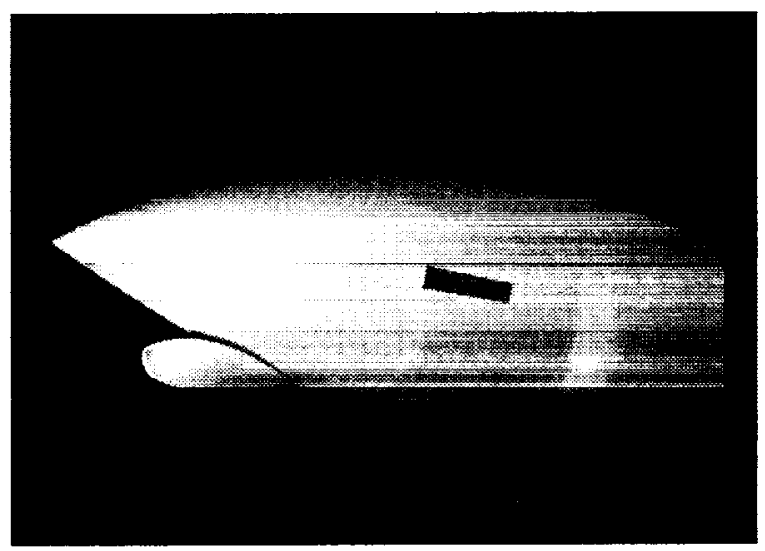

b) Standard F-4C Nose Model.

Figure 61. Nose models for the RF-4C and the F-4C aircraft. 


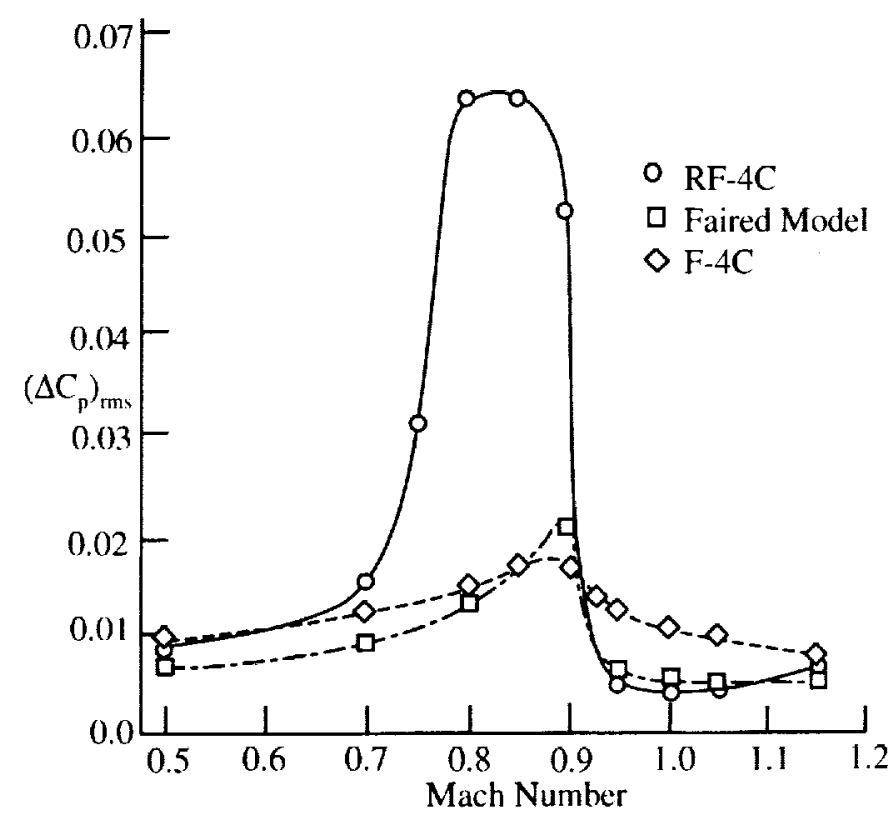

Figure 62. Mcasured fluctuating pressure along the nose of the F-4C, and RF-4C, and a faired model.

\section{Twin Vertical Tail Buffet}

One of the strongest buffet environments is that for twin vertical tails of a fighter aircraft at high angle of attack. Vortices form over the leading edge extensions (LEX) and breakdown into highly turbulent flow at high angles. When this turbulent flow passes near the vertical tails, large buffeting responses can be generated. An example of this situation is shown in Figure 6.3 as demonstrated by a flow visualization example from flight test. The vortex emanating from the LEX is very tightly wound until just past the cockpit and then breaks down creating a very strong impingement buffet flow. This problem has been extensively studied and a buffeting test was conducted in the TDT ${ }^{56}$. Several tests have since been conducted to further investigate this problem. The tests were multi-faceted tests involving buffet and buffeting, active controls work, smart materials efforts, and unsteady pressure measurements. Two tests have been conducted on a F- $18^{57.58}$ model and one test on an early F-22 model.

The F-18 model is shown mounted in the TDT in Figure 64. It was a 1/6-scale, rigid, full span model of the F/A-18A/B that was refurbished and stingmounted in the TDT. Three flexible and two rigid vertical tails were fabricated. The flexible tails were designed to match the vibration mode shapes and scaled frequencies of the full-scale airplane. Two of

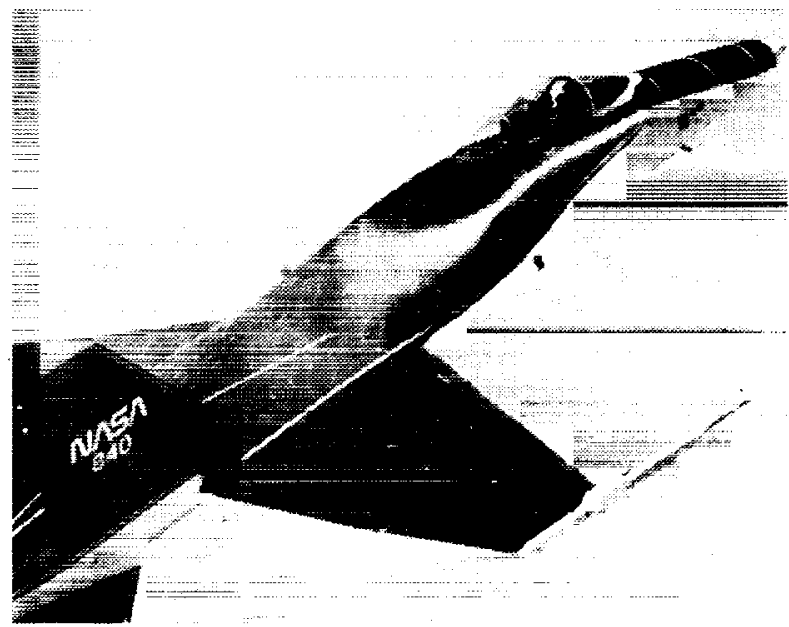

Figure 63. LEX vortex development and breakdown on the F-18.

the flexible and both of the rigid tails were instrumented on both sides of the tail with unsteady pressure transducers as shown in Figure 65. The test conditions were established by reduced-frequency or Strouhal number scaling to match flight conditions which resulted in a low tunnel speed of $110 \mathrm{ft} / \mathrm{sec}$ corresponding to a dynamic pressure of $14 \mathrm{ps}$. The objective of the unsteady pressure measurements was to examine the spectral and correlation characteristics of the buffet flow encountered by the tail. Correlations include the time delays between transducers as illustrated in Figure 66 and thus require sample rates higher than the time for flow hetween the transducers. For Test 515 , a sample rate of 65.38 Hz was thus used.

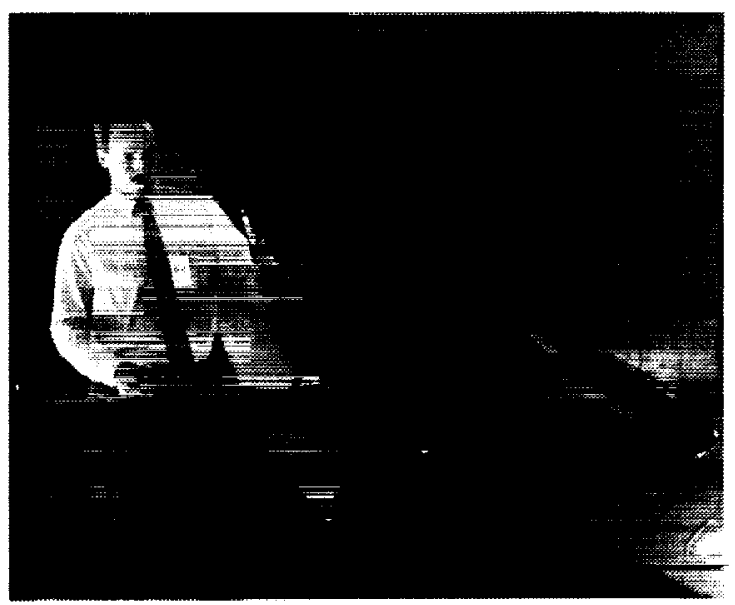

Figure 64. F-18 tail buffet model mounted in the TDT. 


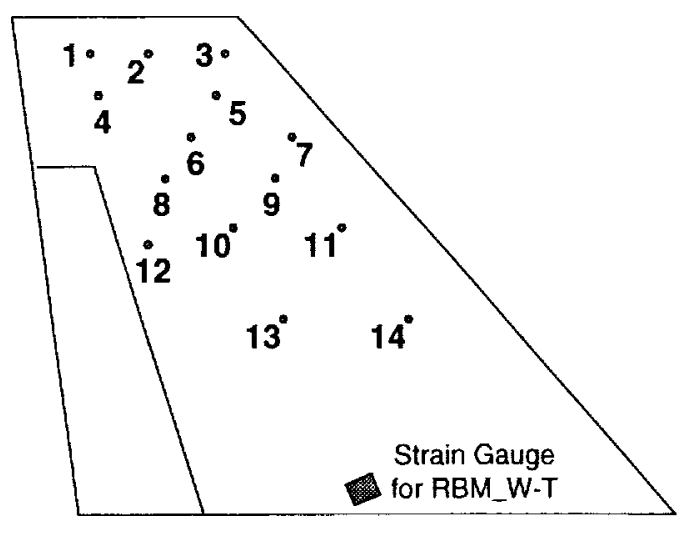

a) Flexible Tail

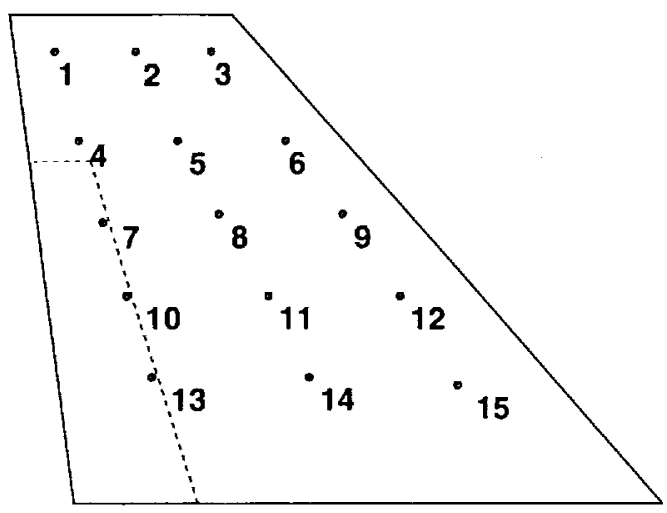

b) Rigid Tail

Figure 65 . Instrumentation layout for the $1 / 6$ scale F18 model.

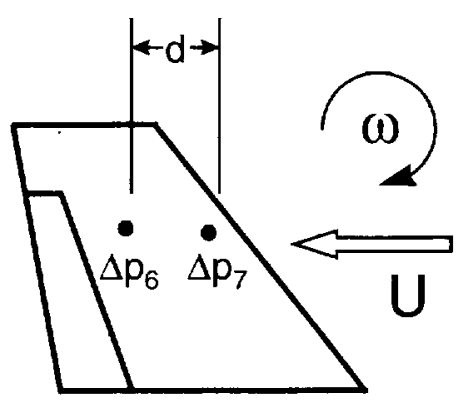

Figure 66. Visualization of flow, frequency, and distance between pressure measurement stations
Sample power spectral density plots for the flexible tail pressures are shown in Figure 67 and corresponding tail root bending moment data are shown in Figure 68. A significant increase in both buffet and buffeting is evident as angle of attack is increased. Sample cross-spectral density functions between transducers located near the leading edge and near the trailing-edge are shown in Figure 69. The linear variation of phase indicates the time delay between points in the flow from which convective rates of the turbulent flow have been determined.

The correlation functions corresponding to the cross spectral densities have indicated that the correlation is not 100 percent and must be taken into consideration in applying measured pressure to determine input forces for buffeting calculations. Comparisons have also been made with results of testing a full-scale production model F/A-18 in the $80 \times 120$ Foot Wind Tunnel at NASA Ames with favorable results ${ }^{59}$. The data have also been compared with full-scale flight tests and have confirmed the results measured in the TDT.

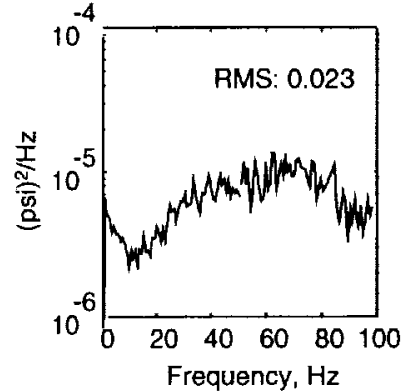

(a) 20 Deg AOA

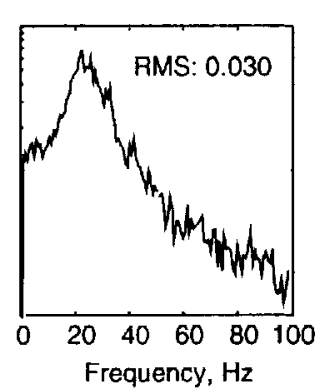

(b) 34 Deg AOA
Figure 67. Differential pressures near mid-chord, mid-span.

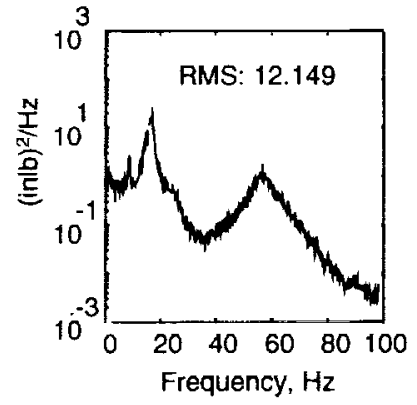

(a) 20 Deg AOA

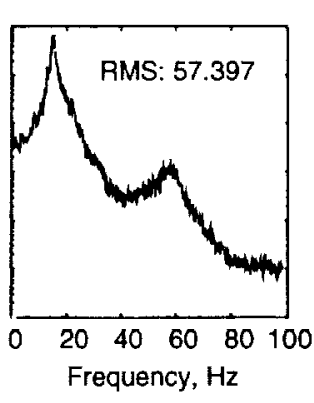

(b) $34 \mathrm{Deg} A O A$
Figure 68. Root bending moment near mid-chord root. 


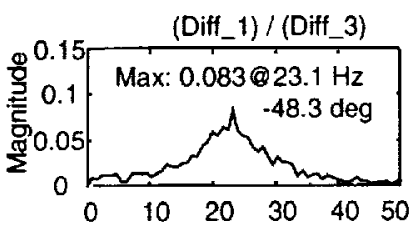

(Diff_4) / (Diff_6)
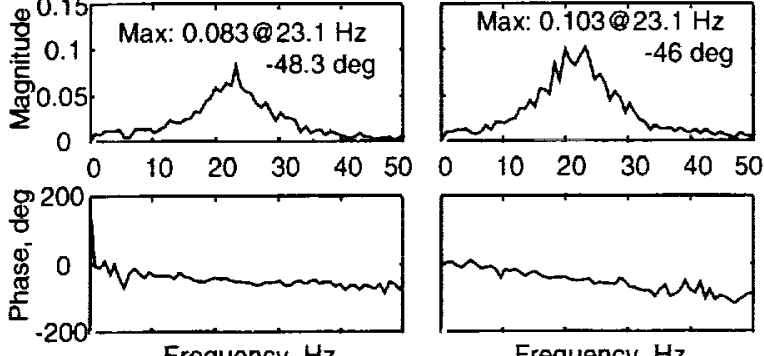

a) Near Tip
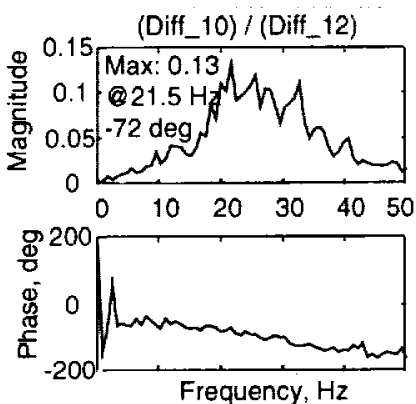

c) $40 \%$ Span

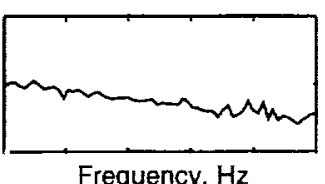

b) $75 \%$ Span

(Diff_13) / (Diff_15)

Max: $0.097 @ 32.7 \mathrm{~Hz}$ -133 deg
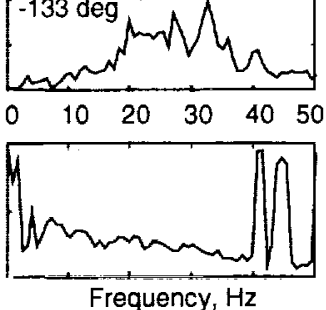

d) $25 \%$ Span

Figure 69. Cross-spectral density functions between differential pressures at stations on rigid tail, 34 deg. AOA. (See Figure 65 for station locations)

A similar test has been conducted on an early concept of the F-22 $22^{(x)}$. The forward portion of the wing for the F-22 has a different type of LEX. The model is shown as mounted in the TDT in Figure 70. There were forward unsteady pressure transducers on the wing root as well as transducers located on the left vertical tail as shown in Figure 71. Sample buffet PSDs are shown in Figure 72. The pressures vary both in peak frequency and magnitude with angle-ofattack peaking near 22 degrees and $30 \mathrm{~Hz}$. The peaking of the pressures is also shown in Figure 73 in terms of RMS values as measured on the tail and the wing root. The RMS values on the wing peak at higher angles-of-attack than for the tail due to the forward motion of the vortex burst as angle-of-attack is increased. A sample cross-spectral density is shown in Figure 74. The trends are similar to those of the F-18, with a nearly linear variation of phase with frequency.

These tail-buffet tests have provided insight to the buffeting of twin vertical tails and into the use of scaled models to assess high angle of attack trends.

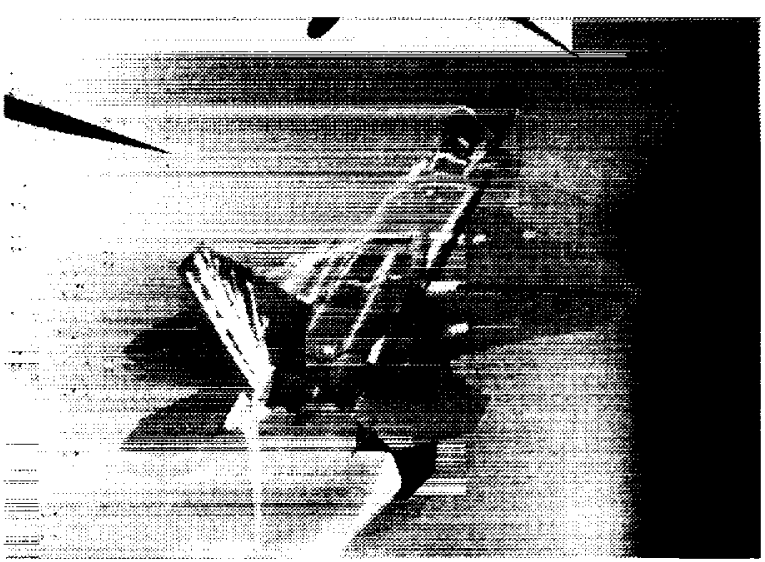

Figure $70.13 .3 \%$-scale F-22 model mounted in the TDT.

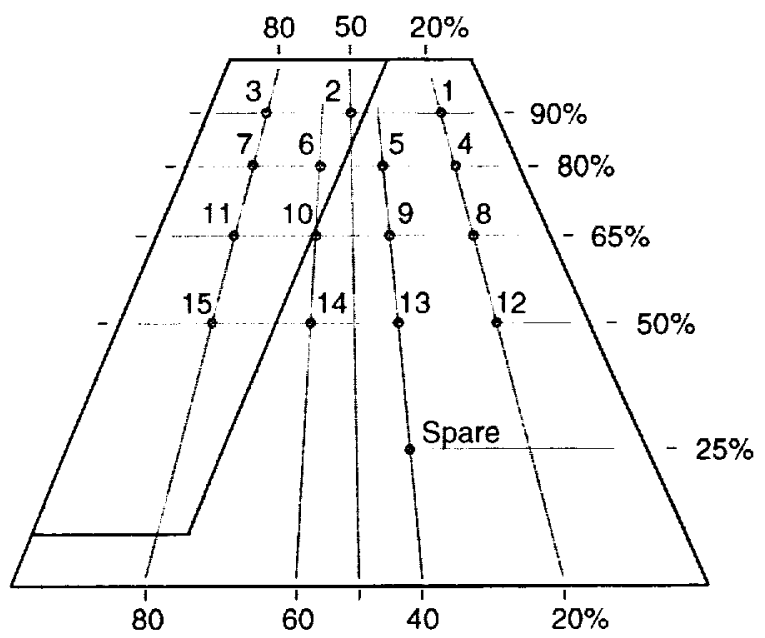

Figure 71. Stations of pairs of unsteady pressure transducers on the "rigid" port fin.

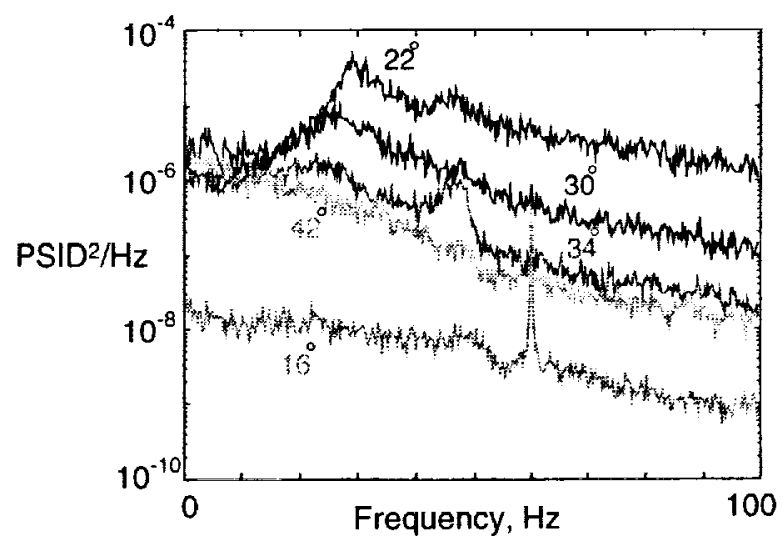

Figure 72. PSD of buffet pressures measured at station 5, outboard transducer, Mach 0.092 . 


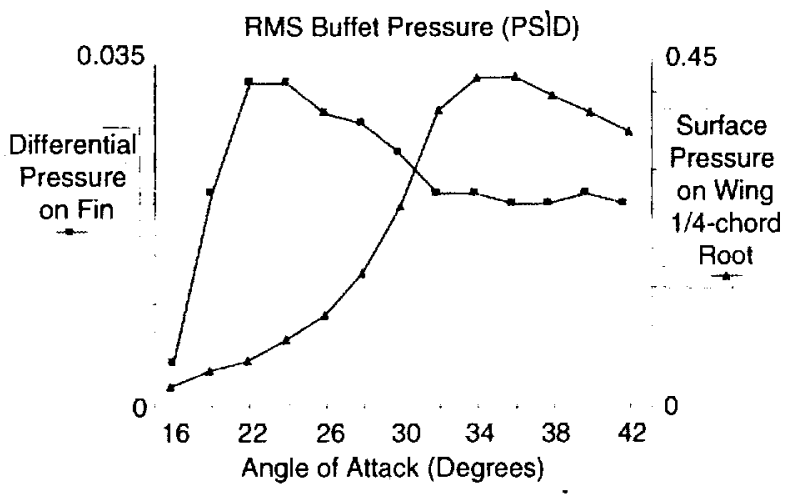

Figure 73. RMS values of the unsteady buffet pressures measured at station 5 (differential) and at wing 1/4-chord root (surface), Mach 0.092.
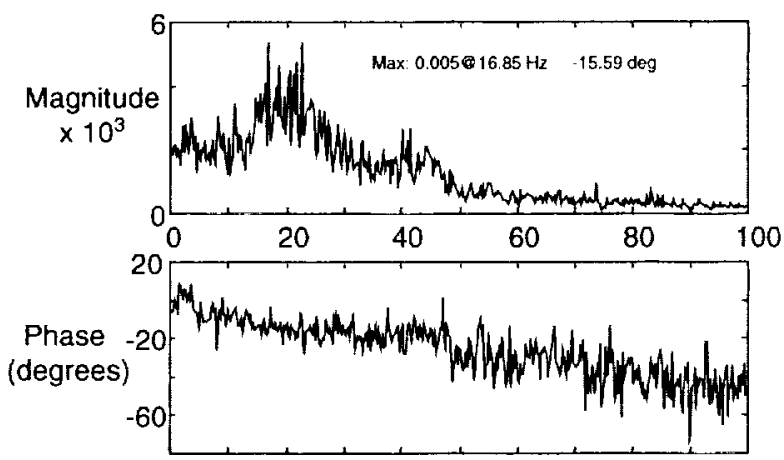

Frequency, $\mathrm{Hz}$

Figure 74. Cross-spectral density of differential pressures, station 5 with respect to station 4, Mach 0.106, 38 degrees angle-of-attack.

\section{MISCELLANEOUS TDT UNSTEADY PRESSURE TESTS}

\section{Saturn-Apollo Command Module Blast Wave Study}

During the development of the Saturn Apollo vehicle for the lunar landing flights, there was concern about the blast wave transient loading that would result in the event of an explosion of the booster rocket. The escape tower with a solid rocket motor was provided to remove the Apollo capsule from the overall vehicle, but a detonation blast wave would interact with the capsule. In order to evaluate this transient loading, a model of the Apollo capsule with the escape tower was mounted in the TDT and a series of Tri-Nitro-Toluene (TNT) charges were detonated from a tower behind the capsule. This setup is illustrated in Figure 75. Unsteady pressures were measured to evaluate the blast wave effects. Safety problems with such a test were of considerable

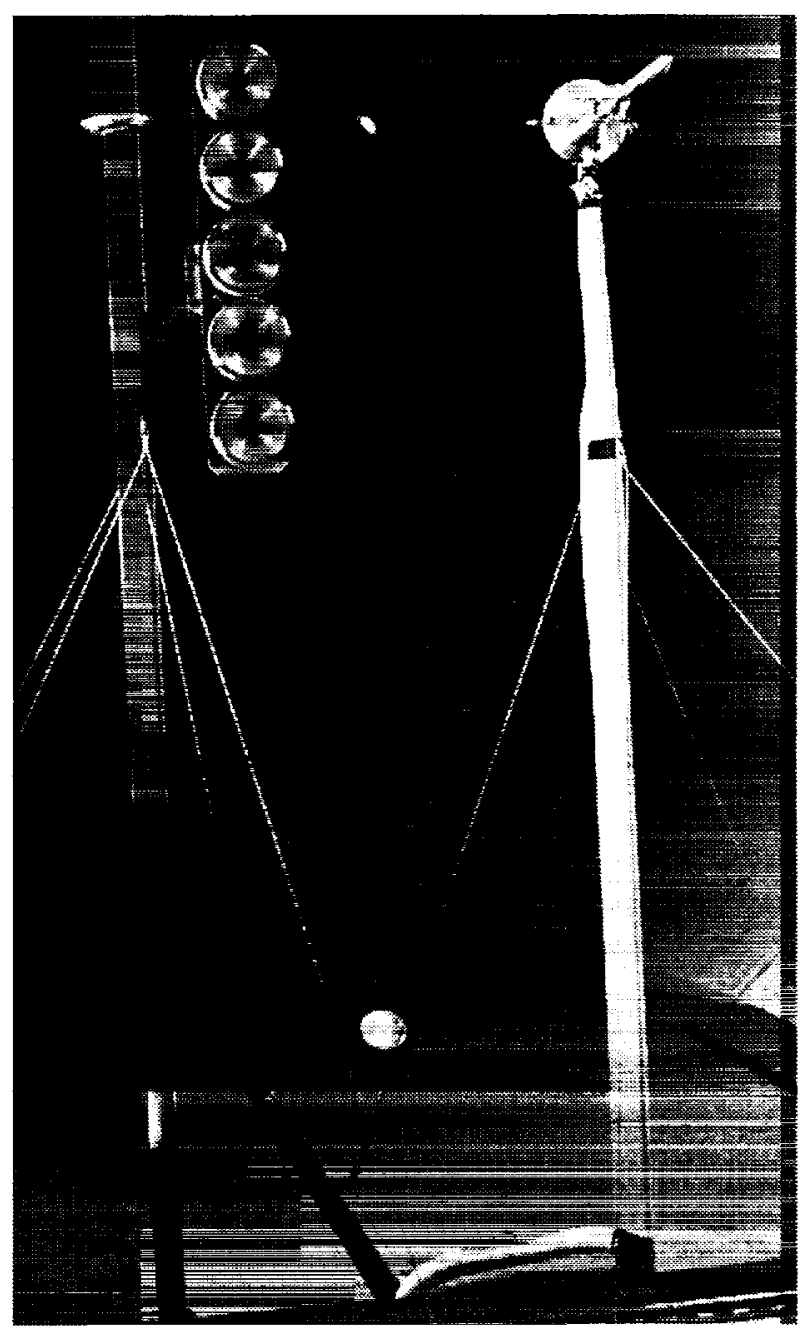

Figure 75. Setup in TDT for measuring blast loads on Apollo Command Module.

concern, and consequently the amount of TNT was limited to 0.1 pound. The results were provided to the project personnel and were not published.

\section{Transition Cone}

There have been several efforts over the years to use unsteady pressure measurements to characterize the flow unsteadiness of the freestream flow of the tunnel and have generally been undocumented. One notable example was an effort to measure the overall flow turbulence levels by determining transition location on a slender cone and comparing the results with flight test data ${ }^{61.62}$. Boundary layer data, microphone noise or pressure measurements, and total pressure unsteady measurements were made in many wind tunnels. The cone is shown mounted in the TDT in Figure 76. An important result of these tests was that the turbulence level of the TDT was categorized to be in the "average large tunnel" level. 


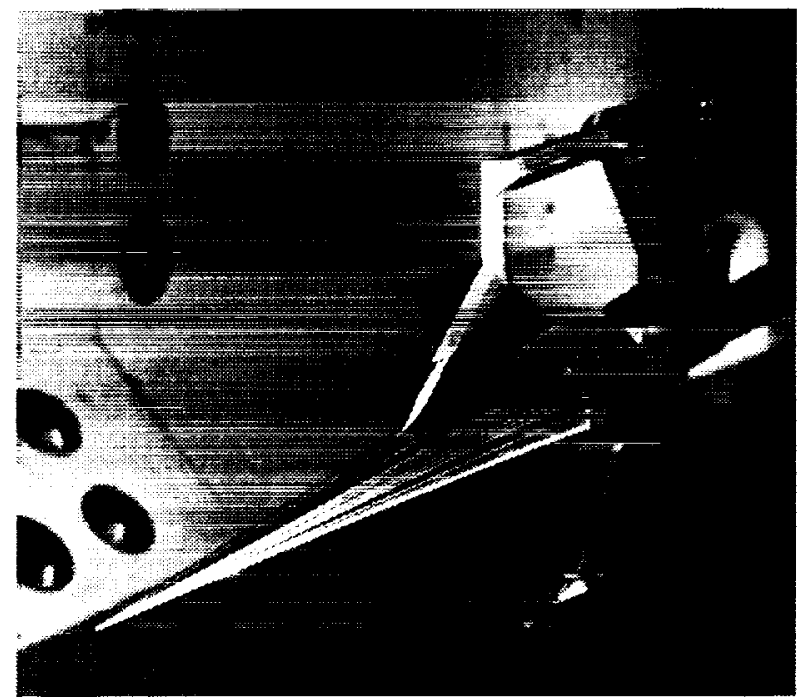

Figure 76. Cone for transition measurements mounted in the TDT.

\section{ONGOING TDT RESEARCH}

\section{MAVRIC-I BUSINESS JET WING}

LaRC's Aeroelasticity Branch is actively developing analytical methods and associated validation experiments to investigate unsteady flows, particularly those that exhibit strong flow nonlinearities. As part of this effort, a program known as Models for Aeroelastic Validation Research Involving Computations (MAVRIC) is heing developed and implemented to provide experimental data for use in high-level aeroelastic code validation. An existing aeroelastically scaled model of a business jet wing has been modified to measure unsteady surface pressures and is scheduled for testing in mid 2000 in the TDT.

This model was originally constructed as a simple, plate, flutter model of a business jet wing mounted low on a fuselage body of revolution. Figure 77 shows the model mounted to the tunnel sidewall. The stepped aluminum plate providing the wing stiffness was fitted with end-grain balsa wood to provide the wing contour. The wing has a taper ratio of 0.29 and a mid-chord sweep of 23 degrees. The wing thickness varies from 13 percent chord at the symmetry plane (for the extended wing-alone configuration analyzed by Edwards ${ }^{6.3}$ ) to 8.5 percent chord at the wing tip. The first eight wind-off modal frequencies of the model range from $4 \mathrm{~Hz}$. to $75 \mathrm{~Hz}$. The model was tested with three wingtip configurations: cutoff wingtip, winglet, and tip "pencil" store body of revolution. Flutter boundaries were measured in air and in heavy gas for most of the combinations of wing tip configuration and gas. Figure 78 shows flutter boundaries measured in air for the three tip configurations with the flutter dynamic pressure normalized by it's value at $M=0.6$ for the "nominal" winglet configuration.

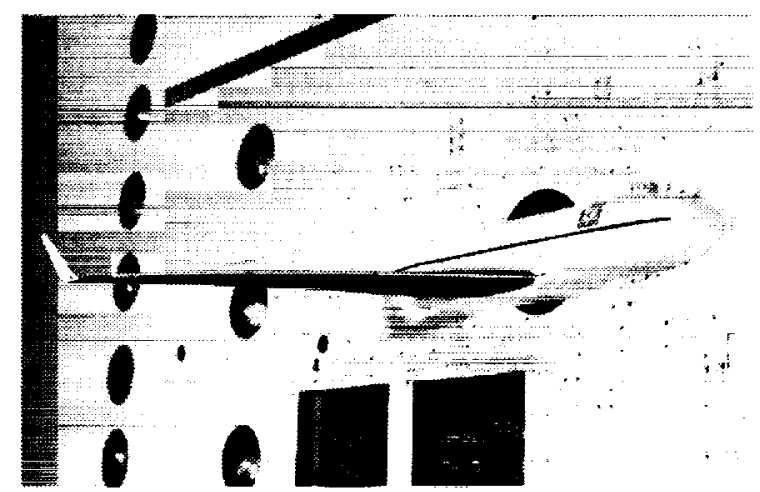

Figure 77. Original business jel wing model mounted in TDT test section.

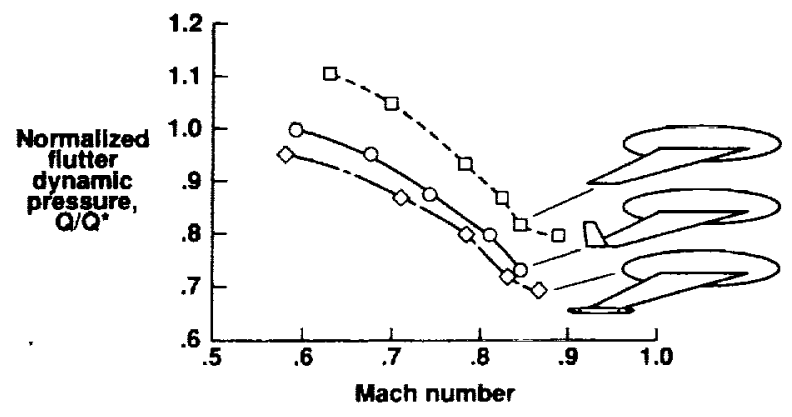

Figure 78. Measured business jet wing flutter boundary with three wing tip configurations.

Unsteady pressure instrumentation has been added to the model and it has been selected for further testing based upon its simple construction, simple finite element structural modeling, and its aeroelastic behavior in the 0.80 to $0.90 \mathrm{Mach}$ number range. At these conditions, the model motions were predominantly in the first wing-hending mode and exhibited a characteristic response termed Limit Cycle Oscillation (LCO). Here wing motions are seen to have a generally periodic response whose average amplitude is rather constant for constant tunnel conditions, and which increases in amplitude for small increases in tunnel conditions (Mach number, dynamic pressure, and sometimes angle of attack). For the cutoff wingtip, tip amplitudes reached \pm 3 inches (the tip chord is 6 inches) before testing was terminated for the $M=0.89$ case. Instances of LCO behavior are of great interest to aeroelasticians and are encountered under conditions of high-speed separation onset. They involve strong 
shock-boundary layer interaction and have been very difficult to study experimentally or computationally. Edwards $^{6.3}$ has published calculations of the LCO behavior of the cutoff wingtip for the $M=0.89$ case using an interactive boundary layer model. Figure 79 shows the computed transient time history of the wingtip responses for large and small initial wing displacements. The characteristics of the LCO behavior is seen, with the response growing to the limit cycle amplitude for the smaller initial condition and decaying to the limit cycle amplitude for the larger value.

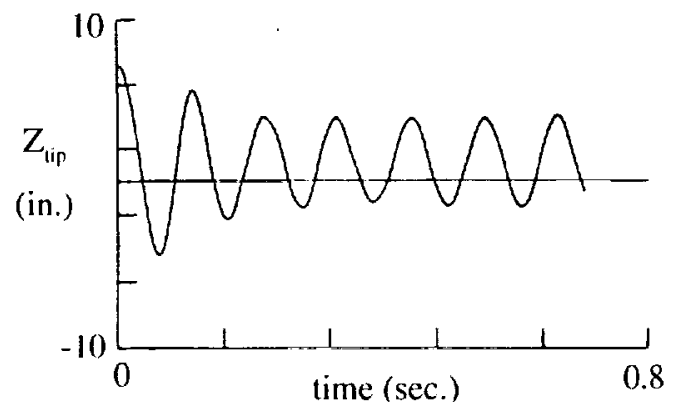

a) Amplitude decaying to limit cycle

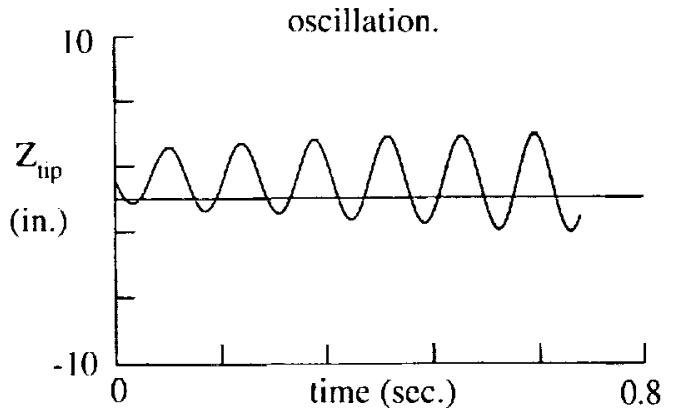

b) Amplitude growing to limit cycle oscillation.

Figure 79. Computed wing tip deflection time histories showing limit cycle oscillation.

The model will be retested in the TDT as the MAVRIC-I. Figure 80 indicates the location of instrumentation that has been added to the model. Three chords of unsteady pressure transducers are installed at span stations $0.22,0.63$, and 0.87 . Each chord has 28 upper surface and 18 lower surface close-mounted transducers. Eight accelerometers are mounted along the leading and trailing edge of the wing and bending/torsion strain gages are installed at the root. The intent of the retest is to obtain unsteady pressure and wing response data under conditions of transonic buffeting, separation onset, and LCO in order to validate CFD codes for such conditions.

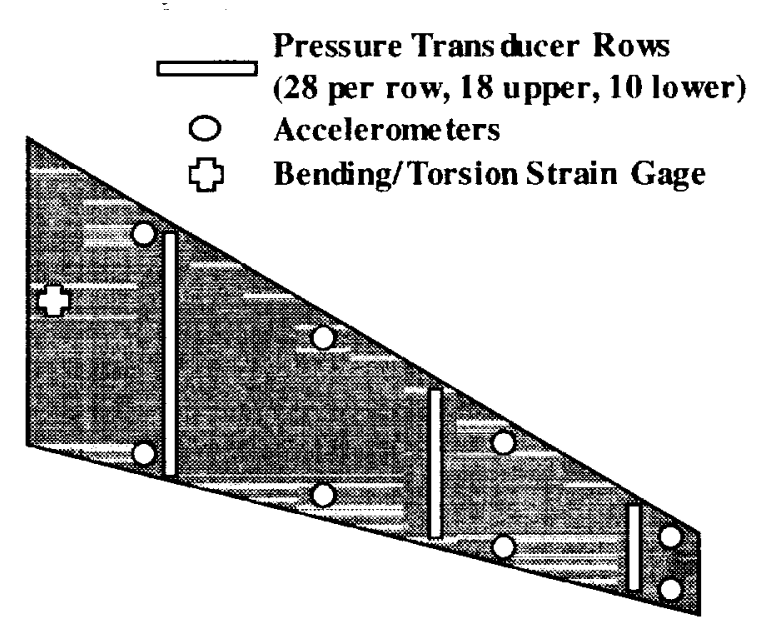

Figure 80. Instrumentation layout for refurbished MAVRIC-I business jet wing model.

\section{TDT OSCILLATING TURNTABLE}

The TDT and its associated hardware and software have been steadily upgraded over the life of the tunnel. A detailed discussion of the history of these upgrades is discussed in Reference 5. A recent modification that directly impacts unsteady pressure testing at the TDT is the development and installation of an oscillating turntable for large-scale models.

Development of accurate and efficient unsteady aerodynamics analytical methods requires validation data against which the temporal character of computed pressures can be compared. One method for obtaining such datasets is to mount structurally rigid wind-tunnel models capable of measuring unsteady surface pressure data to an oscillating turntable. By this technique, unsteady pressure data can be obtained for a model oscillating in pitch at a variety of amplitudes and frequencies. The relationship between the magnitude and phase of the pressure data with respect to the model molion can then be determined and compared against theoretical unsteady aerodynamics methods. This type of testing has been previously performed at the TDT and numerous other facilities around the world. However, these tests typically consist of relatively small models due to the limitations of the available mounting hardware and oscillation apparatus. These small models often limit the unsteady pressure instrumentation suite that can be included in the test. In addition, the oscillation mechanisms used to perform these tests often have a relatively limited frequency range over which they can pitch the model. At low frequencies phase differences between the 
model motion and the unsteady pressure data are usually small and difficult to measure. Therefore, it is impossible to confidently assess the temporal accuracy of theoretical methods, especially the outof-phase components of pressure, using lowfrequency experimental data.

A forced-oscillation device capable of pitching largescale models at relatively high frequencies would be a valuable tool for generating computational code validation data and general research in the area of unsteady aerodynamics. To this end, an oscillating turntable (OTT) mechanism has been developed, installed, and tested in the TDT. This device is shown in Figure 81. The OTT is mounted on a platform that is cantilevered off the east wall of the TDT. The OTT sits on a pair of floor rails that allow it to be retracted away from the TDT wall for ease of maintenance and access to the tunnel wall. In the figure, the OTT is in the retracted position. Models are mounted to the end of the pitch strut after the unit has been moved to its forward position. The turntable consists of a rotary hydraulic actuator and support equipment capable of generating 495,000 in-lbs of torque, a bearing housing for the pitch strut, and a disk brake mechanism for stopping model oscillations. The unit is designed to sinusoidally oscillate models about mean angles-of-attack between -15 and +45 degrees with pitch inertias as large as $65,000 \mathrm{lbm}-\mathrm{in}^{2}$ at frequencies up to $40 \mathrm{~Hz}$ and 1 degree pitch amplitude. Models with pitch inertias up to 250,000$) \mathrm{lbm}-$ in $^{2}$ can be oscillated at up to $20 \mathrm{~Hz}$ and I degree amplitude. It is also capable of oscillating both of these models at $1 \mathrm{~Hz}$ and up to 10

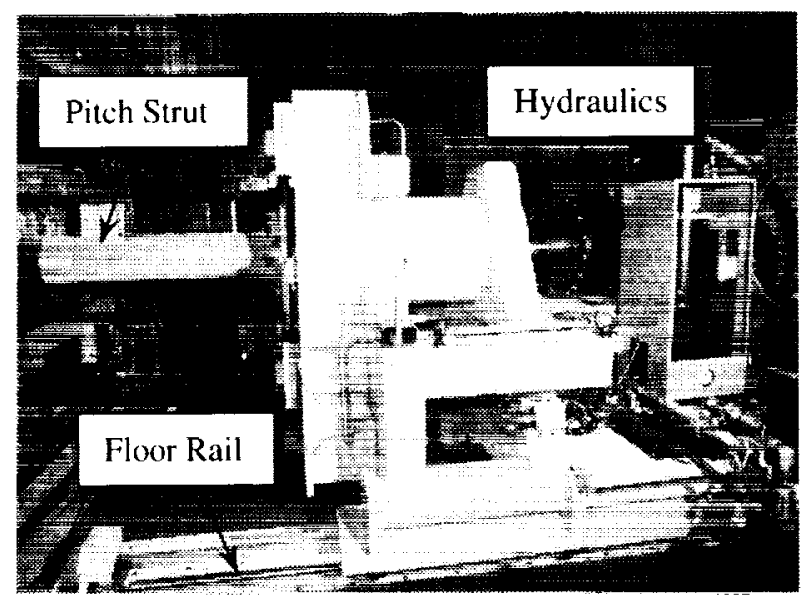

Figure 81. TDT Oscillating Turntable (OTT).

degrees amplitude. Given these capabilities and the power required to meet them, numerous fail-safe, emergency shutdown, and safety features have been designed into the OTT. At the heart of this system is a disk brake capable of stopping the model within 15 degrees of motion after the brake is applied. In addition to fail-safe systems that activate the brake in an emergency stop situation or when electrical and/or hydraulic power are lost, the hydraulic actuator also jogs to a low-power mode whenever the TDT test section access door is open.

The OTT and its support systems have been installed in the TDT. The OTT has been tested in a wind-off mode in the tunnel and its performance specifications have been verified. Wind-on testing with the OTT is scheduled for mid to late 2000 using the HSR-RSM, previously described in this paper, as the test article. A second entry to test a large commercial transport model is scheduled for late 2000 to early 2001 .

\section{CONCLUDING REMARKS}

Tests involving unsteady pressure measurements have been conducted in the TDT for nearly four decades. Configuration flutter research, computational method validation, controls research, and buffet testing are among the areas where these types of mcasurements provide valuable insight into the physical characteristics of unsteady aerodynamics and aeroelasticity. The flowfields for which unsteady pressure measurements have been performed range in complexity from primarily attached, nearly twodimensional flows to separated and transient attached/separated, highly 3-D flows. With the exception of buffet, where configuration details can play a dominant role in the flow characteristics, the majority of unsteady pressure measurements have been performed on wing alone or wing/generic fuselage configurations. The majority of the nonbuffet unsteady pressure data have also been acquired on semispan models. Many factors contribute to the evolution of this approach. Model cost and volume constraints associated with unsteady pressure testing are two of these. Generic models are cheaper to construct than highly detailed models, and for a given wind tunnel, semispan models can be designed to a larger scale factor than their full-span counterparts. The available analytical methods have also played a role in this somewhat generic approach to unsteady pressure testing.

The availability, quantity and complexity of experimental unsteady pressure data has typically been well ahead of the capabilities of the computational methodology, which has been largely occupied with code validation and calibration using extensive steady pressure datasets. However, as steady computational methods have matured, 
attention is being directed toward development of accurate and efficient unsteady computational methods. Many of the datasets described in this paper should serve as an excellent set of henchmarks for this development. Recent publications citing computations on the Benchmark Active Controls Technology Wing ${ }^{64-65}$ and the High Speed Research Semispan Models ${ }^{67}$ are evidence that this is indeed the case. Several of the datasets presented in this paper are included as test cases in a NATO Research and Technology Organization (RTO) working group document on experimental and computational test cases for computational method validation ${ }^{12}$.

Finally, TDT researchers are continuing to identify unsteady aerodynamic and aeroelastic phenomena relevant to modern aircraft design and develop experiments to investigate these problems. Model construction approaches, instrumentation, test techniques, and data acquisition systems continue to evolve, and TDT researchers are exploiting these developments to formulate new and innovative methods to efficiently and accurately acquire unsteady pressure data. Current and future TDT research activities involving unsteady pressure measurements will focus on highly nonlinear phenomena, such as Limit Cycle Oscillation (LCO), which involve shock-boundary layer interaction, separated flows and structural interactions. As these investigations focus on more detailed aeroelastic phenomena, the configuration of the vehicle will likely play a more dominant role, so the geometric complexity of the unsteady pressure models tested in the TDT will likely increase. The test techniques and cases outlined in this paper provide an outstanding basis for future research in unsteady aerodynamics and aeroelasticity, and the TDT is well-positioned to provide another forty years of fruitful research in this arena.

\section{ACKNOWLEDGEMENTS}

The production of a historical document of this type certainly is a team effort and several other Aeroelasticity Branch members have contributed. The information presented in Table 1 was summarized from the TDT Test Log reconstructed by Donald F. Keller and Robert V. Doggett (retired). Many of the data figures were also taken from the reference documents for the tests when available. Dr. Robert W. Moses furnished figures for the twin-tail buffet section and Dr. Walter A. Silva provided figures for the High Speed Research models section.

\section{REFERENCES}

'Rivera Jr., J. A. and Florance, J. R.: "Contributions of Transonic Dynamics Tunnel Testing to Airplane Flutter Clearance," AIAA Paper 2000- 1768, April 2000.

${ }^{2}$ Cole, S. R., Keller, D. F., and Piatak, D. J.: "Contributions of the Transonic Dynamics Tunnel to Launch Vehicle and Spacecraft Development," AIAA Paper 2000-1772, April 2000.

'3erry III, B., Noll, T. E., and Scott, R. C.: "Contributions of the Transonic Dynamics Tunnel to the Testing of Active Control of Aeroelastic Response," AIAA Paper 2000-1769, April 2000.

${ }^{4}$ Yeager Jr., W. T. and Kvaternik, R. G.: "Contributions of the Langley Transonic Dynamics Tunnel to Rotorcraft Technology and Development," AIAA Paper 2000-1771, April 2000.

${ }^{5}$ Cole, S. R. and Garcia, J. L.: "Past Present and Future Capabilities of the Transonic Dynamics Tunnel from an Aeroelasticity Perspective," AIAA Paper 2000-1767, April 2000.

'Corliss, J. M., and Cole, S.R.: "Heavy Gas Conversion of the NASA Langley Transonic Dynamics Tunnel," AIAA Paper 98-2710, June 1998.

'Cole, S. R. and Rivera Jr., J. A.: "The New Heavy Gas Testing Capability in the NASA Langley Transonic Dynamics Tunnel," Royal Aeronautical Society Wind Tunnels and Wind Tunnel Test Techniques Forum, No. 4, Cambridge, UK, April, 1997.

${ }^{8}$ Tijdeman, H. and Bergh, H.: "The Influence of the Main Flow on the Transfer Function of TubeTransducer Systems Used for Unsteady Pressure Measurements," NLR MP 72023 U, National Aerospace Laboratory NLR The Netherlands, September 1972.

'Hess, R. W.; Cazier, F. W., Jr.; and Wynne, E. C.: "Steady and Unsteady Transonic Pressure Measurements on a Clipped Delta Wing for Pitching and Control-Surface Oscillations," NASA TP-2594, Oct. 1986. 


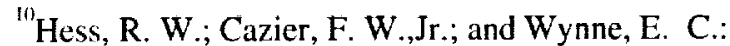
"Static and Unsteady Pressure Measurements on a 50 degree Clipped Delta Wing at $\mathrm{M}=0.9$," AIAA Paper 82-0686, 1982. Also available as NASA TM-83297, 1982.

"Bennett, R. M. and Walker, C. E.: "Computational Test Cases For a Clipped Delta Wing with Pitching and Trailing-Edge Control Surface Oscillation," NASA TM-1999-209104, March 1999.

${ }^{12}$ Ruiz-Calavera, L. P., ed.: "Verification and Validation Data for Computational Unsteady Aerodynamics Codes,"'RTO TR-26, 2000.

${ }^{13}$ Bhatia, K. G.; and Wertheimer, J.: "Acroelastic Challenges for a High Speed Civil Transport," AIAA Paper 93-1478, May 1993.

${ }^{14}$ Sandford, M. C.; Ricketts, R. H.; Cazier, F. W., Jr.; and Cunningham, H. J.: "Transonic Unsteady Airloads on an Energy Efficient Transport Wing With Oscillating Control Surfaces," Journal of Aircraft, Vol. 18 , No. 7, July 1981, pp. 557-561.

${ }^{15}$ Sandford, M. C.; Ricketts, R. H.; and Cazier, F. W., Jr.: "Transonic Steady and Unsteady-Pressure Measurements on a High-Aspect Ratio SupercriticalWing Model With Oscillating Control Surfaces," NASA TM-81888, 1980.

${ }^{16}$ Sandford, M. C.; Ricketts, R. H.; and Watson, J. J.: "Subsonic and Transonic Pressure Measurements on a High-Aspect-Ratio Supercritical-Wing Model With Oscillating Control Surfaces," NASA TM-8320I, 1981.

${ }^{17}$ Sandford, M. C. and Ricketts, R. H.: "Steady and Unsteady Pressure Measrements on a SupercriticalWing Model With Oscillating Control Surfaces at Subsonic and Transonic Speeds," NASA TM-84543, 1983.

${ }^{I}$ Ricketts, R. H.; Sandford, M. C.; Seidel, D. A.; and Watson, J. J: "Transonic Pressure Distributions on a Rectangular Supercritical Wing Oscillated in Pitch," Journal of Aircraft, vol. 21, no. 8, August 1984. pp 576-582. (Also AIAA Paper 83-0923, May 1983 which is available as NASA TM 84616, Mar. 1983).
${ }^{14}$ Ricketts, R. H.; Sandford, M. C.; Watson, J. J.; and Seidel, D. A.: "Subsonic and Transonic Unsteady-and Steady-Pressure Measurements on a Rectangular Supercritical Wing Oscillated in Pitch," NASA TM 85765, August 1984.

${ }^{211}$ Ricketts, R. H.; Sandford, M. C.; Watson, J. J.; and Seidel, D. A.: "Geometric and Structural Properties of a Rectangular Supercritical Wing Oscillated in Pitch for Measurements of Unsteady Transonic Pressure Distributions," NASA TM 85673, November 1983.

${ }^{21}$ Bennett, R. M.; Walker, C. E.: "Computational Test Cases for a Rectangular Supercritical Wing Undergoing Pitching Oscillations," NASA/TM-1999209130 , Apr. 1999.

${ }^{22}$ Whitcomb, R. T.: "Review of NASA Supercritical Airfoils," ICAS Paper No.74-10, August 1974.

${ }^{2.3}$ Murrow, H. N.; and Eckstrom, C. V.: "Drones for Aerodynamic and Structural Testing (DAST)-A Status Report," Journal of Aircraft, Vol. 16, August 1979, pp. 521-526.

${ }^{24}$ Sandford, M. C.; Seidel, D. A.; Eckstrom, C. V.; and Spain, C. V.: "Geometrical and Structural Properties of an Aeroelastic Rescarch Wing (ARW2)," NASA TM-4110, April 1989.

${ }^{25}$ Sandford, M. C.; Seidel, D. A.; and Eckstrom, C. V.: "Steady Pressure Measurements on an Aeroelastic Research Wing (ARW-2)," NASA TM- 109046 , February, 1994.

${ }^{26}$ Seidel, D. A.; Sandford, M. C.; and Ecstrom, C. V.: "Measured Unsteady Transonic Aerodynamics Characteristics of an Elastic Supercritical Wing," Journal of Aircraft, Vol. 24, No. 4, April 1987, pp. 225-230.

${ }^{27}$ Byrdsong, T. A.; Adams, R. R.; and Sandford, M. C.: "Close-Range Photogrammetric Measurements of Static Deflections for an Elastic Supercritical Wing," NASA TM-4194 and Supplement to NASA TM-4194, December 1990.

${ }^{28}$ Seidel, D. A.; Sandford, M. C.; and Eckstrom. C. V.: "Unsteady-Pressure and Dynamic-Deflection Measurements on an Aeroelastic Supercritical Wing," NASA TM-4278, December 1991. 
${ }^{29}$ Seidel, D. A.; Eckstrom, C. V.; and Sandford, M. C.: "Transonic Region of High Dynamic Response Encountered on an Elastic Supercritical Wing," Journal of Aircraft, Vol. 26, No. 9, September 1989, pp. 870-875.

${ }^{317}$ Eckstrom, C. V.; Seidel, D. A.; and Sandford, M. C.: "Unsteady Pressure and Structural Response Measurements on an Elastic Supercritical Wing," Journal of Aircraft, Vol. 27, NO. I, January 1990, pp. $75-80$

${ }^{31}$ Eckstrom, C. V.; Seidel, D. A.; and Sandford, M. C.: "Measurements of Unsteady Pressure and Structural Response for an Elastic Supcrcritical Wing," NASA TP-3443, November, 1994.

${ }^{32}$ Moss, G. F.; and Pierce, D.: "The Dynamics Response of Wings in Torsion at High Subsonic Speeds," AGARD CP226, April 1977

${ }^{33}$ Piette, D. S., Crooks, O. J., and Cazier Jr., F. W.: "Experimental Transonic Steady State and Unsteady Pressure Measurements on a Supercritical Wing During Flutter and Forced Discrete Frequency Oscillation," AIAA Paper 85-0664, April 1985

${ }^{34}$ Bennett, R. M.; Eckstrom, C. V.; Rivera, J., A.; Dansberry, B. E.; Farmer, M. G.; and Durham, M. H.: "The Benchmark Aeroclastic Models Program Description and Highlights of Initial Results," Paper No. 25 in Transonic Unsteady Aerodynamics and Aeroelasticity, AGARD CP 507, Mar. 1992. Also available as NASA TM-104180, 1991.

${ }^{35}$ Rivera Jr., J. A.; Dansberry, B. E.; Durham, M. H.; Bennet,, R. M.; and Silva, W. A.: "Pressure Measurements on a Rectangular Wing with A NACA 0012 Airfoil During Conventional Flutter," NASA TM 104211 , July 1992.

${ }^{36}$ Rivera, J. A.; Dansberry, B. E.; Bennett, R. M.; Durham, M. H.; and Silva, W. A.: "NACA 0012 Benchmark Model Experimental Flutter Results With Unsteady Pressure Distributions," AIAA Paper 92 2396, April 1992. Also available as NASA TM 107581, Mar. 1992.

${ }^{37}$ Rivera, J. A.; Dansberry, B. E.; Farmer, M. G.; Eckstrom, C., V.; Seidel, D. A.; and Bennett, R. M.: "Experimental Flutter Boundaries with Unsteady Pressure Distributions for the NACA 0012 Benchmark Model," AIAA Paper 91-1010, 1991. Also available as NASA TM 104072, 1991.
${ }^{38}$ Dansberry, B. E.; Durham, M. H.; Bennett, R. M.; Rivera Jr., J. A.; Silva, W. A.; and Wieseman, C. D.: "Experimental Unsteady Pressures at Flutter on the Supercritical Wing Benchmark Model," AIAA Paper 93-1592, April 1993.

${ }^{39}$ Dansberry, B. E.; Durham, M. H.; Bennett, R. M.; Turnock, D. L.; Silva, W. A.; and Rivera Jr., J. A.: "Physical Properties of the Benchmark Models Program Supercritical Wing," NASA TM 4457. September 1993.

${ }^{40}$ Dansberry, B. E.: "Dynamic Characteristics of a Benchmark Models Program Supercritical Wing," AIAA Paper 92-2368, April 1992.

${ }^{41}$ Farmer, M. G.: "A Two-Degree-of-Freedom Flutter Mount System with Low Damping for Testing Rigid Wings at Different Angles of Attack," NASA TM 83.302, 1982.

${ }^{42}$ Farmer, M. G.: Mount System for Testing Flutter, U.S Patent No. 4,475,385, October 9, 1984.

${ }^{4.3}$ Durham, M. H.; Keller, D. F.; Bennett, R. M.; and Wieseman, C. D.: "A Status Report on a Model for Benchmark Active Controls Testing," AIAA Paper 911011, April 1991. Also available as NASA TM $107582,1991$.

${ }^{44}$ Scott, R. C.; Hoadley, S. T.; Wieseman, C. D.; and Durham, M. H.: "The Benchmark Active Controls Technology Model Aerodynamic Data," AIAA Paper 97-0829, January 1997.

${ }^{45}$ Silva, W. A.; Keller, D. F.; Florance, J. R.; Cole, S. R.; and Scott, R. C.: "Experimental Steady and Unsteady Aerodynamic and Flutter Results for HSCT Semispan Models," AIAA Paper 2000-1697, April 2000.

${ }^{46}$ Schuster, D. M. and Rausch, R. D.: "Transonic Dynamics Tunnel Force and Pressure Data Acquired on the HSR Rigid Semispan Model," NASA CR 199 209555, September, 1999

\footnotetext{
${ }^{47}$ Schuster, D. M.; Spain, C. V.; Turnock, D. L.; Rausch, R. D.; Hamouda, M-N; Vogler, W. A.; and Stockwell, A. E.: "Development, Analysis, and Testing of the High Speed Research Flexible Semispan Model," NASA CR 199-209556, September, 1999
} 
${ }^{1 R}$ Jones Jr., Gcorge W, and Foughner, J. T.:

"Investigation of Buffet Pressures on Models of Large Manned Launch Vehicle Configurations," NASA TN D-1633, May 1963.

${ }^{4 y}$ Hanson, P. W. and Doggett Jr., R. V.: "Aerodynamic Damping and Buffet Response of an Aeroelastic model of the Saturn I Block II Launch Vehicle," NASA TN D-2713, March 1965.

511 Pearson, A. O.: "Surface Pressure Distributions on 0.0628-Scale Models of Proposed Project FIRE Space Vehicles at Mach Numbers from 0.25 to 4.63 ," NASA TD D-1961, September 1963.

${ }^{51}$ Muraca, R. J.: "Aerodynamic Load Distributions for the Project FIRE Configurations at Mach Numbers from 0.25 to 4.63," NASA TN D-2604, February 1965.

${ }^{52}$ Henderson, W. P.: "Pressure Distributions Over the Forward Portion of the Project FIRE Space-Vehicle Configuration at Mach Numbers from 0.25 to 0.65 ," NASA TN D-1612, February 1963.

${ }^{53}$ Moseley, W. C., Jr.; and Martino, J. C.: “Apollo Wind Tunnel Testing Program - Historical Development of General Configurations." NASA TN D-3748, Dec. 1966.

${ }^{54}$ Cole, S.C.: "Dynamic Response of a Hammerhead Launch Vehicle Wind-Tunnel Model", AIAA Paper 91-1050, April 1991. Also available as NASA TM 104050 , Feb 1991.

${ }^{55}$ Doggetl, R. V. and Hanson, P. H.: "Wind Tunnel Buffet Pressure Investigation on the Lower Nose Portion of the RF4C Aircraft," NASA LWP-227, June 1966.

${ }^{56}$ Moss, S. W.; Cole, S. R.; and Doggett Jr., R. V.: "Some Subsonic and Transonic Buffet Characteristics of the Twin Vertical-Tails of a Fighter Airplane Configuration," AIAA Paper 91-1049, April 1991.

${ }^{57}$ Moses, R. W.; and Ashley, H.: "Spatial Characteristics Of The Unsteady Differential Pressures On 16\% F/A-18 Vertical Tails," AIAA Paper 98-0519, Jan. 1998.

${ }^{58}$ Moses, R. W.; and Shah, G. H.: "Spatial Characteristics Of F/A-18 Vertical Tail Buffet Pressures Measured In Flight," AIAA Paper 98-1956, April 1998.
${ }^{54}$ Moses, R. W.; and Pendleton, E.: "A Comparison of Pressure Measurements Between a Full-Scale and a 1/6-Scale F/A-18 Twin Tail During Buffet," AGARDR-815, Loads and Requirements for Military Aircraft, February 1997, pp. 6-1 - 6-15.

${ }^{611}$ Moses, R. W.; and Huttsell, L. J.: "Fin Buffeting Features of an Early F-22 Model," AIAA Paper 20001695, April 2000.

${ }^{61}$ Doughtery, N. S., Jr.: "Influence of Wind Tunnel Noise on the Location of Boundary-Layer Transition on a Slender Cone at Mach Numbers from 0.2 to 5.5 . Volume I. - Experimental Methods and Summary of Results. Volume II. - Tabulated and Plotted Data", AEDC --TR-78-44, March 1980.

${ }^{62}$ Dougherty, N. S., Jr.; and Fisher, D. F.:

"Boundary-Layer Transition on a 10-Degree Cone: Wind Tunnel/Flight Correlation", AIAA Paper 800154 , Jan. 1980.

${ }^{63}$ Edwards, J. W.: "Calculated Viscous and Scale Effects on Transonic Aeroelasticity," in AGARD-R822, March 1998.

${ }^{64}$ Schuster, D. M., Beran, P. S., and Huttsell, L. J.: "Application of the ENS3DAE euler/Navier-Stokes Acroclastic Mehtod," AGARD-R-822, Numerical Unsteady Aerodynamic and Aeroelastic Simulation, March 1998, pp. 3-1 - 3-11.

${ }^{6.5}$ Roughen, K. M., Baker, M. L., and Fogarty, T. G.: "CFD and Doublet-Lattice Calculation of Unsteady Control Surface Aaerodynamics and Correlation with Wind Tunnel Test," AIAA Paper 99-1469, April 1999.

${ }^{66}$ Bartels, R. E. and Schuster, D. M.: "A Comparison of Two Navier-Stokes Aeroelastic Methods Using BACT Benchmark Experimental Data," AIAA Paper 99-3157, June 1999.

${ }^{67}$ Baker, M. L., Mendoza, R., and Hartwich, P. M.,: "Transonic Aeroelastic Analysis of a High Speed Transport Wind Tunnel Model," AIAA Paper 99-1217, April 1999. 